\title{
Die Sozialstaatsillusion und der Widerspruch von Lohnarbeit und Kapital
}

Die folgenden Uberlegungen sind aus Diskussionen zur Vorbereitung einiger Aứsätze entstanden. in denen konkret sogenannte sozialstaatliche Eingriffe des bürgerlichen Staates in der BRD untersucht werden und die in loser Folge in der SOZIALISTISCHEN POLITIK erscheinen sollen. Bei der Arbeit am empirischen Material - Wohnungspolitik, Sozialgesetzgebung, Bildungspolitik -, aber auch bei der Untersuchung konjunktur- und wirtschaftspolitischer Eingriffe des Staates, ergab sich die Notwendigkeit, die Kategorien zur Bestimmung des Verhältnisses von Kapitalvenwertungsprozeß und bürgerlichem Sraat zu klären, wobei sich vor allem eine Auseinandersetzung mit den revisionistischen Theorien zu dieser Frage als notwendig erwies. Es handelt sich im folgenden also zunächst um eine Zusammenfassung verschiedener Spielarten der revisionistischen Staatsauffassung. sodann um ihre Charakterisierung und um die Entwicklung ihrer inneren Tendenzen. Weiter werden Ansätze der Kritik entwickelt, vor allem an der Verselbständigung der Sphäre der Einkommensdistribution von der Produktionssphäre und an der Darstellung der Durchsetzung einer spezifischen sozialstaatlichen Funktion, wie sie Marx am Beispiel der Fabrikgesetzgebung gegeben hat. Erst auf der Basis dieser Vorüberlegungen kann der Versuch unternommen werden, die konkreten Erscheinungsformen der sozial- und wirtschaftspolitischen Staatstätigkeit in empirischen Untersuchungen auf den Kapitalvenwertungsprozeß und seine widersprüchliche Entwicklung zu beziehen. An den Diskussionen waren außer den Verfassern u.a. Elmar Alivater, Bernhard Blanke, Kristina Blunck, Uirich Huttenlocher und Alex Schubert beteiligt, ohne daß in allen Fragen Ubereinstimmung erreicht wurde. In den Zusammenhang dieser Diskussion gehört auch die von Elmar Altvater veriaßte Konjunkturanalyse in SOPO 5/70; er war zudem an der Ausarbeitung des III. Teils direkt beteiliget.

Um Mißverständnissen vorzubeugen, bemerken wir noch folgendes: der vorliegende Aufsatz befaßt sich mit den revisionistischen $T h$ e o r i e $n$ vom Sozialstaat, gibt also keineswegs eine $R$ e a $l$ a $n$ zly s e des heutigen Sozialstaats - dies wird erst in der Untersuchung einzelner Bereiche geschehen. Daher wird auch nur am Rande behandelt, wi e sich die Sozialstaatsillusion entwickelt, wie sie notwendig in den materiellen Verhältnissen und ihrer historischen Entwicklung begründet ist; im ganzen erscheint die Geschichte der Theorie also abgelöst von der Geschichte des Kapitals. Als erster Schritt der Kritik und Vorstufe zur Untersuchung erschien uns jedoch die Auseinandersetzung mit der Verselbständigung des Staates bzw. der Einkommensverteilung in der revisionistischen Theorie unerläßlich.

\section{Zur politischen Relevanz revisionistischer Staatstheorien}

Die theoretische Einschätzung des Verhältnisses von Staat und kapitalistischer Gesellschaft war in der Geschichte der Arbeiterbewegung eines der wesentlichen Momente in der Auseinandersetzung um die richtige politische Strategie und Organisationsform der Arbeiterklasse. Revolutionäre und revisionistische Positionen lassen sich in diesen Auseinandersetzungen nach ihrer Einschätzung der Rolle des Staates in der kapitalistischen Gesellschaft unterscheiden.

Die Auffassung des Staates als einer gegenüber den Widersprüchen in der Gesellschaft mehr oder weniger $\mathrm{s}$ e I b s t ä $n$ d i ge $n$ Institution war und ist die Voraussetzung für alle revisionistische Strategie und Praxis. Die revisionistische Strategie behauptet zunächst, daß sie den Kapitalismus durch den Sozialismus ersetzen wolle, aber eben auf dem Wege gesetzlicher Reformen auf der Basis der bestehenden Gesellschaft, durch schrittweise Ubernahme der Staatsmacht durch die Arbeiterklasse lauf diese Begriffe aus der Klassenbewegung der Arbeiter verzichten die revisionistischen Theoretiker erst allmählich; sie sprechen dann z.B. nicht mehr von der Arbeiterklasse, sondern von den "demokratischen Kräften"). Aber diese Entscheidung für eine kontinuierliche "Revolution von oben" (1) (auch hier ist die revolutionäre Sprache als Phrase beibehalten) hat in der bisherigen Ge-

1 Vg!. P. Lapinski: "Der Sozialstaat. Etappen und Tendenzen seiner Entwicklung", UNTER DEM BANNER DES MARXISMUS, 1928, 2. Jg., S. 383, wieder abgedruckt in: GEGEN DEN STROM, I. Jg. - Nr. 1, Aug. 1969, S. 39. 
schichte der Arbeiterbewegung noch immer damit geendet, den Sozialismus als politisches Ziel ganz ausdrücklich aufzugeben. "Wer sich daher für den gesetzlichen Reformweg a $\mathrm{n} \mathbf{s} \mathrm{t}$ a $\mathrm{t} \mathbf{t}$ und im G e ge n s a t z zur Eroberung der politischen Macht und zur Umwälzung der Gesellschaft ausspricht, wählt tatsächlich nicht einen ruhigeren, sicheren, langsameren Weg zum gle i c h e n Ziel, sondern auch ein a n d e re s Ziel, nämlich statt der Herbeiführung einer neuen Gesellschaftsordnung bloß unwesentliche Veränderungen in der alten." (2)

Eine Strategie, die den bürgerlichen Staat zum Subjekt gesellschaftlicher Änderung erhebt, kann nur dann als erfolgversprechend eingeschätzt werden, wenn der Staat als ein "geheiligtes Gefäß" verstanden wird, in das man je nach der historischen Situation einen kapitalistischen oder sozialistischen Inhalt einfüllen kann, und wenn der Staat die Formen produziert, in der die Geselfschaft die Reproduktion ihres Lebens vollzieht. Demgegenüber sagt Marx, daß die "Zusammenfassung der bürgerlichen Gesellschaft in der Form des Staates" (3) erfolge, daß die "bestehende Gesellschaft ... als G ru n d I a ge des bestehenden Staates" (4) aufzufassen sei, daß also der bürgerliche Staat das Resultat der entwickelten warenproduzierenden, also der kapitalistischen Gesellschaft und ihrer auf dieser Form der Produktion beruhenden Widersprüche sei, und daher auch eine durch diese Widersprüche geprägte Institution (5). Die Revision dieser Staatsauffassung in den revi-

2 Rosa Luxemburg: SOZIALREFORM ODER REVOLUTION, in: dies.: POLITISCHE SCHRIFTEN, Frankfurt 1966, Bd. I, S. 114. Vgl. dort insgesamt II. 3: Die Eroberung der politischen Macht.

3 Marx: GRUNDRISSE, Berlin (DDR) 1953, S. 29. Vgl. auch: DEUTSCHE IDEOLOGIE, in: Marx-Engels: WERKE (MEW) Berlin-DDR, Bd. 3, S. 62: "Da der Staat die Form ist, in welcher die Individuen einer herrschenden Klasse ihre gemeinsamen lnteressen geltend machen und die ganze bürgerliche Gesellschaft eine Epoche in sich zusammenfaßt, so folgt, daß alle gemeinsamen Institutionen, die durch den Staat vermittelt werden, eine politische Form erhalten. Daher die Illusion, als ob das Gesetz auf dem Willen, und zwar auf dem von seiner realen Basis losgerissenen, dem f $r$ e i e n Willen, berwhe." - Alle Zitate aus den Arbeiten von Marx und Engels werden nach der Ausgabe der MEW zitiert, soweit sie darin erschienen sind. Bei Zitaten aus dem KAPITAL wird vor dem Schrägstrich jeweils die Seitenzahl der braunen Volksausgabe (Berlin 1947, u.ö.) angegeben; Stellen aus dem ersten Band des KAPITAL werden mit den bloß in der Volksausgabe aufgenommenen Hervorhebungen von Marx' Hand zitiert, die den Sinn of $t$ deutlicher werden lassen.

4 Marx: "Kritik des Gothaer Programms", MEW Bd. 19, S. 28. Vgl. auch: Marx: "Zur Kritik der Hegelschen Rechtsphilosophie, Kritik des Hegelschen Staatsrechts", MEW Bd. 1, S. 304 f, 306: "... was ist der I $\mathrm{n} \mathrm{h} \mathrm{a} \mathrm{lt}$... des politischen Zweckes, was ist der Zweck dieses Zwekkes? ... Welche Macht übt der politische Staat über das Privateigentum ... aus? Daß er es is o1 i e $r \mathrm{t}$ von der Familie und der Sozietät, daß er es zu seiner a bs trakten Verselb$s t \ddot{a} n d$ i g u n g bringt. Welches ist also die Macht des politischen Staates über das Privateigentum? Die e ig n e M a cht des Privateigent ums, sein zur Existenz gebrachtes Wesen. Was bleibt dem politischen Staat im Gegensatz zu diesem Wesen übrig? Die I l I u s i o n, daß er bestimmt, wo er bestimmt wird." "Die "UnveräuBerlichkeit' des Pri$v$ a t e igentums ist in einem die 'VeräuBerlichkeit' derallgemeinen Wille nsfreiheit und Sit t lich keit. Das Eigentum ist hier nicht mehr, insofern 'ich meinen Willen darin lege', sondern mein Wille ist, 'insofern er im Eigentum liegt'. Mein Wille besitzt hier nicht, sondern ist besessen." Vgl, ebda. $\$ .231 \mathrm{ff}, 303 \mathrm{ff}$.

Marx zeigt also in seinen frühen Schriften, daß gerade der bürgerliche Staat den $\mathrm{S} c \mathrm{~h}$ e in seiner Selbständigkeit in besonderem Maße erzeugt, und da $B$ die kapitalistische Produktionsweise die Grundlage der Staatsillusion ist. Er zeigt gleichzeitig, daß diese fllusion von der uneingeschränk ten Handlungsfähigkeit des Staates schon bei der Fiktion von der Willensfreiheit des Privateigentümers, des Kapitalisten, beginnt.

5 Daß die Widersprüche der Gesellschaft als Widersprüche des Staates selbst sich niederschlagen, stellt Marx schon sehr früh am Beispiel der Administration, der staatlichen Bürokratie dar, in: "Kritische Randglossen zu dem Artikel eines Preußen", MEW Bd. 1, S. 401 f. "Den W i d e rs p r u $\mathrm{ch}$ zwischen der Bestimmung und dem guten Willen der Administration einerseits, und ihren Mitteln wie ihrem Vermögen andrerseits, kann der Staat nicht aufheben, ohne sich selbst aufzuheben, denn er b e $\mathrm{r} u \mathrm{~h} t$ auf diesem Widerspruch. Er beruht auf dem Widerspruch zwischen dem öf fent li che $n$ und dem $P r i v a t l e b e n$, auf dem Widerspruch zwischen den a $1 \mathrm{lg}$ eme in en In teressen und den $S$ onderinteressen. Die A d m i n istration muß sich daher auf eine formelle und $n$ e $g$ at ive Tätigkeit beschränken, denn wo das bürgerliche Leben und seine Arbeit beginnt, eben da hat ihre 
sionistischen Theorien implizierte folgerichtig auch die Ablehnung der Auffassung, daß die Aufheoung der kapitalistischen Produktionsweise nicht durch den Staatsapparat, sondern aliein von der revolutionären Arbeiterklasse selbst vollzogen werden könne (6).

Die Bestimmung des bürgerlichen Staates als Produkt der entwickelten warenproduzierenden, der kapitalistischen Gesellschaft und die daraus folgende Bestimmung der Strategie der Arbeiterbewegung macht es notwendig, die Kritik des Revisionismus nicht als isolierte Kritik der Auffassung van den politischen Institutionen zu betreiben. Auf dieser Ebene jedoch bewegte sich mit Vorliebe die bisher politisch relevant gewordene Auseinandersetzung mit revisionistischen Staatstheorien seitens der Linken in der BRD und West-Berlin, die Parlamentarismuskritik. In der Diskussion über die Beteiligung an den Bundestagswahlen, in der sich der SDS vor allem mit der politischen Funktion einer sozialistischen Partei im bürgerlichen Parlament unter monopolkapitalistischen Bedingungen auseinanderzusetzen hatte, wurde die Kritik des bürgerlichen Parlamentarismus von Marx, Engels, Pannekoek und anderen rezipiert; zusammen mit Agnolis TRANSFORMATION DER DEMOKRATIE (Berlin-West 1967) diente die so entwickelte Auffassung als Begründung dafür, daß das Parlament nicht zur 'Tribüne des Klassenkampfes' tauge, und schon gar nicht ein Instrument zur EinPührung des Sozialismus sei, wie in der DKP noch angenommen (7). In der gegenwärtigen Unsicher-

Macht aufgehört. Ja, gegenüber den Konsequenzen, welche aus der unsozialen Natur dieses bürgerlichen Lebens, dieses Privateigentums, dieses Handels, dieser Industrie, dieser wechselseitigen Plünderung der verschiedenen bürgerlichen Kreise entspringen, diesen Konsequenzen gegenüber ist die $\mathrm{O} h \mathrm{~nm}$ a $\mathrm{ch}$ t das $\mathrm{N}$ a t u r g e s e t $\mathrm{z}$ der Administration. Denn diese Zerrissenheit ... d e r b ürger liche $\mathrm{n} \mathrm{Gesells} \mathrm{ch}$ a f t, ist das Naturfundament, worauf der mode r $\mathrm{n}$ e Staat ruht ... Wollte der moderne Staat die $\mathrm{O} h \mathrm{n} \mathrm{m}$ a $\mathrm{ch}$ t seiner Administration aufheben, so müßte er das jetzige $\mathrm{Pr}$ iv a $\mathrm{t} l$ e b e $\mathrm{n}$ aufheben. Wollte er das Privatleben aufheben, so müßte er sich selbst aufheben, denn er existiert $\mathrm{n} \mathrm{u} \mathrm{r}$ im Gegensatz zu demselben." Dagegen heute z.B. in der Theorie des staatsmonopolistischen Kapitalismus: "Es wurde darauf hingewiesen, daß sich die Monopole vermittels des Staates eines Instrumentes bedienen müssen, das un ter Umständen gegen sie ausgenutzt werden kann." In: BURGERLICHE OKONOMIE IM MODERNEN KAPITALISMUS, hrsg. Herbert Meißner, Berlin (DDR) 1967, S. 422. Die Theorie des staatsmonopolistischen Kapitalismus vergißt, auch wenn sie an den Widersprüchen der kapitalistischen Gesellschaft verbal weiter festhält, daß sich diese Widersprüche auch im Staatsapparat und seinen politischen Aktionsmöglichkeiten niederschlagen und dieser daher auch kein einheitliches Instrument sein kann, das an sich neutral und deshalb von jeder Klasse in ihrem Interesse benutzbar ist.

6 Lenin: STAAT UND REVOLUTION. Die Lehre des Marxismus vom Staat und die Aufgabe des Proletariats in der Revolution. (Geschrieben Aug./Sept. 1917) In: ders.: AUSGEWAHLTE WERKE, Berlin (DDR) 196I, Bd. 2, S. 315-420. (Vgl. aber die unten gemachten Einschränkungen.) Marx selbst hat zum erstenmal in der Kritik der Hegelschen Rechtsphilosophie, in der Kritik also am Hegelschen Staatsmystizismus, in welchem der Staat als Inkarnation der Vernunft erschien, herausgestellt, daB nur das Proletariat als Widerspruch zur bürgerlichen Gesellschaft Subjekt der Aufhebung ihrer Widersprüche sein könne. Dazu Karl Polak: "Karl Marx über Staat, Eigentum und Recht", in: KARL MARX, BEGRUNDER DER STAATS- UND RECHTSTHEORIE DER ARBEITERKLASSE, Berlin (DDR) 1968, S. $35 \mathrm{ff}$. In der Kritik der Hegelschen Rechtsphilosophie hat Marx erkannt, "daß der Widerspruch, der Klassenkampf das beherrschende Prinzip der Wirklichkeit ist, daß die politische Macht, also der Staat, Ausdruck dieses Widerspruchs und Kampfes ist." (S. 51) Und: "Die Jakobinerdiktatur war der Versuch, durch politische Macht die Widersprüche der bürgerlichen Gesellschafi zu meistern; er mißlang und mußte mißlingen." (S. 42) Vgl. ausführlich: A. Gurland: PRODUKTIONSWEISE - STAAT - KLASSENDIKTATUR, Diss. Leipzig 1928.

7 Vgl. dazu die Aufsätze von F. Deppe und J. Agnoli in der Neuen Kritik, VIII (1967) Nr. 44, S. 48-66, IX (1968) Nr. 47, S. 24-33, sowie Pannekoek/Lukacs/Friedländer/Rudas, PARLAMENTARISMUSDEBATTE, Berlin-West 1968.

Die FU-Projektgruppe DKP und Bernd Rabehl haben sich in ihrer Veröffentlichung: DKP EINE NEUE SOZIALDEMOKRATISCHE PARTEI (Parlamentarismusdebatte 2, Berlin 1969) mit dieser Diskussion auseinandergesetzt und in diesem Zusammenhang auch die Tradition der revisionistischen Staatstheorie und ihre heutigen Erscheinungsformen, sowie deren politisch-strategische Konsequenzen dargelegt und kritisiert. Sie zeigen dabei Analogien auf zwischen dem Revisionismus der Sozialdemokratie in Deutschland und Osterreich während der zwanziger Jahre (Otto Bauer, Karl Renner, Rudolf Hilferding, Eduard Bernstein, Karl Kautsky u.a.; 'These vom 'organisierten Kapitalismus' als neuer und potentiell krisenfreier 
heit der Einschätzung des Handlungsspielraumes der SPO-Regierung und ihrer Möglichkeit zur. "Krisenmanipulation' innerhalb der Linken zeigt sich jedoch, daßs die Parlamentarismuskritik, also die politische Kritik einer polltischen Institution, nur e in Moment der Revisionismuskritik sein kann und daB diese Kritik, nimmt sie sich selber ernst, zur Kritik der Entwicklung der verschiedenen Funktion des heutigen Staates - seines 'Instrumentariums' zur Steuerung der "Wirtschaft' und zur 'Befriedigung' der Gesellschaft - und seiner konkreten Schranken und Widersprüche übergehen mußB. Denn Darstellung und Kritik der staatichen Institutionen als Manipulationsinstrumen. te der herrschenden Klasse lassen die Grenzen dieser Manipulation nicht sichtbar werden. Diese können epst durch eine Analyse aufgezeigt werden, die die Notwendigkeiten und Schranken staatlicher Eingriffe aus den Widersprüchen des kapitalistischen Produktionsprozesses, als Arbeits- und Verwertungsprozesses, im einzelnen aufweist. (Dafür ist dieser Aufsatz eine Vorbereitung; vgl.auch Elmar Aivaters Konjunk turanalyse in SOPO 5/70.

In diesem Sinn ist 2.B. Lenins Imperialismustheorie relevanter für die Einschätzung des bürgerlichen Staates und seiner Funktionen für den Prozeß der Kapitalvenwertung als Lenins Darlegung der marxistischen Staatstheorie in STAAT UND REVOLUTION. Hier neigt Lenin nämlich dazu, vom Staat im allgemeinen, unabhängig von der besonderen Form, die er in verschiedenen historischen Entwicklungsphasen der Organisation der materiellen Reproduktion der Gesellschaft annimmit, zu sprechen. So verblassen in dieser aktuellen polemischen Auseinandersetzung mit den Menschewiki und der revisionistischen deutschen Sozialdemokratie kurz vor der Oktoberrevolution die Unterschiede zwischen feudalem und bürgerlichem Staat. Dies entspringt folgerichtig der von Lenin in STAAT UND REVOLUTION verfolgen Absicht, eine poli $t$ is che Kritik der polit ischen Institutionen mit dem Ziel durchzuführen, die Notwendigkeit des Sturzes und der Zerschlagung des Staatsapparates durch die revolutionäre Arbeiterklasse aufzuzeigen. Die Frage ist in STAAT UNO REVOLUTION: Welche politische Strategie soll die Arbeiterklasse in einer revolutionären Situation gegenüber der politischen Institution Staatsapparat einschlagen? Geht es allerdings darum, den Handlungsspielraum und die Perspektive für Aktionsstrategien einer sich erst neu konstituierenden sozialistischen Bewegung zu bestimmen, so hilft eine marxistische Staatstheorie im Sinne von Lenins STAAT UND REVOLUTION wenig weiter, die ganz allgemein von der Notwen. digkeit der Zerschlagung des Staatsapparates spricht, aber keine Handhaben zur Einschätzung der Effektivität und Reichweite staatlicher Eingriffe in den Kapitalverwertungsprozeß gibt. (Daher ist die Schrift auch nicht als Einführungsschrift in 'die' marxistische Staatstheorie geeignet, wozu sie vielfach bei der Schulung herhalten muß.) Zur Entwicklung von Strategien ist es heute aber vor al. lem notwendig, Kriterien zu erhalten, wieweit die manipulativen Möglichkeiten des Staatsapparates reichen, wo sie aufhören, wo sie neue Widersprüche hervorbringen, wo sie in kapitalistischer Form Elemente einer wirklichen Vergesellschaftung der Produktion anthalten (2.B. bei der Standardisierung der Produktionselemente) usw. Es geht also nicht um eine allgemeine marxistische Staatstheorie, sondern um die Frage nach den spezifischen Funktionen des Staates für die Sicherung des Kapitalverwertungsprozesses im entwickelten Kapitalismus und um die Schranken dieser staatlichen Funktionen.

Gestalt der kapitalistischen Produktionsweise), der heutigen DKP-Theorie vom staatsmonopolistischen Kapitalismus sowie der politischen Soziologie von Habermas und Offe, die sowohl die Tradition der sozialdemokratischen Staatstheorie der Weimarer Republik als auch der bürgerlichen Soziologie seit Max Weber fortführen. Auf Seite 65 bis 119 des Buches sind die verschiedenen Formen und Inhalte der hier zunächst nur in großen Zügen gekennzeichneten revisionistischen Staatstheorie genauer nachzulesen. Vgl. ebenso: den Einleitungsaufsatz zur Neuausgabe von P. Lapinski u.a. in: GEGEN DEN STROM, vgl。 oben Anm. 1. Diedort ebenso wie im DKP-Buch immer wieder erhobene Forderung nach "historisch-genetischer" Analyse des kapitalistischen Staates wird in diesen Veröffentichungen selbst noch nicht eingelöst (was wohl auch noch nicht beabsichtigt war). Beim Versuch, einen Gesamtüberblick der revisionistischen politischen Vorstellungen zu geben, setzt die Kritik immer wieder im einzelnen an, ist dort auch durchaus zutreffend, indem sie sich auf die Tradition der Revisionismuskritik in der Arbeiterbewegung stützt; dabei geht aber immer wieder der systematische Zusammenhang der revisionistischen Theorien verloren, ebenso wie der Zusammenhang der Kritik an ihnen. So kommt es auch, daß es schwer ist, aufgrund dieser Ausführungen theoretische Ansätze für eine wirklich materialistische Kapitalismus- und Klassenanalyse zu finden. 
Der Pevisionismus ist die Form, in der der Klassengegner sich innerhalb der Arbeiterbewegung selbst festsetzt, in der die Ideologie der herrschenden Klasse sich als herrschende Ideologie auch in der Arbeiterklasse verbreitet. Diese Verbreitung erfolgt natülich nicht 'auf dem Rücken der bloßen Idea', sondam aut der Gundiage tatsächlicher Erfahrungen, die beidem: der revisionistischen Theorie und dem falschen Bewußztsein der Arbeiter, gemeinsamer Hintergrund ist. Wesentlich für die Herausbildung des Revisionismus in der Geschichte der Arbeiterbewegung ist die Erfahrung von 'sozialpolitischen' Gesetzen des bürgerlichen Staates, die bestimmte Formen der Ausbeutung der Arbeiter im kapitalistischen Betrieb einschränken und die materielle Existenz der Lohnabhängigen für Zeiten, in denen sie ihre Arbeitskraft nicht als Ware auf dem Markt verkaufen können (Krankheit, Alter, Arbeitslosigkeiv), auf der Basis eines Existenzminimums sichern (Arbeiterschutzgesetzgebung und Sozialversicherungssysteme). Diese Gesetze konnten leicht als Einschränkung der Herrschaft des Kapitals über die lebendige Arbeit erscheinen, zumal ihre Durchsetzung immer auch vermittel tes Ergebnis der Klassenkämpfe war. Der Staat konnte so in den Augen der Arbeiterklasse, insbesondere aber ihrer Organisation (8) als ein Instrument erscheinen, mit dessen Hilfe man sich auf dem Wege der 'Salamitaktik' stückweise die politische und gesellschaftliche Herrschaft aneignen könne. So schreibt Sering richtig: "Dem Entwicklungsgrad dieser Staatsfunktion (Verkehr. Bildung. Sozialpolitik) pflegt übrigens bis zu einem gewissen Grad die Stärke des Re. formismus parallel zu gehen." (9) Zunehmende wirtschafts- und sozialpolitische Eingriffe des Staates, Konzentration des Kapitals und längere Prosperitätsphasen, vor allem vor dem 1. Weltkrieg und nach dem 2. Weltkrieg (10), bilden die hauptsächliche Erfahrungsbasis für die von der Möglichkeir der schrittweisen Überführung des Kapitalismus $m$ it $\&$ \& $\mathrm{s}$ des staatlichen Apparates. Sie erscheint im Gewande der Bernsteinschen Theorie vor dem 1. Weltkrieg, der Theorie vom orga nisierten Kapitalismus und der Wirtschaf tsdemokratie in derWeimarer Republik (Hilferding, Naphtali usw.) und am Anfang der BRD (Münchner Programm des DGB 1949); auch in den Theorien, die die gegenwärtige Phase der kapitalistischen Entwicklung als staatsmonopolistischen Kapitalismus bestimmen $(2, B$. "Imperialismus heute"); und schließlich in der Theorie vom Wohlfahrts und Inaerventionsstaat im Sinne der Frankfurter Schule (Habermas, Offe u.a.).

Der Zusammenhang zwischen dem empirischen Bewußtsein der Arbeiter (und auch der Studenten) und der revisionistischen Theorie besteht darin, daß die Theorie die Erfahrungen noch begründet,

Entspricht nicht die revisionistische Theorie vor allem dem Bewußtsein jener Funktionäre der bereits bürokratisierten Arbeiterorganisationen, die nicht mehr den Konflikt mit dem Kapital am eigenen Leibe erfahren, sondern wesentlich durch ihre teilweise erfolgreiche Vermittlungstätigkeit zu "Spitzenverbänden" und staatlicher Verwaltung geprägt sind? Hat dagegen die Masse der Arbeiter nicht vielmehr jenes 'dichotomische Bewußisein' ('die da oben'), das nach zahireichen Untersuchungen bis heute vorherrscht? Ist im vorliegenden Text nicht das Bewußtsein der Organisierten und das des organisierenden Apparats allzu umstandslos gleichgesetzt? Kann man überhaupt die Ausbildung eines revisionistischen Bewußtseins erklä. ren, ohne darzustellen, durch welche Organisationsform vermittelt der Klassenkampf tatsächlich abläuft? Kann man von 'tatsächlichen Erfahrungen' ohne Berücksichtigung der orga. nisatorischen Ebene und des genauen gesellschaftichen Ortes, wo solche Erfahrungen gemacht werden, sprechen? Wir formulieren diese Fragen, um anzudeuten, was wir hier offen lassen. Vgl. dazu auch unten II. 4.

9 P.Sering: "Wandlungen des Kapitalismus", in: ZEITSCHRIFT FÜR SOZIALISMUS, Prag $1935, \mathrm{Nr} .22 / 23, \$ .717$.

10 Für den gewerkschaf thichen Apparat war sicher das Erlebnis der Unentbehrlichkeit, der "erfolgreichen' Zusammenarbeit mit dem Staatsapparat im 1. Weltkrieg (bis zur Denunziation unbotmäßiger Arbeiter) und danach von entscheidender Bedeutung. Wichtig für die lllusion nen vom "organisierten Kapitalismus" war die Erinnerung an den sogenannten Kriegssozialis. mus, der staatlich (d.h. wesentlich von den Interessevertretern der großen Rüsturgskonzerne) organisierten Kriegswirtschaft; das gilt z.B. für Wissel und Hilferding. Vgl. dazu den schon angeführten Aufsatz von Lapinski, der sich ausführlich mit der Entstehung insticutionalisierter Zusammenarbeit der Klassen während des 1. Weltkriegs beschäftigt und ihre Fortführung in der Weimarer Republik zeigt. Die Bildung der Zentralen Arbeitsgemeinschaft zwischen Gewerkschaften und Unternehmern im November 1918 zum $Z$ weck der (aus verschiedenen Mctiven) gemeinsamen Abwiegelung der Revolution ist hier nur ein Höhepunkt. Vgl. auch Deppe/Freyberg/Kievenheim/Meyer/Werkmeister: KRITIK DER MITBESTIMRUSG, Frankfurt/ Main 1969, sowie EU.Projekitgruppe DKP/Rabehl, a.a.0.S. 74. 
rechtfertigt und ihnen damit noch den Schein der Notwendigkeit anheftet. 111) Das bedeutet zweierlei: Ers te $\mathrm{ns}$ kann politische Agitation in der Arbeiterklasse nicht ohne Berücksichtigung einer langen reformistischen Tradition stattfinden. Für die Agitation der Studenten an der Universität ist die Kritik der reformistischen Vorstellungen womöglich noch wichtiger, da ihre Situation enger als die der Lohnabhängigen an den Staat gebunden ist. Diese Auseinandersetzung kann nur geführt werden, wenn die Zusammenhänge zwischen den ökonomischen Verhältnissen und den politischen Formen, zwischen ökonomischem und politischem Kampf jeweils im einzelnen aufgezeigt werden. $\mathrm{Z}$ we i t e n s muß daraus die Schlußfolgerung gezogen werden, daß Revisionismus und falsches $\mathrm{Be}$ wußtsein endgültig nicht bloß theoretisch destruiert werden können, sondern hierzu soziale Kämpfe und Klassenkämpfe notwendig sind.

\section{Zur Theorie vom Sozialstaat}

\section{Die Souveränität des Staates bei der Verteilung des Sozialprodukts}

Eines ist den meisten revisionistischen mit den politologischen sowie vielen nationalökonomischen Theorien gemeinsam: sie gehen davon aus, daß der Staat im Kapitalismus die Möglichkeit zu umfassender und bewußter Regulierung ökonomischer, gesellschaftlicher und politischer Prozesse hat. Dabei ist das eigentliche Terrain, auf dem der Staat als 'Sozialstaat' sich als selbständig gegenüber der kapitalistischen Produktion erweisen soll, die Sphäre der 'Verteilung des Sozialprodukts'. Hier soll er seine Hebel zur Verbesserung oder gar schrittweisen Uberführung der kapitalistischen Gesellschaft in Richtung auf den Sozialismus ansetzen können. Eine solche Vorstellung schließt also die Annahme ein, "daß die Distribution als selbständige, unabhängige Sphäre neben der Produktion haust" (12). Die Produktion und die sie beherrschenden Gesetze sollen also der "Verteilung' (13) keine grundsätzlich nicht manipulierbaren Schranken setzen. Eine derartige Auffassung läßt sich in den revisionistischen ebenso wie in zahlreichen bürgerlichen (vor allem politologischen) Theorien ausmachen, wie an einigen Beispielen gezeigt werden soll.

11 Vgl. aber das oben (Anm. 8) bezeichnete Problem.

12 Marx: GRUNDRISSE, S. 11.

13 Bereits der Begriff der 'Verteilung' bzw. 'Distribution' ist in der bürgerlichen Wissenschaft von vornherein auf die Ebene des Nettosozialprodukts bzw. des 'Volkseinkommens' beschränkt; die Möglichkeit der Verteilung auf anderer Ebene, z.B. auf der der Produktionsagenzien - Arbeitskraft/Produktionsmittel -, ist so bereits erledigt. Vgl. dazu Teil III. - Es fällt in diesem Zusammenhang regelmäßig der Hinweis, daß der vom Staat verteilte Teil des Sozialproduk ts immer weiter anwachse. Dazu zunächst einige Angaben: der vom Staat in Gestalt von Steuern und Beiträgen zur Sozialversicherung beanspruchte Teil des Bruttosozialprodukts betrug $191311,8 \%(8,9+2,9 \%), 192923,1 \%(16,7+5,6 \%), 196334,4 \%(25,1$ $+9,3 \%$ ), Deutsches Reich bzw. Bundesrepublik und West-Berlin (nach: K. Elsholz: "Strukturänderung der Sozialpolitik", KLEINE SCHRIFTEN ZUR SOZIALPOLITIK UND ZUM ARBEITSRECHT, 4. Folge, Heft 10, München o.J. (1963), S. 36. Abgesehen davon, daß in den letzten Jahrzehnten eine deutliche Verlangsamung des Wachstums des Staatshaushalts in seinem Anteil am BSP zu beobachten ist, ändert auch der gestiegene Anteil nichts an der Tatsache, daß vor dem staatlichen Steuer- und Sozialabgabeneinzug die 'Verteilung' des Sozialprodukts im direkten Gegenüber der beiden Klassen erfolgt, konkret in Tarifverhandlungen, bzw. den dahinter stehenden latenten oder offenen Klassenkämpfen. Bei den Abgaben zur Sozialversicherung (1963 9,3\%) kann schon auf den ersten Blick von einer staatlichen Umverteilung kaum gesprochen werden, da es sich hier um nichts anderes, als um eine staatlich garantierte $\mathrm{V}$ e r s i ch e r u $\mathrm{g}$ handelt, und niemand auf die Idee käme, etwa eine Privatversicherung als Eingriff in die kapitalistische Verteilung zu betrachten. Es handelt sich bei der Sozialversicherung blo $B$ um eine Umverteilung innerhalb der Lohnquote, und im ganzen gesehen, gehören sowohl die sofort ausgezahlten wie die erst nach der Verwertung der Arbeitskraft als Rente ausgezahlten Summen zum Wert der Arbeitskraft. Da zu diesem Wert auch ihre 'Bildungskosten' gehören (z.B. die Kosten für Volksschulen), so ist auch der entsprechende Teil der staatlichen Ausgaben letzten Endes ein Teil des vom Gesamtkapital vorgeschossenen variablen Kapitals, der freilich nicht als individueller Lohn zirkuliert. Ein sehr beträchtlicher Teil der Staatsausgaben fält so unter die Kategorie des variablen Kapitals bzw., ungefähr gesprochen, der Lohnquote. Ebenso müßte man einen Teil des gesamtgesellschaftli- 
So unterscheidet z.B. der von der Linken in der BRD in den letzten Jahren gern zitierte Otto Kirchheimer (1930) zwischen der "Direktionssphäre" und der "Verteilungssphäre", wobei die Di. rektionssphäre "der Eigengesetzlichkeit der kapitalistischen Wirtschaftsordnung" unterliegt, während die Verteilungssphäre "dem freien Spiel der politischen Kräfte vorbehalten ist" (14). Der autonom durch staatliche Manipulationen regulierbaren Verteilungssphäre wird eine "Direktionssphä. re $^{\prime \prime}$ gegenübergestellt, die für Kirchheimer identisch ist mit der kapitalistischen Produktion. Bei Paul Sering, an dessen Schrift JENSEITS DES KAPITALISMUS (1946) sich eine ganze Generation von Linksgewerkschaftlern und Linkssozialdemokraten in der BRD geschult hat, tritt die Loslösung der Distribution von der Produktion deutlich zutage: es werde "immer sichtbarer, daß die tatsächliche Einkommiensverteilung nicht durch unveränderliche ökonomische Gesetze entschieden wird, sondern durch den politischen Kampf um den Einfluß auf die Wirtschaftspolitik der Regierung geänder werden kann" (15). Wie es für den von Lenin gegeißelten Ö k o n o m is mus ty. pisch ist, ökonomische Prozesse als letztlich die politische Sphäre determinierend anzusehen, so erscheint die konträre Spielart des Revisionismus als "P o l i t i z is m u s", der die politischen Mög. lichkeiten des Staates gegenüber den ökonomischen Gesetzen ve r a b s o l u t i e $r t$, indem er die Totalität der kapitalistischen Gesellschaft säuberlich in Sphären trennt, unter denen die politische hervorragt als diejenige, in der wesentliche gesellschaftliche Veränderungen möglich seien, ohne daß an der ökonomischen Sphäre etwas Wesentliches geändert würde. Dies versucht man gerade am Beispiel sozialpolitischer Maßnahmen des kapitalistischen Staates zu zeigen; so etwa Bernstein, nach dessen Auffassung sich "der klassische Begriff des Kapitalismus gewöhnlich auf drei g e t r e n n. t e Gebiete (bezieht): die Produktionsform, die Verteilungsform und die gesetzlichen Beziehungen. Nur die erste sei in der vorangegangenen Zeit nicht wesentlich verändert worden; die beiden anderen seien großen Veränderungen unterworfen gewesen" $(16)$.

Diese absolute Trennung der beiden Sphären, in der die Verselbständigung des Staatsapparates unvermittelt zur Autonomie des Staats gegenüber der kapitalistischen Produktionsform führt, kommt auch in der Theorie vom 'politischen Lohn' zum Ausdruck, wie sie von Rudolf Hilferding (1927) formuliert worden ist. Danach wird der Lohn nicht mehr durch ökonomische Gesetze, sondern

chen Mehrwerts einzelnen Sparten des Staatshaushalts zuordnen können, wo er teils bloß auf bestimmte Kapitalzweige umverteilt wird (Subventionen, Steuervergünstigungen), teils zur ideologischen, militärischen usw. Sicherung des Kapitalverhältnisses ausgegeben wird. Die Vorstellung von der Umverteilung würde sich sehr reduzieren. Dies als Hinweis auf eine der Aufgaben der Realanalyse des Sozial- und Interventionsstaates.

14 O. Kirchheimer: "Weimar und was dann?" (1930) In: ders.: POLITIK UND VERFASSUNG, Frankfurt 1964, S. 42 f. Schon Tugan-Baranowski erschien die Verteilung als reines Machtproblem, während er die Produktion durch ökonomische und technische Gesetze bestimmt sah (vgl. E. Preiser in: HANDWORTERBUCH DER SOZIALWISSENSCHAFTEN, Stichwort: Distributionstheorie, (Band VIII), S. 623.

15 Sering: JENSEITS DES KAPITALISMUS. Ein Beitrag zur sozialistischen Neuorientierung. Nürnberg $1946^{1}, 1948^{3}$, S. 5 9. Eine Auflage von mehreren tausend Exemplaren wurde von der IG-Metall aufgekauft; Fritz Vilmar (RUSTUNG UND ABRÜSTUNG, Frankfurt/Main 1965) z.B. stützt sich stark auf Sering. Rudi Dutschke zitierte gern aus Sering, vorzugsweise allerdings aus den Aufsätzen der dreißiger Jahre.

16 Peter Gay: DAS DILEMMA DES DEMIOKRATISCHEN SOZIALISMUS, Nürnberg 1954, referiert hier das Konzept einer Rede Bernsteins aus dem Jahre 1925, S. 270 (keine Hervorhebung im Original) Vgl. schon Marx' Kritik an John Stuart Mill, KAPITAL Bd. 3, S. 884 f. Demgemäß schon Rosa Luxemburgs Kritik an Bernstein in "Sozialreform oder Revolution" a.a.0. S. 105: "Bernstein formuliert auch wiederholt seinen Sozialismus als das Bestreben nach einer 'gerechten', 'gerechteren', ja einer 'noch gerechteren' Verteilung... Die Sozialdemokratie will die sozialistische Verteilung durch die Beseitigung der kapitalistischen Produktionsweise herbeiführen, während das Bernsteinsche Verfahren ein direkt umgekehrtes ist; er will die kapitalistische Verteilung bekämpfen und hofft auf diesem Wege allmählich die sozialistische Produktionsweise herbeizuführen."

AUSFƯHHRICHER PROSPEKT U̇BER UNSERE REPRINTS

NR.1-11 WIRD KOSTENLOS VERSANDT。

POLITLADEN, 852 ERLANGEN, HINDENBURGSTR 17 
durch die Stärke der parlamentarischen Vertretung der Arbeiterklasse, von der Stärke ihrer Organisation und den-sozialen Machtverhältnissen außerhalb des Parlaments bestimmt (17). Die Regu. lierbarkeit des ökonomischen Antagonismus im 'Generalkartell' findet ihre Entsprechung in der politischen Regulierung der Masseneinkommen, nun aber unabhängig von den ökonomischen Gesetzen. Ganz in diese Tradition revisionistischer Verklärungsversuche gehört denn auch die These von Claus Offe (1969): das Individualeinkommen unterliege heutzutage "politischen Regulationen" und lasse sich nicht mehr aus der kapitalistischen Produktionsweise, sondern aus den soziologischpolitischen Konstellationen der verschiedenen Bevölkerungsgruppen erklären (18).

Die Verteilung arscheint also nicht mehr als notwendiges Moment des Produktions- und Zirkulationsprozesses des Kapitals, sondern als Feld für politisch bestimmte Staatsakte.In welchePortionen die produzierte Warenfülle, der "Kuchen des Sozialprodukts" (Erhard) vom Staat verteilt wird. das ist abhängig von der Intensität und Vehemenz, in der die verschiedenen sozialen Gruppen ihre 'Interessen' gegenüber dem Staat vertreten, von der Kampfstärke der Arbeiterklasse, vom Stand des politischen Bewußtseins der 'Bürger', von der Sorge des Staates ums 'Systemgleichgewicht', davon, ob der politische Willensbildungsprozeß demokratisch oder autoritär erfolgt, von der Effizienz der Verwaltung, vom Sieg der einen oder anderen Partei bei den Wahlen, vom Grad der politischen Be. teiligung usw. (19), also von politisch-gesellschaftlichen Verhältnissen, die, da von ökonomischen

17 PROTOKOLL DES SPD-PARTEITAGES IN KIEL 1927, S. 170. Hilferding, der in der Weimarer Republik zum Revisionismus überwechselt, ging schon im Finanzkapital, wo er unter weitgehender Absehung vom Produktionsprozeß primär die Zirkulationssphäre behandelt, davon aus, da $B$ der Entwicklungsproze $B$ der kapitalistischen Produktion auf die Bildung eines Generalkartells hinauslaufe, und damit auf die Beseitigung der Anarchie der Produktion. Für die sozialistische Revolution galt es dann vor allem noch, die Ungleichheiten in der Verteilung zu beseitigen. Er schränkte damals ein, eine solche Entwicklung sei zwar ökonomisch möglich, jedoch nicht politisch und sozial. (Vgl. FINANZKAPITAL, 1910, Neudruck Frankfurt/Main 1968, S. 322 und 403). Auf der Basis dieser Vorstellungen entwickelte er in der Weimarer Republik seine Theorie vom 'organisierten Kapitalismus' und im Zusammenhang damit seine Vorstellung vom 'politischen Lohn'. Zur Kritik dieser Theorie: M. Kriwizki: "Die Lohntheorie der deutschen Sozialdemokratie", in: UNTER DEM BANNER DES MARXISMUS, II (1928/29, S. 381 ff), neu abgedruckt in: GEGEN DEN STROM, a.a.O. S. 75 ff; vgl. auch W. Gottschalch: STRUKTURVERANDERUNGEN DER GESELLSCHAFT UND POLITISCHES HANDELN IN DER LEHRE VON RUDOLF HILFERDING, Berlin-West 1962.

18 Vgl. Claus Offe: "Politische Herrschaft und Klassenstrukturen. Zur Analyse spätkapitalistischer Gesellschaftssysteme", in: Kress/Senghaas: POLITIKWISSENSCHAFT, Frankfurt/Main 1969, S. 176 f. Habermas spricht (in: Habermas/Friedeburg/Oehler/Weltz: STUDENT UND POLITIK, Neuwied 1961) von tiefen Eingriffen des Staates ins "System der Güterherstellung und -verteilung" (S. 22), muß dann aber doch zugestehen, daB "weiterhin die privase Verfügung über Produktionsmittel Grundlage... des Wirtschaftsprozesses sei" (S. 23), and hält sich bei seiner Sozialstaatstheorie vor allern an die Explikation der Souveränität der Staatsgewalt als verteilenuler gegenüber dem kapitalistischen Produktionsprozeß, was vor allem bei seinen Thesen über die Determinanten politischen Handelns der Staatsgewalt sichtbar wird. (Vgl. unten II, 4.: Sozialstaat und pluralistische Demokratie.)

19 Dies ist ein kurzer Uberblick über die Momente, die in den Sozialstaatstheorien von Hiferding, Sering, Offe, Habermas, Hennis u.a. entscheidend sind für den Vertellungsschlüssel, nach dem das Sozialprodukt auf die verschiedenen 'sozialen Gruppen' autgeveilt wird, und für die Inhalte der Verteilungstätigkeit des Staates (Sozialkonsum/Sozialinvestitionen/Rü stung). Was den Begriff des Sozialstaats angeht, so sei hier noch folgendes angemerkt: Der Unterschied zwischen solchen Staatstheorien, die den gegenwärtigen kapicalistischen Staat schon als Sozialstaat bezeichnen (Habermas, Offe), und solchen, die davon ausgehera, dais durch langsame Zurïkdrängung der Macht der Monopole, durch Mitbestimnung und demokratische Kräfte im Parlament, der Sozialstaat allmählich Boden gewinnen könne, liegt vor allem darir, daß die letzteren von einem unmittelbaren Einfluß der Monopole auf den Staat ausgehen, ihn als Instrument der Monopole betzachten, während die ersteren davon ausgehen, daß es heutzutage "problematisch" sei, "die Abhängigkeit der politischen Aktionen von cien ökonomischen Interessen" zu unterstellen. (Habermas: THEORIE LND PRAXIS, Neuwied/ Berlin 1963, S. 200. Ebenda S. 163 ausdrücklich vom "Stadium des organisierten Kapitalismus", wo der "Bereich des Warenverkehrs" bereits weitgehend "politisch vermittelt" werde.) 
Gesetzmäßigkeiten unabhängig, dem "gesellschaftlichen Zufafl" unterworten sind (20). Wenn auch die "ökonomische Tendenz zur Ungleichheit" nicht einfach geleugnet wird, so wird doch gerade aufgrund der "Verselbständigung" der politischen Sphäre dem Staat die Möglichkeit zur "politischen Kompensation" der naturwüchsig dem Produktionsprozeß entspringenden Ungleichteit ein. geräumt. Dem Staat stehen aufgrund dieser behaupteten Selbständigkeit der "politischen gegentüber der ökonomischen Macht" die Schiüssel zur Verteilung des "Sozialproduk:s' zur Disposition (21).

Kapilalistische Produktion und Verteilung, sowohi der für die Erweicerung der Produktion als auch der für den individuellen Konsum bestimmten Waren, haben sich durch das Dazwischentreten der Staałsgewalt voneinander gelöst. Der Staat erscheint als gegenüber den Produktionsverhältnissen au. tonomes Subjekt. So erhält er in der bürgerlichen Theorie konsequent die Bezeichnungen "Verteilerstaat", "Wohlfahrtsstaat", "Interventionsstaat". "Dienstleistungsstaat", "Gefalligkeitsstaat". kurzum "Sozialstaat" (22). Denn der Sozialstaat zeichnet sich ja nach dieser Auffassung dadurch aus, daß er über einen wachsenden Anteil am Sozialprodukt verfügt und diesen nach politischen und sozialen Gesichrspunkten in Form von Sozialieistungen, Subventionen und öfentichen Auf* trägen zur Produktion von Schulen, Krankenhäusern, Straßen oder von Raketen, Bomben und Granaten verwenden und verteilen kann. Die Entstehung des zu Verteilenden, des "Sozialprodukts", also der Produktionsprozeß, existiert nicht als Problem der Verteilung. Daher können die

Da aber auch die Theorie vom staatsmonopolistischen Kapitalismus vor allem hierin auf der Ebene politischer Einflußnahmen argumentiert, wird kein deutlicher Zusammenhang zwischen Staat und Kapitalverwertungsprozeß sichtbar (eben im Unterschied zur bloßen 'Abhängig keit' von 'ökonomischen Interessen').

20 Marx: GRUNDRISSE, S. 8: "Die Produktion soll... im Unterschied von der Distribution etc. eingefaßt in von der Geschichte unabhängige ewige Naturgesetze dargestellt werden, bei welcher Gelegenheit dann ganz unter der Hand bürgerliche Verhältnisse als unumstöBliche Naturgesetze der Gesellschaft in abstracto unterschoben werden... Bei der Distribution dagegen sollen die Menschen in der Tat allerlei Willkür sich erlaubt haben." Marx deutet hier und im folgenden an, wie durch die "rohe AuseinanderreiBung" von Produktion und Distribution der Produktionsprozeß als Naturprozeß erscheint, und der Distributionsprozeß damit zu ei. nem Vorgang wird, der allein durch "gesellschaftliche Gesetze" (S. 10) (was in diesem Zu. sammenhang synonym ist mit "gesellschaftlichem Zufall", S. 11) bestimmt wird. Die Un. fähigkeit, die kapitalistische Produktion als Kreislaufprozeß des Kapitals zu begreifen, resultier $\mathrm{t}$ in der Loslösung der Distribution aus diesem Zusammenhang; daher dann die Illusion von der staatlichen Umverteilung auf der Ebene der 'Einkommen'. Der Revisionismus knüpft von Anfang an an grundsätzliche Denkmuster der bürgerlichen Okonomie an (was nicht verhindert, daß er weit größeren Illusionen verfällt). Dies kritisiert Marx hier. Vgl. dazu auch: Marx: "Kritik des Gothaer Programms", MEW Bd. 19, S. 25 f: "Der Vulgärsozialismus hat es von den bürgerlichen Ókonomen übernommen, die Dist ibution als von der Produksionsweise unabhängig zu betrachten und zu behandeln, daher den Sozialismus hauptsächlich als um die Distribution sich drehend darzustellen." Die eigentliche Entwicklung dieser Kritik ist natürlich im 'Kapital' enthal ten.

21 Vgl. dazu Habermas: STUDENT..., a.a.O. S. 42 und 50, desgleichen schon Bernstein, Kauts. ky, Cunow, Renner u.a., nachzulesen bei: I. Fetscher, Hrsg.: DER MARXISMUS, SEINE GESCHICHTE IN DOKUMENTEN, Bd. III, München 1965, S. 41-56.

Im GODESBERGER PROGRAMM der SPD, Bonn 1959, ist nachzulesen: "Die Markiwirtschaft gewährleistet von sich aus keine gerechte Einkommens- und Vermögensverteilung: dazu bedarf es einer zieitewußten Einkommens- und Vermögenspolitik." (S. 16)

Vgl. auch Otto Brenner: "Technischer Fortschritt und Gewerkschaften", in: AUTOMATION UND TECHNISCHER FORTSCHRITT IN DEUTSCHLAND UND DEN USA, Frark furt/Main 1963, S. 308 ff: "Automation und technischer Fortschritt errnöglichen mehr Woh" stand für alle' Inwieweit die Arbeitnehmer jedoch an diesem Wohistand teilhaken, hängt davon $a b$, wie das erhöhte Volkseinkommen verteilt wird... Das erklärte Ziel der Gewerkschaf. ten war es und wird es bleiben, den Arbeitnehmeranteil am Volkseinkommen zu erhöhen." (S. 312)

22 Ebenso wie der eigentliche Revisionismus sehen heutzutage politologische, staatsrechtiche usw. Apologeten des Kapitals in den verteilenden Tätigkeiten der Staatsgewalt ihre neue und sie bestimmende Qualität, nur mit dem Unterschied, daß sie diese Funktionen der Staatsgewalt, weil gegen das Leistungsprinzip und Markteinkommen verstoßend, mit Begriffen wie 
staatlichen Maßnahmen als bloß politische, als von den politischen Machtverhältnissen und nicht von den ökonomischen Gesetzmäßigkeiten der Reproduktion der kapitalistischen Gesellschaft abhängig aufgefaßt werden.

Die nationalökonomischen Theorien haben demgegenüber im ganzen eine realistischere Vorstellung von diesen ökonomischen Gesetzmäßigkeiten und daher den Schranken der Staatstätigkeit. Das kommt schon in der terminologischen Unterscheidung der "primären". "spontanen" von der "sekundären". "politischen" Verteilung zum Ausdruck. Vielfach (und das gilt besonders für die konservativen Varianten) werden daher die in den "Erfordernissen eines gesunden Wirtschaftsablauff $^{s \theta}$ liegenden Schranken der staatlichen Redistribution deutlicher gesehen (regelmäßig z.B. in den sachverständigen Warnungen vor einer "überschäumenden Sozialpolitik" und der Empfehlung, die beste Sozialpolitik liege in einer guten Wirtschaftspolitik). Doch ist auch hier der wirkliche Zusammenhang von Produktion und Distribution nicht erfaßt, und es kann auch nicht anders sein. Vom bürgerlichen Standpunkt aus kann die Distribution der Produkte bzw. der Einkommen nicht ais bloßes Moment des Kapitalkreislaufs und der in inm enthialtenen Distribution der Produktionsagentien begriffen werden, weil mit dem Begriff des kreislaufenden und sich verwertenden Kapitals zugleich die Produktionssphäre als Ort der Produktion von Mehrwert begriffen wär. Auf die Differenzen in der Einschätzung der staatlichen Umverteilung, wie sie z.B. im Rahmen der Distributionstheorie zum Ausdruck kommen, werden wir noch genauer eingehen (vgl. unten Teil III).

Auch wenn in den revisionistischen Theorien im Anschluß an Marx noch von 'kapitalistischer' Organisation der Produktion gesprochen wird, wie bei Habermas und Offe zum Beispiel - von den vorfaschistischen Vertretern des Revisionismus ganz zu schweigen; sie konnten noch unschuldig mit dem Begriff 'Kapitalismus' operieren - entgeht innen gerade das Spezifikum kapitalistischer Produktionsweise: daß die Basis der ökonomischen Reproduktion der Gesellschaft der Kreislauf des Kapitals ist und die Sphäre der Verteilung der Einkommen lediglich ein Moment im Kapitalkreislauf darstellt. So ist der 'politische Lohn' vom Standpunkt des Kapitals aus betrachtet eben variables Kapital, das vorgeschossen werden muß und mit seiner Größe die Profitrate beeinflußt. Schon vion diesem - noch genauer auszuführenden - Aspekt her erweist sich die Betrachtung der kapitalistischen Form der Produktion und der verteilenden Tätigkeit des Staates als voneinander gelöster Momente der kapitalistischen Gesellschaft als unrichtig.

\section{Unfähigkeit, den Produktionsprozeß in seinem Doppeicharakter zu begreif́en}

Selbstverständlich tritt die Überschätzung staatlicher Eingriffsmöglichkeiten in den Verteilungsmechanismus, wie bereits angedeutet, in jeweils modifizierten Formen in den verschiedenen Theorien auf. Sie reichen von der völligen Aussparung der Produktionssphäre bis zu ihrer beschränkten Berücksichtigung, nämlich im Rahmen der innerhalb der bürgerlichen Wissenschaften vorgegebenen Arbeitsteilung. Die neueren Sozialstaatstheorien, die nicht mehr an einer politischen Praxis der Arbeiterbewegung orientiert (und insofern nicht mehr im eigentlichen Sinn revisionistisch) sind, begreifen sich vorwiegend als politisch-soziologische Theorien und überlassen die Analyse der Wirtschaft' der ökonomischen Theorie, aus der sie dann auch die Sätze übernehmen, die am ehesten in ihr Konzept hineinpassen: Habermas stützt sich auf Joan Robinson zur 'Widerlegung' der Marx.

"Gefälligkeitsstaat", Staat als "ungeheure Ausgleichskasse" etc. denunzieren. Vgl. dazu: Ernst Forsthoff: "Begriff und Wesen des sozialen Rechtsstaats", Veröffentlichungen der Vereinigung der Staatsrechtslehrer, Heft 12, Berlin-West 1954, S. 8 ff; Werner Weber: SPANNUNGEN UND KRÄFTE IM WESTDEUTSCHEN VERFASSUNGSSYSTEM, Stut tgart 1951. Wenn im folgenden wiederholt auf die Analogien in der Analyse der entwickelten kapitalistischen Gesellschaft zwischen Revisionisten und bürgerlich-reaktionären Wissenschaftlern hingewiesen wird, so deshalb, um zu zeigen, daß eben kein dritter Weg zwischen marxistischer und bürgerlicher Gesellschaftsanalyse möglich ist, sondern daß revisionistische Theorien notwendir zuf bürgerliche hinauslaufen. Man kann nicht einfach, wie Habermas z.B. dies immer wieder tut, auf der Basis der 'wissenschaftlichen' Ergebnisse von Forsthoff bis Hennis eine völlig andere gesellschaf tskritische Konsequenz herleiten. Dies bleibt dann in der Tat (moralisierende) Kritik. 
schen Werttheorie (23), Offe auf Shonfield (24) und alle insgesamt auf die Keynesianischen Spielarten innerhalb der bürgerlichen Ökonomie. Sie begreifen daher nichî mehr, daß bereits in der Arbeitsteilung der einzelwissenschaftlichen Theoriebildung die Verabsolutierung einzelner Segmente der Totalität kapitalistischer Produktionsweise impliziert ist und daß auch die Zusammenfassung von Aussagen über die einzelnen Segmente keinen Begriff des Ganzen ergeben kann. Eines ist jedoch dem Revisionismus seit Bernstein gemeinsam, daß der Produktionsprozeß selbst dort, wo er explizit Berücksichtigung findet, nicht als widersprüchliche Einheit von Arbeits- und Venwertungsprozeß begriffen werden kann, sondern als bloßer Arbeitsprozeß erscheint, der sich allein durch seine besonderen juristischen und organisatorischen Formen noch als kapitalistischer ausweist .

Rosa Lusemburg kritisiert schon an Bernstein zu Recht, er verstehe "unter Kapitalist nicht eine Kategorie der Produktion, sondern des Eigentumsrechts, nicht eine wirtschaftliche, sondern eine steuerpolizische Einheit. ... Indem Bernstein den Begriff Kapitalist aus den Produktionsverhältnissen in die Eigentumsverhältnisse überträgt ... überträgt er auch die Frage des Sozialismus aus dem Gebiet der Produktion auf das Gebiet der Vermögensverhältnisse, aus dem Verhältnis von Kapital und Arbeit in das Verhältnis von reich und arm." (25) Hier wird deutlich, wie die Reduktion der Kapitalismuskritik auf die Frage der 'gerechten Verteilung' bei Bernstein, die wiederum die Basis seiner reformistischen Strategie ist - der Staat als Subjekt der gesellschaftlichen Umwandlung seiner bloß soziologisch-juristischen Bestimmung des Kapitalverhältnisses entspringt. Diese aber ist nur möglich, wenn der Produktionsprozeß nicht in seinem Doppelcharakter begriffen wird, sondern als bloßer Arbeitsprozeß, dem die kapitalistischen Bestimmungen nur als zufällige anhaften, die daher bei gutem Willen des Kapitalisten und unter entsprechendem Druck der Arbeiterklasse innerhalb des Kapitalismus beseitigt werden können.

Jeder Begriff davon geht verloren, daß der Produktionsprozeß als Verwertungsprozeß des Kapitals bestimmten Gesetzmäßigkeiten unterliegt, die sich hinter dem Rücken der Individuen durchsetzen und den einzelnen Kapitalisten zu ihrem Vollzugsorgan machen. Zwar wird das Wort 'kapitalistische Produktion' im Munde geführt, wobei man im Sinne von Marx zu sprechen glaubt, doch der $\mathrm{spezifische} \mathrm{Charakter} \mathrm{des} \mathrm{kapitalistischen} \mathrm{Produktionsprozesses} \mathrm{wird} \mathrm{dabei} \mathrm{unterschlagen.}$ Jeder Produktionsprozeß ist Arbeitsprozeß, unabhängig von den Produktionsverhältnissen; es wird in ihm nützliche Arbeit geleistet, deren Zweck die Herstellung von Gebrauchsgütern ist. "Im A r b e it sprozeß bewirkt also die Tätigkeit des Menschen durch das Arbeitsmittel eine von vornherein bezweckte Veränderung des Arbeitsgegenstandes. Der Prozeß erlischt im Produkt. Sein Produkt ist ein $\mathrm{G}$ e b r a u c hswe $\mathrm{r} t$, ein durch Formveränderungen menschlichen Bedürfnissen angeeigneter Naturstoff." (26 a) Demgegenüber ist der Verwertungsprozeß dadurch gekennzeich. net, daß er nicht die Gebrauchswerte um ihrer selbst willen, sondern als Träger von Tauschwert herstellt. Der Kapitalist "will nicht nur einen G ebrauchswert produzieren, sondern eine Wa $r e$, nicht nur Gebrauchswert, sondern Wert, und nicht nur We r t , sondern M e h rwe rt." (26 b) Der kapitalistische Produktionsprozeß findet nur statt, wenn zum einen in ihm mehr Wert erzeugt wird, als der Kapitalist beim Ankauf von Produktionsmitteln und Arbeitskraft in ihn hineingesteckt hat, und wenn zum anderen die erzeugten Produkte als Waren auf dem Markt verkauft werden können, ihre Umwandlung in Geldform zu gelingen verspricht.

23 Vgl. hierzu W. Müller: "Habermas und die Anwendbarkeit der Arbeitswerttheorie", SOPO $1 / 69$, S. 40-44. Die beliebige Verwendung der Begriffe 'Sozialprodukt', 'gesellschaftlicher Reichıum', auch einmal 'Warenfulle', dann wieder 'Produkte' bei den Revisionisten zeigt schon, daß hier das Problem nicht mehr gesehen wird, das Marx gleich zu Anfang des 'Kapitals' ausspricht, daß nämlich der gesellschaftliche Reichtum im Kapitalismus als ungeheure Warenfülle erscheint. Schon durch die beliebige Verwendung der Begrifflichkeit gibt man zu erkennen, daß man die spezifische Problematik der Form der gesellschaftlichen Produktion übersieht, wie sie sich darstellt im Doppelcharakter der Ware als Tauschwert und Gebrauchs. wert, und dementsprechend der Doppelcharakter der Arbeit und des Produktionsprozesses.

24 A. Shonfield: MODERN CAPITALISM. The Changing Balance of Public and Private Power. Royal Institute of International Affairs. London 1965. Deutsche Ausgabe: GEPLANTER KAPITALISMUS - WIRTSCHAFTSPOLITIK IN WESTEUROPA UND LSA. Mit einem Vorwort von Karl Schiller. Köln usw. 1968.

25 R. Luxemburg: SOZIALREFORM..., a.a.O.S. 93 f.

26a Marx: KAPITAL Bd. 1, S. 189-195.

26b Marx: KAPITAL Bd. 1, S. 194-201. 
Sämtliche Methoden und Organisationsformen der Ausbeutung, die in der Geschichte des Kapitalismus praktiziert worden sind, zusammen mit den Krisen und dem mit ihnen verbundenen Elend der Gesamtbevölkerung, entspringen dem Zwang, unter dem jeder einzelne Kapitalist steht, sein Ka. pital verwerten zu müssen als Bedingung seiner Existenz. Der gesamte Produktionsprozeß ist vom Verwertungszwang des Einzelkapitals geprägt, von der hierarchischen Organisation des Betriebes über die technische Gestaltung der Maschinen und die Gestaltung der Fabrikräume bis hin zu den Antreibermethoden aller Art, die die für den Kapitalisten allergünstigste, d.h. bestmögliche Ausnutzung und Auffüllung aller Poren des Arbeitstages, der gekauften Arbeitszeit des Arbeiters ermöglichen sollen. Die Arbeitskraft muß, darüber wacht der Kapitalist, in dem gewöhnlichen Durchschnittsmaß der Anstrengung, mit dem gesellschaftlich üblichen $G$ rad a $n$ In te $n$ si tä t verausgabt werden." (26 c)

Die besonderen juristischen und organisatorischen Formen des kapitalistischen Produktionsprozesses sind nichts anderes als der $\mathrm{n}$ o $\mathrm{t} w$ e n d i g e Ausdruck für den Doppelcharakter des Produktionsprozesses im Kapitalismus als Arbeits- und Verwertungsprozeß. Von den Revisionisten dagegen werden sie nahezu durchgehend als bloß z u fälli ge Akzidenzien angesehen. Dies zeigt sich vor allem an der Bestimmung der Rolle des Kapitalisten gegenüber dem Arbeiter. Dieses Verhältnis wird in der revisionistischen Theorie nicht aus dem ökonomischen Verhältnis zwischen Kapital und Arbeit, also aus ihrer Beziehung innerhalb des Verwertungsprozesses des Kapitals, im unmittelbaren Produktionsprozeß, erklärt. Es wird nicht mehr gesehen, daß der einzelne Kapitalist und dep einzelne Lohnarbeiter ökonomische Charaktermasken des Kapitalverhältnisses sind. In dieser Blindheit haben auch die Ideologien von Wirtschaftsdemokratie und Mitbestimmung ihre Wurzeln. So heißt es bei Fritz Naphtali (1929) (26 d): "Im Betrieb stehen Unternehmer oder überhaupt Leiter des Betriebes und Arbeiter einander gegenüber; hier bedeutet die Überwindung der unternehmerischen Despotie das Mitbestimmungsrecht für die Arbeiter, die nicht mehr als rechtlose Objekte behandelt werden sollen." Die Despotie des Kapitalisten entspringt demnach bloß seiner Willkür und ist auf der organisatorischen Ebene - Schaffung von Mitbestimmungsgremien innerhalb des kapitalistischen Betriebes - zu beseitigen. Der Sozialismus wird zur ethischen Forderung, der Ka. pitalismus zu einer Frage der Unternehmermoral. (Zur genaueren Kritik dieser Auffassung vgl. den Abschnitt über die Fabrikgesetzgebung in diesem Aufsatz.)

Eine andere Variante der Negation des Doppelcharakters des kapitalistischen Produktionsprozesses finden wir in Paul Serings Theorie von der Produktionshierarchie. Der kapitalistische Betrieb erscheint ihm als rationale Organisation, in der die "Produkt i onsint elligenz" (Techniker, Marktexperten) "unermüdlich fürweiteren Fortschrittundfürdie Schaffung kooperativer Formen technischer und wirtschaftlicher Organis at i o n" arbeitet und in der die Manager "in erster Linie Menschen" sind, "die die Fähigkeit erworben und erwiesen haben, Entscheidungen über das Inganghalten einer komplizierten Organisation zu treffen und durchzusetzen." "... der einzige Punkt, wo die alte Einheit der Unternehmerfunktion erhalten bleibt, wo die Leitung der Produktion tatsächlich vom persönlichen Profitin. teressedes Eigentümers abhängt, ist die Spitze der Pyramide-die monopolistische und finanzielle Oligarchie. Und diese Oligarchie verwächst, wie wir gesehen haben, zunehmend mit den Organen der staatlichen Wirtschaftspolitik." (27)

Es wird hier also vom Doppelcharakter des (kapitalistischen) Produktionsprozesses als Arbeitsu n d Verwertungsprozeß abgesehen. Im kapitalistischen Betrieb ist aber der Leiter der Produktion immer auch Mehrwerterpresser. (28) Damit ist die Unterwerfung der lebendigenunter die tote Arbeit, die Mehrwertauspressung und die Ökonomie (d.h. Sparsamkeit) des Kapitals, die darin besteht, daß sie "bei aller Knauserei durchaus verschwenderisch mit dem Menschenmaterial umgeht", (29) aus der Organisation der Produktion im kapitalistischen Betrieb verschwunden. Dieser wird als

26c Marx: KAPITAL Bd. 1, S. 204-210.

26d Fritz Naphtali: WIRTSCHAFTSDEMOKRATIE, 1928, Neudruck mit einem Vorwort von Ludwig Rosenberg und einer Einführung von Otto Brenner, Frankfurt/Main 1966, S. 23.

27 Vgl. Sering: JENSEITS..., a.a.O. S. 47-49.

28 Vgl. dazu besonders Marx: KAPITAL Bd. 1, S. 346-48/350-52.

29 KAPITAL, Bd. III, S. 107-197. 
eine technisch-rationale Anstalt aufgefaßt; kapitalistisch ist nur noch die oberste organisatorische Spitze. Zur Einführung des Sozialismus bedarf es dann nur noch der Auswechslung des Personals an der Spitze, der Zurückdrängung des Einflusses der kapitalistischen Oligarchie auf die Wirtschaftspolitik durch eine starke sozial-demokratische Regierung und die allmähliche Absetzung der Spitzen und ihr Ersatz durch Planungsfachleute. Die gegenwärtig von der DKP im Anschluß an die Theorie vom staatsmonopolistischen Kapitalismus vertretene Strategie zur friedlichen Uberführung des Kapitalismus in den Sozialismus beruht auf ebensolchen Vorstellungen. Von zwei Seiten soll die Macht des Monopolkapitals eingeschränkt werden: durch Mitbestimmung im Betrieb und durch die Entfaltung eines demokratischen Programms der Wirtschaftspolitik im Kampf gegen die Monopole. Es geht um die allmähliche Übernahme des "Apparates zur Lenkung und Leitung der Wirtschaft" und seine "Unterordnung unter die Interessen des Volkes"

"Zwischen der Herrschaft des staatsmonopolistischen Kapitalismus und der Errichtung der Diktatur des Proletariažs für den Übergang zum Sozialismus liegt die Etappe der Erkämpfung, Errich. tung und Entfaltung der gegen den staatsmonopolistischen Kapizalismus gerichteten Demokratie..." $(30)$

\section{Erholgreiche Konjunkturpolitik als Voraussezung der Sozialpolitik}

Die Annahme von der Autonomie staatlicher Verteilungspolitik gegenüber den Verwertungsgesetzen kapitalistischer Produktion kann auf eine Voraussetzung nicht verzichten: die 'Wirtschaft' mus weitgehend $k r i s$ e $f$ re i funktionieren, die ökonomische Reproduktion der Gesellschaft muß in kontinuierlichem $\mathrm{W}$ a ch stu $\mathrm{m}$ ablaufen. Ohne diese Voraussetzung ist die Annahme von der Autonomie der Verteilungspolitik unhaltbar. Denn alle Kategorien der 'Verteilung' (immer: der Einkommen) und damit auch der an ihnen ansetzenden Politik sind - wie für den 'politischen Lohn' schon angedeutet wurde - zugleich und vor allem Kategorien des Kapitalkreislaufs und werden folglich auch durch jede Stockung des Kapitalkreislauifs beeinflußt. Arbeitslosigkeit und ein stagnierendes oder gar sinkendes Sozialprodukt machen schließlich jede Verteilungspolitik unter sozialstaatlichen Gesichtspunkten illusorisch. Folgerichtig gehen auch alle sozialpolitischen Pläne und Prognosen der Bundesregierungen von einem mehr oder weniger kontinuierlichen Zuwachs des Sozialproduktes aus. (31) Die Voraussetzung der Krisenfreiheit muß allerdings begründet werden; und in den Begründungen unterscheiden sich die Sozialstaatstheorien.

Für Bernstein ebenso wie für die Theorien des 'organisierten Kapitalismus' in den 20er Jahren (32) waren es Kapitalkonzentration und Ausbildung des Finanzkapitals, die die Krisen zum Verschwinden bringen sollten; sie sollten - im Gegensatz zum 'Konkurrenzkapitalismus' und der 'Anarchie des Marktes' - dem Kapital unter Hilfestellung des demokratischen Staates, die Planung der Produktion ermöglichen. Die revisionistischen Theorien nach der Weltwirtschaftskrise muRten andere Erklärungsmodelle entwickeln. Denn durch die Weltwirtschaftskrise war die Annahme der Kricer:freiheit als Folge einer ungesteuerten Entfaltung der Gesetze kapitalistischer Akkumulation solbst ad absurbum geführt worden. Seit dieser Zeit gehen beinahe alle bürgerlichen und revisionistischen Theoretiker - von den Wohlfahrtsstaatstheorien über den Neoliberalismus bis zu den rechts- und linkskeynesianischen Ablegern in der heutigen Sozialdemokratie und in den Gewerkschaften - da-

30 IMPERIALISMUS HEUTE, Berlin 19685, S. 239 und 727, hier besonders wichtig das Kapitel "Die demokratische Alternative gegen den staatsmonopolistischen Kapitalismus", S. 724-751; vgl. auch Kritik dazu: Projektgruppe DKP-Rabehl: DIE DKP..., a.a.O. S. 67 ff.

31 So ist für den Staatssekretär Auerbach beim Bundesarbeitsministerium die wirtschaftliche Deckungsmöglichkeit der Renten- und Krankenversicherung nur dann gewährleistet, wenn bis 1985 eine jährliche Steigerung der Bruttolohn- und Gehaltssumme um 5,8\% erfolgt. Nach DER TAGESSPIEGEL, 23.12.69. Vgl. auch: SOZIALENQUETE, Soziale Sicherung in der BRD, Stuttgart, Berlin, Köln, Mainz, o.J. (1966), S. 143 ff; besonders S. 153, wo gezęgt wird, daB jedes Sozialversicherungssystem, vor allem aber die Arbeitsiosenversicherung angesichts einer Massenarbeitslosigkeit total versagen würde.

32 Vgl. dazu die Kritik im Aufsatzs"on Eugen Varga: "Probleme der Monopolbildung und die Theorie vom 'organisierten Kapitalismus', in: ders.: DIE KRISE DES KAPITALISMUS UND IHRE POLITISCHEN FOLGEN, Frankfurt/Main 1969; S. 11-41. Vgl. auch: Projektgruppe DKP/Rabehl: DIE DKP..., a.a.O.S. 97 ff. 
von aus, daß durch staatliche Eingriffe die ökonomische Basis gefestigt werden kann, über die der Staat sich als Sozialstaat dann frei zu erheben vermag. Es ist heute nicht mehr möglich, in ökonomischer Unschuld das Verschwinden der Krisen den naturwüchsigen Mechanismen kapitalistischer Akkumulation selbst anzurechnen. Vielmehr soll heute versucht werden, die Krisenfreiheit der gesamten Produktion durch bewußte Eingriffe des Staates herzustellen, und das heißt: durch ein Subjekt, das in die zu regulierenden Abläufe nicht verwickelt ist. So bedingen sich Politik des Krisenmanagements und Verteilungspolitik des Staates wechselseitig: die krisenverhindernden interventionen des Staates sind Voraussetzung für seine sozialpolitischen Maßnahmen; die Autonomie des Staates in der Sphäre der Einkommens-Verteilung wiederum ist Voraussetzung für seine 'Krisenvermeidungsstrategien".

Das läßt sich an folgendem Beispiel sehr leicht zeigen: Die in der Vorstellung vom 'politischen Lohn' implizierte Annahme, der Lohn könne politisch geregelt werden, wird den bürgerlich-technok ratischen Vorstellungen von der Möglichkeit der Regulierung der Volkswirtschaft mittels 'Einkommenspolitik', 'konzertierter Aktion' bzw. 'Lohnleitlinien' zugrundegelegt. Der 'politische Lohn' als Ausdruck staatlicher Autonomie in der Verteilungssphäre soll nun unvermittelt als ökonomisches Manipulierungsinstrument dienen, um die Produktion antizyklisch zu siabili. sieren. Der Staat setzt also in der Sphäre der Verteilung an, um hier in der Weise in den Kapital. kreislauf einzugreifen, daß ökonomische Krisen 'entschärft' werden. Die Voraussetzung für die Regulierungstätigkeit des Staates von der Verteilungssphäre aus ist demnach, daß die angenommene Autonomie in dieser Sphäre doch nicht so weit geht, daß sich die hier vorgenommenen Eingriffe nicht auf den Produktionsprozeß auswirkten (33). Somit erweist sich die Trennung von Produktion und Verteilung unter diesem Gesichtspunkt nicht mehr als totale, sondern als e inse it ig e: Es wird zwar angenommen, daß die Verteilungs p ol i t i $k$ von den Gesetzmäßigkeiten und Grenzen des Kapitalverwertungsprozesses unabhängig sei. Aber es wird zugleich angenommen, daß der Akkumulationsprozeß - jetzt neutral mit der Phrase vom 'stetigen Wirtschaftswachstum' belegt sehr wohl durch Verteilungspolitik als Krisenvermeidungspolitik beeinflußt werden könne. Damit werden gleichzeitig die relative Autonomie des Staates in der Verteilungssphäre und damit in der Verteilungspolitik und zugleich seine Möglichkeit zur "Krisenvermeidungsstrategie" (34) begründet; das eine wird zur Voraussetzung des anderen und beides läßt sich durch das gleiche Subjekt gewährleisten. Der Akkumulationsprozeß und seine Eigengesetzlichkeit ist somit erst recht als Problem beseitigt bzw. obsolet, insbesondere da in den vergangenen 20 Jahren in der BRD scheinbar die Wirksamkeit staatlicher Politik und die Richtigkeit der auf diesen Annahmen beruhenden Theorien erwiesen worden ist.

Auf diese Weise werden die Widersprüche zwischen kapitalistischer Produktion und Sozialpolitik weitgehend eliminiert. Am deutlichsten wird dies in den linkskeynesianischen bzw. gewerkschaft. lichen Vorstellungen von der Möglichkeit des erfolgreichen 'Krisenmanagements' durch Lohnsteigerungen, da diese ja als Kaufkraftsteigerungen die effektive Nachfrage ankurbeln sollen. So sag. te schon 1928 Fritz Tarnow: "In diesem Zusammenhang handelt es sich nicht um das Soziale, sondern um die volkswirtschaftliche Notwendigkeit, einen stärkeren Gebrauch an Konsumgütern zu erzwingen, um den Weg zu vergrößertem Verbrauch und vergrößerter Produktion freizulegen."

33 Hier liegt eines der Probleme, über die wir in den Diskussionen keine volle Ubereinstimmung erreichen konnten. Welche praktische Bedeutung hat die Illusion von der Autonomie der Distributionssphäre bzw. vom politischen Lohn heute, z.B. in der antizyklischen Konjunkturpolitik? Inwieweit wird hier nicht die Abhängigkeit der Verteilung von der Produktion und der in ihr gesetzten Verteilung de facto anerkannt? Haben etwa die Okonomen (auch innerhalb der SPD oder der gewerkschaftlichen Wirtschaftsinstitute) hier einen größeren Realismus als die Politologen revisionistischen Erbes? Wie weit geht dieser Realismus? Vgl. dazu auch unten Teil III.

34 J.M. Gillman (PROSPERITAT IN DER KRISE, dt. Frankfurt/M. 1968) zeigt, wie in den Welfare-State Theorien der New-Deal Epoche Sozialversicherung als Krisenregulierungsmechanismus angesehen wurde (S. 132). Im folgenden unterzieht Gillman diese These einer Uberprüfung anhand der zyklischen Bewegungen des Kapitals in den USA und zeigt, daß es sich hierbei nur um zweitrangige, nicht entscheidende Faktoren wirtschaftlicher Stabilisierung handeln kann. 
(35) Und im Gefolge dieser bequemen Tradition des bloßen Appells an den Staat und an die 'Ver. nunft' der Kapitalistenklasse anstatt der Vorbereitung der Arbeiterklasse auf revolutionäre Praxis empfiehlt z.B. die IG Metall 1957 dem Staat, den Arbeitern mit "Investitionskrediten die Anschaffung eines PKW zu erleichtern und so gleichzeitig die Automobilindustrie anzukurbeln"; zugleich beklagte sie die mangelnde Moral der Unternehmer, die aus lauter Böswilligkeit und ge gen ihre bessere Einsicht, daß doch erst der Massenkonsum den Absatz ihrer Waren gewährieiste, Sozialausgaben und Löhne in der Krise kürzen (36). Tarnow sah immerhin noch das hier bestehende Problem, wenn er schreibt: "Der e inz e I n e Unternehmer kann zwar nach wie vor so rechnen, daß er von einer Herabsetzung der Löhne nichts anderes als Vorteil hat. Für die Unternehmer im g a $\mathrm{nz}$ e $n$ aber könnte diese Manipulation nicht mehr vorgenommen werden, ohne die Kapitalsund Profitinteressen des Unternehmertums selbst schwer zu verletzen." (37) Daher plädiert er für die Verteilung der Gesamtkaufkraft in einem richtigen Verhältnis zwischen Konsumtion und Akkumulation, die die Basis eines prosperierenden Kapitalismus darstellen solle, in dem die Gesamtinteressen des Kapitals und der Arbeiterklasse harmonisch zusammenfallen. Als Garant solcher Harmonie kann natürlich nur der Staat fungieren. Aber zu solchen Vorstellungen schreibt bereits Marx: "Mit Ausnahme seiner eigenen Arbeiter, erscheint jedem Kapitalisten gegenüber die Gesamtmasse aller andren Arbeiter nicht als Arbeiter, sondern als Konsumenten. ... Er wünscht sich na. türlich die Arbeiter der a ndr e $n$ Kapitalisten als möglichst große Konsumenten se i ne $r$ Ware. Aber das Verhältnis jedes Kapitalisten zu seine n Arbeitern ist das Verhä It n is über. haupt von Kapital und Arbeit, das wesentliche Verhältnis." (38) Die Praxis der staatlichen Krisenmanipulation im Jahre 1967 hat gezeigt, daß es auch dem 'Sozialstaat' geboten ist, dieses "wesentliche Verhältnis" zu berücksichtigen: er kürzte die Sozialleistungen und mußte es zulassen, daß die Löhne stagnierten und zum Teil sogar gesenkt wurden.

35 Fritz Tarnow: WARUM ARM SEIN? Berlin 1928, S. 71 und 49. Vgl. zur Kritik auch neben Kriwizki ("Die Lohntheorie...", UNTER DEM BANNER..., a.a.O.): Erika König: VOM REVISIONISMUS ZUM DEMOKRATISCHEN SOZIALISMUS, Berlin-DDR 1964, S. $158 \mathrm{ff}$.

36 METALL, Nr. 16, 1967, und: WEISSBUCH DER IG METALL, 1968. In der Zeitschrift METALL ist auch nachzulesen, wie Brenner 1967 und 1968 die Theorie von der Regulierung der Krise durch Erhöhung der Masseneinkommen vertritt.

37 Tarnow: WARUM ARM SEIN ? A.a.O. S. 53.

38 Marx: GRUNDRISSE, S. 322. Vgl. S. 323: “... Das Kapital selbst betrachtet dann die $\mathrm{Na}$ ch frage durch de n A r be it e r - i.e. das Zahlen des Salärs, worauf diese Nachfrage beruht - nicht als Gewinn, sondern als Verlust. D.h. das im m a n e $t$ e V e $r$ h ä! t. $n$ is $z w i s c h e n K a p i t a l u n d A r b e i t$ macht sich geltend. $E s$ is $t$ hier wie-

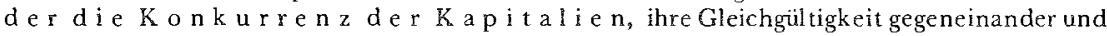
Selbständigkeit voneinander, die dazu führt, daß das einzelne Kapital sich zu den Arbeitern des totalen übrigen Kapitals $n$ i $c h t$ a Is A r b e it e $r n$ verhält: Hinc über die richtige Proportion hinausgetrieben wird." Und im 2. Band des KAPITAL (S. 414/409 f): "Will man aber dieser Tautologie" (Krisen entstehen aus Mangel an zahlungskräftiger Nachfrage) "einen Schein tiefrer Begründung dadurch geben, daß man sagt, die Arbeiterklasse erhalte einen $\mathrm{zu}$ geringen Teil ihres eigenen Produkts, und dem Übelstand werde mithin abgeholfen, sobald sie größern Anteil davon empfängt, so ist nur zu bemerken, daß die Krisen jedesmal gerade vorbereitet werden durch eine Periode, worin der Arbeitslohn allgemein steigt und die Arbeiterklasse realiter größern Anteil an dem für Konsumtion bestimmten Teil des jährlichen Produkts erhält. Jene Periode müßte - von dem Gesichtspunkt jener Ritter vom gesunden und "einfachen' (!) Menschenverstand - umgekehrt die Krise entfernen. Es scheint also, daß die kapiłalistische Produktion vom guten oder bösen Willen unabhängige Bedingungen einschließt, die jene relative Prosperität der Arbeiterklasse nur momentan zulassen, und zwar immer nur als Sturmvogel einer Krise." Vgl. auch M. Kriwizki (LOHNTHEORIE..., a.a.O.), der zeigt, daß die Theorie vom politischen Lohn auf der Annahme beruht, der Kapitalist könne beim konstanten Kapital Einsparungen vornehmen, und diese dem Arbeiter zuschanzen. "Während wir also bei Marx auf die Gegenüberstellung des variablen Kapitals oder des Arbeitslohns mit dem Mehrwert stoßen, wird in allen von uns angeführten Fällen der Arbeitslohn dem konstanten Kapital gegenübergestellt und seine Änderungen mit den Änderungen des konstanten Kapitals verbunden. Es folgt also eine Aufhebung der Spaltung des neugeschaffenen Werts in Wert der Arbeitskraft und Mehrwert. Dadurch wird jenes Kampffeld beseitigt, auf dem der Zusammenstoß der zwei Klassen stattfindet... Es ist die gleiche Verlegung der Analyse von den grundlegenden Produktionsverhältnissen weg zur Technik, die als außerhalb des sozialen Verhäl misses stehend betrach tet wird." (S. $97 \mathrm{f}$ ) 
Daß das Kapital nur a I s e in z e I ne s existiert, der Staat als Vertretung der gesamten Kapitalistenklasse demnach ein interesse des $\mathrm{Ges}$ a $\mathrm{m} \mathrm{t} \mathrm{k}$ a p it a $\mathrm{ls}$ nur insoweit vertreten kann, als es auch das interesse der Kapitale als Einzelkapitale - zumindest aberihrermächtigeren Fraktion ist, wird dabei unterschlagen. Das im Kapitalverhältnis gesetzte widersprüchliche Interesse jedes Einzelkapitalisten an größter Konsumtionskraft aller Arbeiter mit Ausnahme der von ihm angewendeten und an möglichst niedrigem Lohn seiner eigenen Arbeiter, kann auch der Staat nicht überspringen. Das kommt auch darin zum Ausdruck, daß die 'spontane' Verteilung zwischen Lohn und Profit gar nicht vom Staat geregelt wird, sondern in d i r e k t e r Konfrontation der 'Tarifpartner'. (Seine Tätigk eit beschränkt sich, knapp zusammengefaßt, auf die Umverteilung innerhalb der Lohneinkommen ('Sozialleistungen', Ausbildungskosten der Arbeitskraft) und auf eine gewisse Umverteilung des Profits zwischen verschiedenen Kapitalgruppen (Subventionen, Investitionsanreize usw.) Vgl. auch oben Anm. 13.) Die Annahme von der gegenseitigen Ergänzung der krisenmanipu. lierenden und der sozial-politischen Funktion des Staates läßt sich also nicht halten. Es bleibt eine Unmöglichkeit für den Staat im Kapitalismus, die krisenfreie ökonomische Reproduktion der Herrschaftsverhältnisse, d.h. des Kapitalverhältnisses, auch nur zu versuchen und $\mathrm{gle}$ i c h z e it ig die politische Aufhebung dieses Verhältnisses zu betreiben. Eine Milderung dieses allgemeinen Widerspruchs wird nur insofern versucht, als zur Reproduktion des Kapitalverhältnisses auch ein bestimmtes Minimum an sozialer "Stabilität" als Voraussetzung für den reibungslosen Ablauf des Kapitalverwertungsprozesses jeweils gesichert sein muß. Diesem Zweck dient die So z ialpoli. tik a Is B efriedungs politik; sie bleibt auch dabei Moment der Sicherung der stetigen Reproduktion des Kapitalverhältnisses, stellt also das gerade Gegenteil von politischer Autonomie des Staates dar, wie noch ausführlicher zu zeigen sein wird.

Die bürgerliche Wissenschaft ist auch in dieser, aber auch nur in dieser Hinsicht weniger illusionär als die revisionistischen Gewerkschaftstheoretiker seit der Weimarer Republik. Die sozialstaatlichen Aufgaben sind demnach der primären Aufgabe der Wachstums- und Wohistandssicherung unterzuordnen. Dabei wird auch durchaus der Konflikt zwischen diesen beiden Staatsfunktionen gesehen, aber die Übereinstimmung wird dann doch wieder mit der Behauptung hergestellt, daß die beste Sożialpolitik eine gute Wirtschaftspolitik sei, die durch Sicherung des Wachstums erst dem Staat die Mittel zur sozialen Verteilertätigkeit zur Verfügung stelle und zudem 'Erwerbslosigkeit' verhindere. In diesem Sinne geht z.B. die im Auftrag der'Bundesregierung (von zumeist den damaligen Regierungsparteien nahestehenden Professoren) ausgearbeitete SOZIALENOUETE (1966) davon aus, daß im Hinblick auf die Aufgabe der Sozialpolitik, nämlich die Erfüllung des Sicherungsund Versorgungsbedürfnisses der Bevölkerung, im ganzen eine Identität mit den Zielen der Wirtschaftspolitik bestehe. (39) Eine Wirtschaftspolitik, welcher die Sozialpolitik nicht durch Ausgabenerhöhungen zur unrechten Zeit (und die Zeit ist schließlich immer unrecht (40) ) in die Quere kommt, soll danach in der Lage sein, wirtschaftliches Wachstum und 'Vollbeschäftigung' (41) zu

39 Vgl. SOZIALENQUETE, a.a.O.S. $140 \mathrm{f}$.

40 Vgl. ebda., S. 153 f, wonach in der Hochkonjunktur Erhöhungen der Sozialleistungen inflationär wirken, in der Krise dagegen zwar ökonomisch möglich und vielleicht auch sinnvoll seien (hier die gleiche Illusion wie bei den Gewerkschaften), aber aufgrund politischer Tatbestände nicht $\mathrm{zu}$ empfehlen, da solche Maßnahmen später schwer rückgängig zu machen seien, ohne die Gefahr sozialen Unfriedens' heraufzubeschwören.

4 I Immer wieder wäre es notwendig, die die Wirklichkeit oft ganz offensichtlich verhüllenden Begriffe der bürgerlichen Wissenschaft zu umgehen oder wenigstens durch Anführungszeichen zu kennzeichnen. So ist nach der herrschenden Auffassung in der ' $\mathrm{V}$ oll b e s c h ä ft i g u n g' eine amtliche Arbeitslosenquote von 'bloß' 3 bis $5 \%$ eingeschlossen. Die Zahlen der amtlichen Statistik zur 'E r w e r b s l os ig k e i t' sind ihrerseits verhüllend (besonders in der 'Rezession' oder 'Talsohle'), denn sie erfassen nicht die infolge Arbeitslosigkeit vorzeitig 'verrenteten' Arbeiter (besonders Arbeiterinnen), heimgereiste 'Gastarbeiter' usw.; hinter diesen Zahlen versteckt sich also eine viel größere in d u striell e R e se r v e a r$\mathrm{m}$ e e, wie der kapitalistischen Wirklichkeit adäquate Begriff lautet. Mit dieser Bemerkung soll erneut darauf hingewiesen werden, daß man sich innerhalb der bürgerlichen Wissenschaft ständig zwischen Attrappen bewegt, die aber vom Standpunkt der kapitalistischen Gesellschaft und ihrer Wissenschaft notwendig die einzige Wirklichkeit sind und das Handeln der Kapitalagenten und der Staatsfunktionäre tatsächlich bestimmen. Vgl. dazu auch Teil III. 
garantieren. "Sozialpolitik im Ganzen ist ihrer Natur nach längerfristig orientiert und ist rational nur durchführbar, wenn es der Wirtschaftspolitik gelingt, übermäßige Konjunkturschwankungen zu verhindern". (42) Daraus ergibt sich dann die Notwendigkeit der Ausrichtung und Unterordnung der Sozialpolitik unter die wirtschaftspolitischen Maßnahmen, soweit dies ohne Gefährdung des "sozialen Friedens" möglich sei. Die Erhaltung des "sozialen Friedens" ist somit ein Bestimmungsfaktor für die u n tere Grenze der Sozialleistungen (neben der Erhaltung der "Arbeits- und Leistungsfähigkeit, Berufserziehung und Mobilität"). "Preisstabilität" und "Investitionsbereitschaft der Unternehmer" definieren die o b e r e Grenz e (43). Dies ist der Spielraum, in dem sich nach der Einschätzung der Verfasser der SOZIALENOUETE die redistributiven sozialpolitischen Maßnahmen des Staates bewegen dürfen.

\section{Sozialstaat und pluralistische Demokratie}

Die theoretische Trennung der ökonomischen Bedingungen von Produktion und Distribution hat politische Konsequenzen. Historisch ist natürlich die Theorie Konsequenz revisionistischer Praxis, nicht ohne diese weiter zu bestätigen: der Versuch der Sozialdemokratie zur wissenschaftlichen Begründung ibrer nicht-revolutionären Politik, ihrer Zusammenarbeit mit Kapital und bürgerlichem Staat, führte zu immer erneuten Anläufen, einen gegenüber Marx' Zeiten grundsätzlich veränder . ten Kapitalismus und vor allem ein qualitativ verändertes Verhältnis zwischen kapitalistischem Produktionsprozeß und Staat nachzuweisen. Dieser Nachweis sollte dazu dienen, die tatsächlich verfolgte politische Strategie der Zusammenarbeit der Klassen im bürgerlichen Staat zu legitimieren. Dabei bilden die Souveränität des Staates bei der Verteilung des Sozialprodukts und das Verschwinden der kapitalistischen Krisen, sei es als Ergebnis natunwüchsiger Prozesse der kapitalistischen Entwicklung, sei es als Folge staatlichen Krisenmanagements, für die revisionistischen Staatstheorien wesentliche Voraussetzung einer allmählichen Uberführung des Kapitalismus in den Sozialismus, des bürgerlichen Staates in einen sozialen und demokratischen Rechtsstaat. Nachdem die sozialdemokratischen Theoretiker von Bernstein bis Habermas den Sozialstaat auf den festen Grund einer dauerhaft wachsenden 'Güterfülle' gestellt haben, stehen der Verwirklichung einer demokratischen Gesellschaft auch keine unüberwindlichen Hindernisse mehr entgegen: "Der Konflikt der Klassen verliert in dieser Perspek tive seine revolutionäre Gestalt; eine for t s c h re it e n de D emokratisierung der Gesellschaft ist auch innerhalb der kapitalisti. schen $\mathrm{Gesellschaftsordnung} \mathrm{nicht} \mathrm{von} \mathrm{vornherein} \mathrm{ausgeschlossen."} \mathrm{(44)}$

Bernstein wollte eine nicht-revolutionäre Strategie für die Arbeiterklasse fomulieren: Sozialrefor men statt Revolution. Die Behauptung, ein revolutionärer Kampf der Arbeiterklasse habe sich historisch erübrigt, über den Staat lasse sich der Sozialismus schon durch die Arbeiterparteien und unter kräftiger Mitwirkung der Gewerkschaften einführen, führte zur Herausarbeitung der Vorstellung, der Staat stehe den Bedingungen der kapitalistischen Produktion unabhängig gegenüber. Da der Staat im weiteren Verlauf der Entwicklung (Weimarer Republik) seine Eingriffe in die Gesellschaft vor allem auf dem Verteilungssektor entwickelt (wachsender Anteil des Sozialprodukts, der vom Staat verteilt wird) (45), und zwar vermittelt über die parlamentarischen Auseinandersetzungen, kommt es dazu, daß die staatliche Verteilungstätigkeit als die Sphäre der Unabhängigkeit der Staatsgewalt gegenüber der Kapitalakkumulation aufgefaßt wird. Das ist der Ursprung der Theorie

42 SOZIALENQUETE, a.a.O. S. 153.

43 Ebda., S. 144. Auf die hier im ganzen richtig angedeuteten Grenzen der Sozialpolitik wird weiter unten noch näher eingegangen. Allerdings kann der Staat, siehe gegenwärtig USA, auf die untere Grenze weitaus weniger Rücksicht nehmen. Sie gilt nur für Prosperitätsphasen des Kapitals. Vgl. auch S. 145. Es heißt dort weiter: “... die Investitionsbereitschaft der Unternehmer ist sowohl im Interesse des Wachstums der Gesamtversorgung als auch im lnteresse der Vollbeschäftigung erforderlich" ... "Das Exportvolumen kann im Interesse der dauernden internationalen Leistungsfähigkeit der Wirtschaft nicht gekürzt werden"... "E i n e A u s. we itung des Sozialbudgets konkurriertalsoinerster Linie mit einer Steigerung der realen Lohneinkommen. "(Hervorhebung: M./N.)

44 J. Habermas: THEORIE UND PRAXIS, Neuwied-Berlin 1963, S. 196 f (Hervorhebungen v. Verfasser).

45 Vgl. oben Anm. 13. 
vom politischen Lohn bei Hilferding und der entsprechenden Auffassungen bei Kirchheimer, Sering und anderen sozialdemokratischen Theoretikern.

Nach Hilferding werden die politischen Stärkeverhältnisse der Klassen im demokratischen Staat durch die Wahlen dauernd gemessen. Diese Kräfte werden unmittelbar über das Parlament in die Bildung des Staatświllens umgesetzt, der in der Demokratie Resultat des Willens der Staatsbürger sei. So ergebe sich eine "Anschmiegsamkeit der Staatsmacht an die wechselnden Stärkeverhältnis-

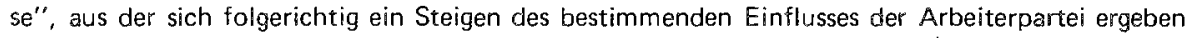
müsse - der Anteil der Arbeiterschaft an der Gesamtbevölkerung wächst (46). Dem müsse ein Ansteigen des Lohnes nachfolgen, da der Lohn politisch und nicht ökonomisch bestimmt sei. "Die Arbeiterschaft betrachtet nunmehr den Staat als das politische Instrument zum Aufbau des Sozialismus." (47) Wahlen und Parlament sollen als Mittel für die friedliche Austragung der Kämpfe von Lohnarbeit und Kapital dienen.

Als die SPD im Jahre 1949 dem Grundgesetz für die BRD im Parlamentarischen Rat zustimmte, war sie von der Vorstellung bestimmt, der provisorische Charakter des neuen Staatswesens, die Offenheit der Verfassung in Richtung auf Sozialisierung der großen Industrie (Art. 15), die starke Stellung der Regierungspartei und des Kanzlers nach dem Grundgesetz, die Kompetenzen des Bundesgesetzgebers und die grundgesetzlich fixierte Sozialstaatsklausel (Art. 20) - also sämtlich Sicherungen im Bereich $\mathrm{s} t \mathrm{a}$ a $\mathrm{t} / \mathrm{i} \mathrm{ch}$ e $\mathrm{r}$ Machrausübung - genügten, um die Umwandlung der zu dieser Zeit bereits restaurierten kapitalistischen Gesellschaft in eine sozialistische zu ermöglichen.

Mit parlamentarischer Mehrheit - die SPD rechnete damals fest mit einem Wahlsieg - gedachte sie, durch die Übernahme der Staatsmacht ihre gesellschaftlichen und politischen Vorstellungen zu realisieren. Revolutionäre Massenaktionen und Kämpfe der Arbeiterschaft waren in diesem Konzept nicht vorgesehen, wie die ambivalente bis ablehnende Haltung der SPD in den Verfassungsverhandlungen zum politischen Streikrecht, wie auch das Fehlen jeglicher Absicherung plebiszitärer Aktionen in der Verfassung selbst deutlich machen.

Aber auch die Inhalte ihrer politischen Vorstellungen handein weniger von der Arbeiterklasse als historischem Subjekt gesellschaftlicher Prozesse als vielmehr vom Staat. Der Gegensatz zwischen CDU/CSU und SPD hinsichtlich des Verhältnisses von Staat und Gesellschaft kulminierte darin, daß die CDU/CSU dem Staat nur eine subsidiäre, nachträglich korrigierende Rolle gegenüber der gesellschaftiichen und ökonomischen Entwicklung zusprach, Sozialpolitik also als problemlos sich ergebendes Abfallprodukt eines auf kapitalistischer Basis sich ungehemmt entfaltenden ökonomischen Wachstums sah, während demgegenüber die SPD die staatliche Verantwortlichkeit gegenüber den gesellschaftlichen und ökonomischen Prozessen, die Verwirklichung sozialer Gerechtigkeit durch Eingriffe des Staates in die Ökonomie, durch Planung und Sozialisierung auf dem Gesetzeswege hervorhob. Angelpunkt der politischen Konzeption der SPD für das Deutschland nach dem Faschismus war der Sozia le Sta a t; gesellschaftliches Ziel, "daß man den Menschen herausnimmt aus der großen Objektsituation" (Carlo Schmid) historischer Akteur die SPD als Partei im Parlament und Schumacher als Bundeskanzler mit Richtlinienkompetenz, Einführung des Sozialismus also durch eine "gewisse Revolution von oben" (48).

Die Aufgabe des Sozialismus als Ziel im Godesberger Programm und das praktische Einschwenken auf die sozialpolitischen Vorstellungen der CDU seit der Großen Koalition ist also nichts anderes als die Entfaltung dessen, was in der politischen Konzeption der SPD unmittelbar nach dem Zusammenbruch des Faschismus schon enthalten war: diese Konzeption wiederum ist wesendlich eine Erneuerung des revisionistischen Traditionsbestandes der Weimarer Republik.

46 Vgl. R. Hilferding: "Probleme der Zeit", in: DIE GESELLSCHAFT, 1.Jg. 1924, Bd. 1, S. 13.

47 Ders.: "Raalistischer Pazifismus", in: DIE GESELLSCHAFT, 1. Jg. 1924, Bd. 2, S. 111. Vgl dazu auch: W. Gottschalch: STRUKTURVERANDERUNGEN DER GESELLSCHAFT UND POLITISCHES HANDELN IN DER LEHRE VON RUDOLF HILFERDING, BerlinWest 1962, S. 198-218:

48 Vgl. zu diesem ganzen Komplex: H.-H. Hartwich: SOZIALSTAATSPOSTULAT UND GESELLSCHAFTLICHER STATUS QUO, Berlin 1969, (bisher als Manuskript vorliegend), S. $1-66$. 
Immerhin wird in der revisionistischen Theorie nach dem Kriege noch ein weiterer Schritt volizogen, der die immanente Logik ihrer Ansätze vor dem Faschismus voll entwickelt -- dies aber eben aufgrund besonderer historischer Entwickiungen: dem Zurücktreten der SPD als erklärter Vertretung der Arbeiterklasse, ihre Neugeburt als Volkspartei. Im Zuge dieser Entwicklung wird nun nicht mehr allein der Staat als unabhängig vom Kapitalverwertungsprozeß aufgefaßt, sondern die Gesellschaft selbst als eine in eine Vielzahl von Interessengegensätzen sich auseinandersetzende, als pluralistische Gesellschaft verstanden.

Der Logik einer Theorie folgend, der der antagonistische Konflikt zwischen Kapital und Arbeit lediglich als Konflikt um die Verteilung knapper Mittel erscheint, verschwindet für den madernen Revisionismus der Klassengegensatz überhaupt: mit abnehmender Knappheit aufgrund eines wachsenden Sozialprodukts wird der Klassengegensatz zur pluralistischen Auseinandersetzung um einen immer größer werdenden Kuchen: "Die industriell-fortgeschrittenen Gesellschaften haben, auf einem hohen und immer erhöhten Stand der Produktivkräfte, eine Expansion des gesellschaftlichen Reichtums erreicht, angesichts derer die Erwägung nicht unrealistisch ist, daß ein fortbestehender, wenn nicht vervielfäl tigter Pluralismus der Interessen die antagonistischeSchärfe konkurrierender Bedürthisse im Maße der absehbaren Möglichkeit ihrer Befriedigung verlieren kann." Eine "Gesellschaft im Überfluß' erübrigt "einen von knappen Mitteln diktierten Ausgleich." (49) Die Klassentheorie hat sich damit zur Pluralismustheorie gewandelt. Der vom Revisionismus in der Weimarer Republik verbal noch aufrechterhaltene 'Kampf der Klassen' ist zum Ausgleich der pluralistischen Interessen über konkurrierende Verbände und Volksparteien geworden. (50) Ging die Sozialdemokratie der Weimarer Republik noch davon aus, daß die für die politische Willensbildung relevanten gesellschaftlichen Interessen nach wie vor durch den Gegensatz zwischen Kapital und Arbeit sich konstituieren, dieser Gegensatz aufgrund von Entwicklungen der Ökonomie im Abnehmen begriffen sei und demzufolge auch der Staatsapparat, insbesondere das Parlament, zum instrument einer allmählichen Einführung des Sozialismus tauge, so vollzieht der Revisionismus nach dem 2. Weltkrieg einen weiteren Schritt fort von der Marxschen Theorie. Der politische Willensbildungsund Entscheidungsprozeß ist danach das Ergebnis von Interessenauseinandersetzungen pluralistischer gesellschaftlicher Gruppen. Wenn die Sozialstaatstheorie die Souveränität des krisenregulierenden und verteilenden Staates gegenüber der (kapitalistischen) Produktionssphäre behauptet, so kennt sie eine entsprechende Souveränität nicht gegenüber den gesellschaftlichen Gruppen. Im Gegenteil: der Staat wird in dieser Theorie als ausführendes oder bloß vermitteindes Instrument gesellschaftlicher Interessen und Interessengruppen begriffen, die demzufolge auch die Inhalte staat-

49 J. Habermas: STRUKTURWANDEL DER OFFENTLICHKEIT, Neuwied 1962, S. 254 f. Parallelen ergeben sich hier zu folgendem Erhard-Wort: "Es ist sehr viel leichter, jedem einzelnen aus einem größer werdenden Kuchen ein größeres Stück zu gewähren, als einen Gewinn aus der Auseinandersetzung um die Verteilung eines kleinen Kuchens ziehen zu wollen." in: Erhard: WOHLSTAND FUR ALLE, Düsseldorf 1957, S. 10. Rabehl hat darauf hingewiesen, daß in der "Soziologie des Staates" "nicht Klassenkämpfe diese monopolistische Gesellschaft bestimmen, sondern daß der demokratische Kampf der "Unterprivilegierten' um staatliche Anerkennung und Unterstützung diese Epoche trägt." (FU-ProjektgruppeRabehl: DIE DKP..., a.a.O. S. 93). Diese politische Vorstellung beruht eben auf der Reduktion der kapitalistischen Widersprüche aufs Verteilungsproblem. Unterprivilegierte sind die sozialen Gruppen, denen vom Staat kein genügend großer Happen in den Mund geschoben wird. Ihre Unterprivilegierung endet mit der Vergrößerung des Happens. Folgerichtig Offe: "Generell bemißt sich der r e p r e s s i v e, d.h. Herrschaftsverhältnisse befestigende Charakter eines politisches Systems daran, ob ... a) ... b) die verschiedenen Kategorien der miteineinander in Widerspruch stehenden gesellschaftlichen In teres se $\mathrm{n}$, Bedürfnisse und Ansprüche in gleicher oder nur in verzerrter, spezifisch gewichtiger Weise die $\mathrm{C} h$ a n c e politischer Berücksichtigung ge n ießen." (A.a.O.S. 162). Hier haben sich die unterprivilegierten Gruppen zu unterprivilegierten Bedürfnissen verfeinert.

50 E. Fraenkel: "Strukturanalyse der modernen Demokratie", in: AUS POLITIK UND ZEIT. GESCHCHTE, Beilage zur Wochenzeitung: DAS PARLAMENT, 6.12.69, S. 23: "Der Pluralismus ist die Staatstheorie des Reformismus. Er lehnt implicite die These ab, daß der Antagonismus zwischen Kapital und Arbeit, dessen Existenz er nicht in Zweifel zieht, mit geschichtlicher Notwendigkeit dazu führen muß, daß er in der klassenlosen Gesellschaft 'aufgehoben' wird." Vgl. auch: ders.: DEUTSCHLAND UND DIE WESTLICHEN DEMOKRATIEN, Stuttgart 1964, sowie unten Teil IV. 
licher Politik bestimmen können. Eine solche Auffassung, die den Staat einerseits als a b hä $\mathrm{ng}$ ig von den gesellschaftlichen Interessengruppen (zunächst mit Vorrang von Lohnarbeit und Kapital), andererseits aber als s o u v e rä n gegenüber dem 'wirtschaftlichen Prozeß' begreift, führé notwendig auch zu einer Auseinanderreißung des Zusammenhangs zwischen dem Produktionsprozeß und der Konstituierung gesellschaftlicher Interessengegensätze. Wo der Staat real oder zumindest der Möglichkeit nach ats Subjekt der Verteilung des 'Sozialprodukts' und der Regulierung des Wirtschaftsprozesses begriffen wird, wo ihm die Gesetze der Verteilung und Regulierung nicht als Gesetze des Kapitalverwertungsprozesses prinzipiell vorgegeben sind, muß auch der Zusammenhang zwischen den bloß noch als 'gesellschaftlich' erscheinenden Interessengegensätzen und der kapitalistischen Produktionsweise abgestritten werden. Kann nämlich der Staat die Verteilung des 'gesellschaftlichen Reichtums' ändern, ohne das Kapitalverhältnis aufzuheben, so können auch gesellschaftliche Interessenwidersprüche beim Kampf um die Verteilung nicht mehr als bloße Resultate des Kapitalverhältnisses begriffen werden. Die Sphäre der Gesellschaft verselbständigt sich zum Kampiplatz von Interessen, dessen Börse der Staat ist (51).

Bedarf der Staat lediglich "positiv einer Anweisung, wie Gerechtigkeit im sozialstaatlichen Eingriff zu verwirklichen ist", so können es nicht prinzipiell die Gesetze der Kapitalverwertung sein, die diese positive Anweisung im gegenwärtigen Zustand der kapitalistischen Gesellschaften und Staaten verhindern, sondern hier müssen Hindernisse am Werk sein, die sich auf einer von der materiellen Reproduktion losgelösten gesellschaftlichen Ebene konstituieren. So wird für den zeitqenössischen Revisionismus die Frage nach dem demokratischen und sozialen Rechtsstaat zur Frage nach seinem demokratischen Potential, zur Frage nach der "politischen Mündigkeit des Volkes" (52), zur Frage nach den demokratischen und friedliebenden Kräften, deren Stellung im Produktionsprozeß man nur noch durch das Beiwörtchen "antimonopolitisch" zu definieren versucht. Mit der Erweiterung des demokratischen Potentials, mit dem Entstehen politischen Bewußtseins müssen sich automatisch auch die Handlungsspielräume der Staatsgewalt in Richtung auf die Realisierung sozialer Gerechtigkeit erweitern. Ein kontinuierlicher Übergang in eine Gesellschaft, die die Regulierung ihres Lebens selbst in die Hand nimmt, ist also in dem Maße möglich, in dem ein wachsendes demokratisches Potential auf den Staatsapparat eindringt und ihn als Instrument der Herstellung einer gerechten und vernünftigen Sozialordnung benutzt. Denn da der Staat zum "Träger der Sozialordnung avanciert" (53) ist, hängt es vom Bewußtsein derer, die ihn benutzen ab, welche Sozialordnung er realisiert. Mit dieser Begründung untersuchten Soziologen des Frankfurter Instituts für Sozialforschung gegen Ende der 50er Jahre die Studenten: sie sind für diese Theorie als de mok rat i sches (!) Potential deshalb besonders relevant, weil sie später die leitenden Positionen in "den großen Apparaten der Industrie" und die höheren Beamten stellen (54). Das politische und gesellschaftliche B e w u B t s e in der Manager und hohen Staatsbeamten ist danach ein wesenticher Bestimmungsgrund für Vernunft oder Unvernunft des 'ökonomischen und politischen Prozesses' und der Formen und Inhalte der Bedürfnisbefriedigung. Die gesellschaftlichen Widersprüche reduzieren sich letztlich auf das Bewußtsein der Individuen, auf den guten oder bösen Willen der Kapitalisten bzw. ihrer Manager, auf das reaktionäre oder fortschrittliche Bewußtsein der Staatsbeamten, auf die Frage zum Beispiel, aus welchen gesellschaftlichen Schichten sich die Elite regeneriert, womit man bereits bei Dahrendorf angelangt ist (55).

51 P. Sering: "Der Faschismus", in: ZEITSCHRIFT FUR SOZIALISMUS, Nr. 24/25, 26/ 27 (1935) S. 775.

52 Habermas...: STUDENT..., a.a.O. S. 35 und 45.

53 Ebda., S. 35.

54 Ebda., S. 52 f.

55 In dieser Richtung läuft auch die kritische Eliteforschung, wie sie z.B. in den Analysen von Helge Pross (MANAGER UND AKTIONÄRE IN DEUTSCHLAND, Frankfurt/M. 1965) und W. Zapf (WANDLUNGEN DER DEUTSCHEN ELITE, München 1965) vorliegt. Vgl. dazu auch die Theorie vom staatsmonopolistischen Kapitalismus (sowie die entsprechenden zahlreichen zeitgeschichtlichen Untersuchungen in der DDR-Geschichtswissenschaft), die aus $\mathrm{p}$ e $\mathrm{r}$ s o $\mathrm{n}$ e $1 \mathrm{l}$ e $\mathrm{n}$ Identitäten zwischen der faschistischen und der bundesrepublikanischen Oberschicht den besonders reaktionären und aggressiven Charakter der Monopole und des Staates in der BRD nachzuweisen versucht. Das wichtigste Argument für die These, daß der Bonner Staat ein Staat der Monopole sei, ist nach dieser Auffassung die personelle Identität in der ökonomischen und politischen Führungsschicht. 
Die Frage nach Vernunft oder Unvernunft der Organisation der Produktion und der gesellschaftilchen Bedürninisbefriedigung wird, ebenso wie die Frage nach der Vernunft politischer Entscheidun gen,zur Frage des inhalts in den Köpien (und yor allem den Köpfen der Eliten). Demokratie wird zur Frage nach der iedologischen und politischen Orientierung der herrschenden Eliten: Demokratietheorie verkümmert zur Elitetheorie. Mag auch die historische Herleitung des gegenwärtigen Gesellschaftszustandes und der gegenwärtigen Formen der politischen Willensbildung in differenzierteren soziologischen Kategorien erfolgen, so endet die Analyse doch dabei, sich von einer personelIen Neubesetzung des Herrschaftsapparates durch Individuen kritischen Bewußtseins den Beginn des 'Abbaus von Herrschaft' zu versprechen.

Eine illusionslose, nicht mehr am Begriff gesellschaftlicher Emanzipation orientierte Konsequenz der Habermasschen Sozialstaatstheorie ist Offes Konstruktion des Wohlfahrts- und Interventionsstaates, die den Klassengegensatz als bewegende Kraft der gesellschaftlichen Entwicklung ausschaltet und die Kritik der politischen Ökonomie ausdrücklich als theoretischen Ansatz zur Aufschlüsselung der Bewegungsformen und Gesetze der monopolkapitalistischen Gesellschaft ablehnt. "Unter den Bedingungen des wohlfahrtsstaatlich regulierten Kapitalismus (ist) die Herrschaft von Menschen über Menschen weithin abgelöst worden durch die Dominanz weniger gesellschaftlicher Funktionsbereiche gegenüber den anderen. Der Bruch, der in den früheren Phasen der kapitalistischen Entwicklung $\mathrm{z}$ wi s $\mathrm{ch}$ en den großen Positionsgruppen" (gemeint sind Klassen) "verlief, verlagert sich gleichsam in die Individuen hinein" (56).

Gleichsam illusionsloser ist Offes Konstruktion deshalb, weil für sie die Barrieren, die den "Aktionsspieiraum des politisch-administrativen Zentrums" (57) umgrenzen, und die die Staatsgewalt auf gesellschaftlich-irrationales Handeln festlegen, nahezu unüberwindbar erscheinen. Der in sich festgefahrene und erstarrte Prozeß, die Formen, in denen politische Willensbildung stattfindet, die ge sellschaftlichen Mechanismen der Bedürfnisartikulation und die Selbstdefinition der Staatsgewalt als Garant des Systemgleichgewichts hindern ein praktisches, d.h. vernünftiges Tätigwerden der Staatsgewalt. Die Barrieren, die zu überwinden sind, liegen in den erstarten Formen, in denen die Gesellschaft ihre Bedürfnisse formuliert.

Ändern sich diese Formen, so allerdings auch die Handlungen der Staatsgewalt. Der Weg zur Änderung ist eine Revolution der individuellen Bedürfnisse, denn nur eine solche ermöglicht eine Änderung der Gestalten und Organisationsformen, die bisher den Prozeß politischer Willensbildung be stimmen. Dies wenigstens wäre die Konsequenz aus Offes Ansatz. Sie wird allerdings zu Recht nicht formuliert. Denn woher sollte auch den Individuen ein Anlaß dazu gegeben sein, ihr Bewußtsein und ihre Bedürfnisse zu revolutionieren, wenn der Staat bei seiner "Krisenvermeidungsstrategie" Erfolg hat und scharfe gesellschaftliche Widersprüche von vornherein mit der Aussicht auf 'Erfolg' ausgeschaltet werden können? (Offes Terminologie bringt seine theoretischen Ausgangspunkte auf den Begriff).

Auch für Offe gilt ebenso wie für Habermas: Zu einer grundsätzlichen Änderung der inhalte und Formen der Verteilungstätigkeit der Staatsgewalt - die einem Vernünftigwerden der gesamten Prozesse der gesellschaftlichen Reproduktion gleichgesetzt wird - ist keine grundlegende Umwälzung der Produktionsverhältnisse nötig, sondern allein Änderungen im Prozeß politischer Willensbildung, Abbau der 'Herrschaftsmechanismen', die inn gegenwärtig determinieren. Dazu gehören nach Offe vor allem die Prozesse, die politische Willensbildung innerhalb der Parteien bestimmen (Zwang zum Ausgleich von partialen Gruppeninteressen) (58) sowie das "pluralistische" Verbandssystem. Denn dieses bewirkt, daß nur Partialinteressen an den Staat herangetragen werden, da nur diese organisierbar und konfliktfähig seien. Nur sie können den Staat, dessen Funktion die Erhaltung des Systemsgleichgewichts durch Konfliktvermeidungsstrategie ist, zum Handein bewegen. Sie bestimmen, in welcher Form und zu welchem Zweck das Sozialprodukt vom Staat verteilt wird. Aufträge zum Bau von Schuien und Krankenhäusern und zur Enwwicklung des öffentlichen Verkehrssystems werden danach also deshalb vom Staat nicht in genügendem Maße vergeben, weil sie nur allgemein-gesellschaftlichen Bedürfnissen entsprechen, die durch organisierbare und konfliktfähige Partialinteressen nicht formuliert werden. (59) Es ist die Organisation der Gesellschaft in

56 Claus Offe: "POLITISCHE HERRSCHAFT...", a.a.O. S. 178.
57
Ebda., S. 186.
58 Ebda., S. 165 f.
59 Ebda., S. 168. 
einem pluralistischen Verbandssystem und dessen spezifische Einwirkung auf die staatliche Willensbildung, die ein rationales Handeln der Staatsgewalt mit dem Ziel der Befriedigung atigemeiner Bedürnisse verhindern.

Was die Analyse der Sicuation angeht, so treffen sich hier schließlich, trotz aller Vorbehalte gegen den autoritären Staat, die "linken" mit den rechten Sozialstaatstheoretikern. Der konservative Sozialstaatstheoretiker - als Beispiel sei hier Hennis genommen (60), der sich heutzutage zur SPD hingezogen fühlt - geht davon aus, daß der Staat, gerade weil er heute wesentlich verwaltet, versorgt und verteilt, sich von den 'Zufälligkeiten' demokratischer Willensbildung befreien müsse, um sein Geschät effizient und im Sinne einer alls e i tig befriedigenjen Versorgung der Staatsbürger wahrnehmen zu können. In seinem Staatszweck, der Wohistandssicherung und Versorgung, liege seine demokratische Legitimation; dazu sei eine Organisation seines institutionellen Apparates auf 'sachgesetzliche Forderungen' hin erforderlich. Um also demokratisch im Sinne seiner Legitimation sein zu können, müsse er sich von allen Formen vorstaatlicher Willensbildung emanzipieren, um bei der Erfüllung seiner demokratischen Aufgaben nicht durch gesellschafuliche Interessenauseinandersetzungen gestört zu werden. Dabei spielen die von Erhard empiohlenen 'Spezialisten fürs Gemeinwohl' eine zunehmende Rolle, wenn auch unter wechselnden Namen: Hennis z.B. spricht von "institutionalisierten Augen und Ohren", die den Staat gegenüber dem Druck der Gruppeninteressen an seine allgemeinen Aufgaben zu erinnern haben. Politologen sollen hier endlich eine würdige Aufgabe finden. Der Umgestaltung des Staatsapparates in Richtung auf autoritäre Formen politischer Willensbildung entspreche die Notwendigkeit, das Volk "regierungsłähig" (Hennis) zu machen, deutlicher ausgedrückt: "Die Reife einer Gesellschaft entspricht heute dem Grad ihrer Manipulierbarkeit". "Und von der wissenschaftlichen Forschung her, die hier besters im Fortschritt ist, gibt es für diese Manipulierbarkeit weder faktische noch normative Grenzen." (Rüdiger Altmann, Ideologe der sog. Formierten Gesellschaft) (61) Formierte und in. formierte Gesellschaft gehören nach der Regierungserklärung von Érhard im Jahre 1965 zusammen. Autoritärer Sozialstaat und Manipulation der versorgten 'Bürger' sind die beiden Seiten der gleichen Medaille.

Die Argumentation kann also folgendermaßen zusammengefaßt werden: Will der Staat demokratisch sein, d.h. will er den Wünschen der 'Staatsbürger' entgegenkommen, für ihr Wohl sorgen, so muß er seine Arbeit möglichst auf der organisatorischen Ebene 'effektivieren', er muß sich zum autoritären Staat transformieren. Da der gesellschaftliche Interessenpluralismus, also die Ebene 'gesellschaftlicher Interessenformulierung', den Staat bei einer effektiven Organisation der Verteilung behindert (z.B. bei der Schwergewichtsverlagerung von 'Sozialkonsum auf Sozialinvestitioneu', (62) also Bildung, Seraßen usw. notwendig zur weiteren Sicherung des wirtschaftlichen Wachstums"), ist er zu beseitigen, einzuschränken oder korporativistisch zu organisieren. Eine Folgerung. die auch aus Offes Analyse der Hindernisse für eine rational handelnde Staatsgewalt gezogen werden könnte. Denn warum soliten nach dieser Analyse nicht auch aufgeklärte Staatsmänner, denen es gelingt, ihren Handlungsspiel raum durch Liquidierung des den Staat bestimmenden und beschränkenden Interessenpluralismus zu erweitern und die ihr aufgeklärtes Ohr einer die Politik beratenden Wissenschaft leihen, zur Einrichtung einer besseren Gesellschaft beitragen, also zur Berücksichtigung jener Bedürfnisse nach "Wohnung, Gesundheit, Verkehr, Bildung, bürgerlicher Rechtsordnung. Freizeit", die durch die gegenwärtige Organisation der Bedürfnisformulierung in Verbänden und in den durch Wahlen immer wieder auf die Vertretung von Parteiinteressen festgelegten Parteien unberücksichrigr bieiben müssen.

Demgemäß sieht auch Habermas in den Wissenschattlern, die als Politikberater auftreten und die sich durch Veröffentilchung ihrer Ergebnisse aufgeklärte Massen verschaffen, um so ihrer aufgeklärten Beratung einen entsprechenden politischen Druck verliehen, eine Möglichkeî zur 'Rationalisierung' der politischen Entscheidungen (63). Die 'Staatsbürger' bilden dabei Objekte 'massen-

60 Vgl. zum folgenden: W. Hennis: "Aufgaben einer modernen Regierungsiehre", in: POLITISCHE VIERTELJAHRESSCHRIFT, VI. Jg. (1965) S. $422-441$.

61 R. Altmann: SPÄTE NACHRICHT VOM STAAT, Stuttgart o.J. (1969) S. 51.

62 Der Ausdruck wurde zuerst in Unternehmerpublikationen und in der Regierungserklärung Erhards 1965 verwendet.

63 Vgi.J.Habermas: "Wissenschaft und Politik", in: OFFENE WELT, Nr. 86, 1964, S. 413-423. 
hafter Aufklärung' durch die wissenschaftlichen Eliten. Der technokratische Bildungsökonom und -planer Widmayer stützt sich folgerichtig auf Habermas und Offe, wenn er wissenschaftliche Beratung der Politik und Zurückdrängung des Einflusses der Verbände und der durch Wahten korrumpierten Parteien auf den Staat als Heilmittel aller Schäden dieser Gesellschaft anempfiehtt $\{64\}$.

Für die rechten Sozialstaatstheoretiker liegt das Problem klar auf der Hand. Sozialstaat heißt Vorsorge im Doppelsinn der Sicherung des Lebens und der Entmündigung der Versorgten. Wachsender Wohlstand läßt sich nur auf der Basis einer zunehmenden Manipulation der Versorgten sichern. So ist es konsequent, daß die konservative Sozialstaatsauffassung ihr Modell des Verteilerstaats an die Organisationsprinzipien des kapitalistischen Industriebetriebs anlehnt. Als 'Gesamtunternehmer' im hochorganisierten kapitalistischen 'Gesamtbetrieb' ist er auf Effektivität hin orientiert, wobei sich das Ausmaß seiner Wirksamkeit "nach dem Grade seiner organisatorisch-instrumentalen Adaption an die neue Lage" bestimmt (65). Für den Industriebetrieb gilt in der bürgerlichen Wissenschaft und natüriich bei den Kapitalisten, daß das Bedürfnis der Bürger als Konsumenten nach wachsender,Warenmasse bei freier Konsumwahl die Diktatur des Kapitalisten über die Lohnabhängigen im Betrieb zur Voraussetzung hat. Die Bedürńnisse der Produzenten nach verbesserten Arbeitsbedingungen lassen sich nur insoweit berücksichtigen, als sie der Wirtschaftlichkeit des Betriebes keinen Abbruch tun: "Wenn der Mensch sich in die Produktionsstätten eingliedert, unterstellt er sich damit zwangsläufig den dort herrschenden Gesetzen der Wirtschaftlichkeit. Wirtschaft ist nicht Selbstzweck und der Mensch ist nicht etwa Mittel zum Zweck. Sinn der Wirtschaft ist die Befriedigung der materiellen Bedürfnisse des Menschen, damit er auf diese Weise frei wird für seine höheren geistigen und sittlichen Ziele. Das ist aber nur möglich, wenn der Mensch sich in den Produktionsprozeß eingliedert, wobei er sich den Betriebszielen unterordnen muß und insofern Mittel zum Zweck wird. Das ist gewiß ein innerer Widerspruch, der aber in der Natur der Sache liegt." (66) Im Jargon der wissenschaftlichen Apologeten des Kapitals besteht ein unauflöslicher Widerspruch zwischen den Bedürfnissen des Lohnarbeiters als konsumierendem und geistig-situlichem Wesen und seinem Bedürfnis nach Aufhebung seiner Existenz im Betrieb als bloßes 'Mittel zum Zweck'. Grundsätzlich stehen sich diese Bedürfnisse entgegen, was Mitbestimmung im indu. striebetrieb auch nur soweit zuläßt, als sie "die Beziehungen zwischen dem menschlichen Leistungsfaktor und der Unternehmung so gestaltet, daß die Ziele der Unternehmung in möglichst vollkommener Weise ërreicht werden. ... Der einzelne Arbeiter und Angestellte soll den Eindruck gewinnen, daß er nicht bloßes Objekt, sondern daß er irgendwie an der Gestaltung seines eigenen

64 H.P. Widmayer: "Aspekte einer aktiven Sozialpolitik. Zur politischen Okonomie der Sozialinvestitionen", Vortrag vor der Gesellschaft für Wirtschafts- und Socialwissenschaften, Verein für Socialpolitik (Manuskript 1969).

65 Hennis: a.a.O. S. 429; vgl. S. 427: "Wenn es erlaubt ist, in der Regierungslehre so etwas wie eine Betriebswirtschaftsiehre des modernen Staates zu sehen, so erweckt unser Fach (die politische Wissenschaft) den Eindruck einer Betriebswirtschaftslehre, deren einziges Thema die Mitbestimmung ist." Das Ganze wurde zum erstenmal werbewirksam in der Ideologie von der formierten Gesellschaft (Voegelin usw.) formuliert, worauf auch einige kritische Linke hereingefallen sind.

66 Karl Hax: PERSONALPOLITK UND MITBESTIMNUNG, Köln-Opladen 1969, \$. 16. Vgl. dazu Marx: KAPITAL I, S. 374/377: "Es ist sehr charakteristisch, daß die begeisterten Apologeten des Fabriksystems nichts Ärgres gegen jede allgemeine Organisation der gesellschaftlichen Arbeit zu sagen wissen, als daß sie die ganze Gesellschaft in eine Fabrik verwandeln würde." Die frühbürgerlichen Okonomen waren nicht so kühn, vom Lohnarbeiter totale Unterwerfung in der Arbeitszeit zu fordern, damit er für "seine höheren geistigen und sittlichen Ziele" frei werde; sie verteilten vielmehr diesen "inneren Widerspruch" weise auf verschiede ne Klassen. So pries H.F. von Storch (1815) die Vorzüge der kapitalistischen Gesellschaft: "Der Fortschritt des gesellschaftichen Reichtums erzeugt jene nützliche Klasse der Gesell. schaft ... welche die langweiligsten, gemeinsten und ekelhaftesten Beschäftigungen ausübt, in einem Wort alles, was das Leben Unangenehmes und Knechtendes hat, auf ihre Schultern nimmt und ebendadurch den andren Klassen die Zeit, die Heiterkeit des Geistes und die konventionelle Charakterwüde verschafft ..." (Zitiert nach Marx: KAPITAL Bd. I, S. 682 f/ 677.) 
betrieblichen Schicksals mitwirken kann." (67) Allerdings setzen die Kapitalisten diesen forschen Empfehlungen ihrer wissenschaftlichen Apologeten, Mitbestimmung als Manipulationsinstrument zur Effektivitätssteigerung zu benutzen (von denen sich die Versuche der Gewerkschaften, dem Kapital die Mitbestimmung schmackhaft zu machen, heute kaum noch unterscheiden), nach wie vor ihr Argument vori der effektivitätsmindernden Wirkung der Mitbestimmung entgegen. Die Diktatur im Industriebetrieb scheint ihnen ein zuverlässigeres Mittel zur Auspressung des Mehrwerts als die Manipulation (68).

Um was es hier aber geht: der entscheidende Widerspruch besteht danach nicht zwischen Kapital und Lohnarbeit, sondern zwischen dem Bürger als Konsumenten und als Arbeitnehmer. Seine Freiheit und gute Versorgung als Konsument erfordert seine Versklavung als Produzent. Produktion und Konsumtion stehen sich danach in der Person j edes e in z eln e n Arbeiters - für den Kapitalisten besteht das Problem natürlich nicht - ałs unversöhnliche Widersprüche gegenüber. Auch die Sozialstaatstheorie, sei sie nun revisionistisch oder konservativ, kommt am Ende dazu, die Widersprüche, an denen die rationale Organisation der Gesellschaft scheitert, 'gewissermaßen' in die Individuen selbst hineinzuverlagern. 'Linke' Sozialstaatstheoretiker beschreiben den Interessenwiderspruch im Individuum als Ergebnis historischer Prozesse und als vermittelt über die Ebene gesellschaftlicher Interessenformulierung. Rechte Sozialstaatstheoretiker begreifen ihn als Naturkonstante. Daraus ergibt sich der Unterschied in der politischen Strategie. Massenhafte Aufklärung, verabfolgt von einer aufgeklärten Elite, oder Manipulation. In beiden Fällen sind die Massen Objekte der Behandlung durch die Eliten.

Daraus ergibt sich dann auch die Verschiedenheit des politischen Ziels. Ist für den Konservativen der autoritäre Staat eine unumgängliche Notwendigkeit, so für den Revisionisten (69) ein historisch entstandenes und damit auch veränderbares Institut. Daß aber auch für die Revisionisten gesellschaftliche Veränderungen nur als 'Revolution von oben' infrage kommen, wobei ihr Postulat Abschaffung von Herrschaft - leere Formel bleibt, das läßt sich daraus herleiten, w i e sie die historischen Bedingungen, unter denen sich das gegenwärtige politische Bewußtsein der 'Staatsbürger' gebildet hat, darstellen, und wie sie den Prozeß der ökonomischen Reproduktion der Gesellschaft fassen. Da der kapitalistische Wohlfahrtsstaat in Zukunft keine Krisen mehr zulassen wird, da er ökonomische Krisen manipulieren kann, wird es für die Lohnabhängigen in Zukunft nicht mehr möglich sein, aufgrund ihrer eigenen Erfahrungen zum Bewußtsein der Widersprüche der Gesellschaft zu kommen. "Das Verhältnis der Leistungsempfänger zum Staat ist... nicht politische Beteiligung, sondern eine allgemeine Forderungshaltung, die Versorgung erwartet, aber nicht eigentlich Entscheidungen durchsetzen will." (70) Wie sollen also die Individuen von selbst zu einer Änderung ihres Bewußtseins kommen, wenn der Staat ihnen die Versorgung gewährt, wenn sich also am gegebenen Zustand nichts ändert, bzw. der gegebene Zustand sich sogar noch verbessert, indem quantitative Steigerung der staatlichen Versorgungsieistungen in Aussicht steht, wenn der Kapitalismus seine Krisen durch seinen Staat regulieren kann, wenn sich also die kapitalistisehen Widersprüche abstumpfen? "Was wir auf diesem Wege erhalten, ist eine Begründung des sozialistischen Programms durch 'reine Erkenntnis', das heißt, einfach gesagt, eine idealistische Begründung, während die objektive Notwendigkeit durch den Gang der materiellen Entwicklung da-

67 Dazu als Beleg das allbekannte und nach wie vor schlagende Zitat "Demokratisierung der Wirtschaf $t$ ist so unsinnig wie die Demokratisierung von Schulen, Kasernen und Zuchthäusern" aus dem INDUSTRIEKURIER im Jahre 1965.

68 Hax, a.a.O. S. 24 und S. 16.

69 Wenn wir in diesem Aufsatz auch neuere Autoren aus der BRD unter dem Begriff des Revisionismus zusammenfassen, so liegt hier ein Problem, das hier wenigstens angedeutet werden soll, nämlich die Frage nach dem Zusammenhang einer von ihren eigenen Organisationen auf den Staat orientierten Arbeiterbewegung mit den da $z$ u g e h $\ddot{r} r$ g e n Theoretikern. Während dieser Zusammenhang z.B. bei Hilferding und Tarnow auf der Hand liegt, ist er bei Habermas und Offe nicht ohne weiteres ersichtlich; bei anderen Frankfurter Soziologen im Umkreis einiger Gewerkschaftszentralen ist er allerdings unbestreitbar. Andrerseits ist zu klären, inwieweit es richtig ist, bei der gegenwärtigen Rolle der Gewerkschaften und der SPD noch von Reformismus zu sprechen, auf den sich eine gegenüber dem revolutionären Marxismus revisionistische Theorie beziehen würde. Habermas: STUDENT..., a.a.O. S. 32. 
hinfällt" (71). Die Einführung des Sozialismus aber durch "reine Erkenntnis", durch Aufklärung der Massen ist bei Habermas folgerichtig eine Sache der aufgeklärten Eliten (72).

Da zudem bei den zeitgenössischen Revisionisten der Produktionsprozeß aus der gesellschaftlichen Analyse entweder vollends herausfälit, oder aber als Ort der Ausbeutung, der Produktion von Mehrwert (2.B. durch die 'wertschaffende Potenz der Wissenschaft') in Fortfall gekommen ist, kann sich das Bewußtsein der Individuen nur an der Verteilungssphäre orientieren. Politisches Bewußt. sein bezieht sich in dieser Begrifflichkeit vor allem auf den Staat, auf die Politik; seine Kritik als 'kritisches Bewußtsein' beschränkt sich auf die Normen der Verteilung von 'Einkommen' und 'Lebenschancen': gerecht oder ungerecht, ausreichend oder unzureichend.

Eine wissenschaftliche Methode, die beim Staat als Untersuchungsobjekt ansetzt, aus seinen Erscheinungsformen seine Souveränität gegenüber dem Produktionsprozeß ableitet, ihn zum Träger der Sozialordnung werden läßt, und dann auch die gesellschaftlichen Konflikte nicht mehr durch die besondere Weise der gesellschaftlichen Produktion konstituiert sieht, löst schließlich den gesamten gesellschaftlichen Prozeß in verschiedene Sphären auf und kommt dabei zu dem Ergebnis, auch das Individuum selbst in verschiedene Sphären aufzuteilen. Dies zeigt sich in der zeitgenössischen revisionistischen Theorie am Begriff des politischen Bewußrseins, der allein auf das Verhältnis des 'Staatsbürgers' zum Staat bezogen wird. Auf dieser Basis kann dann auch schnell vom unpolitischen Bewußtsein des deutschen Proletariats gesprochen werden, nachdem dieses sich nicht wie ein Mann in den Kampf gegen die Notstandsgesetze - eine hochpolitische Angelegenheit führen ließ, um den 'demokratischen Staat' zu verteidigen. Kämpfe zwischen Lohnarbeit und Kapital im Betrieb werden dann als 'bloß ökonomisch' und an falschen Konsumbedürfnissen orientiert abgetan. Das Verhältnis von Lohnarbeit und Kapital kommt dann überhaupt nichi mehr als Erfahrungsbasis für die Ausbildung politischen Bewußtseins in Frage. Die Klagen über das mangelnde politische Bewußtsein des Proletariats machen es den Klagenden leicht zu vergessen, daß sie selbst es sind, die an der Legitimierungsideologie des kapitalistischen Staates eifrig mitarbeiten.

Die Geschichte der 'Industriegesellschaft' erscheint ihnen vor allem als Geschichte des Kapitais und seines Staates, nicht aber als Geschichte der Arbeiterklasse, ihrer Kämpfe und Niederlagen (73). Sie zeigen diese Geschichte in der bürgerlichen Verkehrung, wo die tote über die lebendige Arbeit herrscht, und in dieser Verkehrung ist ihr Bewußtsein befangen. Die Arbeiterklasse erscheint schon immer als bloßes Objekt der Entwicklung. Mit der praktischen und theoretischen Liquidierung des revolutionären Kampfes des Proletariats durch die sozialdemokratischen Organisationen werden die tatsächlichen Kämpfe des Proletariats aus dem Geschichtsbewußrsein verdrängt (74). Wenn diese intellektuellen Kritiker heute beklagen, daß der Sozialstaat aufgrund der 'Passivität des Proletariats' sich zum autoritären Staat zu entwickeln drohe, so soliten sie nicht vergessen, daß die Arbeiterschaft spätestens seit der Novemberrevolution von der SPD (und seit ihrer Legalisierung zunehmend auch von einer Partei, die sich selbst als kommunistische versteht) auf den bürgerlichen

71 Luxemburg: SOZIALREFORM..., a.a.O.

72 Hier ist wieder auf die schon von Rosa Luxemburg gekennzeichnete Folgerichtigkeit von nichtrevolutionären Rezepten gegen den Kapitalismus hinzuweisen; sie zeigt, wie schon gesagt, am Beispiel Bernsteins, daß der nichtrevolutionäre Weg auch zu einem anderen Ziel, nämlich der Beibehaltung der alten Gesellschaftsordnung mit einigen Verbesserungen führt, wobei man sagen muß, daß diese innere Logik von Habermas sehr flott in die äußere Erscheinung umgesetzt worden ist.

73 VgI, dagegen z.B. die ILLUSTRIERTE GESCHICHTE DER DEUTSCHEN REVOLUTION (Berlin 1929, Nachdruck Frankfur /Main 1968), in der häufig die eigene Erinnerung der Kämpfenden zu Wort kommt.

74 FU-Projek tgruppe DKP/Rabeh1: DIE DKP..., a.a.O. S. 154: "Da er (der Reformismus) den monopolkapitalistischen Staat als Garantie der Einfürung des Sozialismus in die Gesellschaf $t$ verstand, fixierte er die Arbeiter an die demokratische Verfassung, d.h. er erzog sie in der Phase der Krise zur Passivität." In dieser ganzen Schrift wird allerdings nicht recht deutlich, warum der an ihren Folgen richtig kritisierten positiven Fixierung auf den Staat in der Geschichte der Sozialdemokratie eine negative Fixierung auf denselben Stat als einziges politisches Heilmittel entgegenzusetzen sei. So schreibt Rabehl auf Seite 106: "Die revolutionäre Theorie wird zur Aktionsstrategie, die zwar der Widerspruchsebene der kapitalistischen und monopolkapitalistischen Produktion folgt, der Disproportionalität zwischen den industriellen Abteilungen, den Stagnations- und Teilkrisen, dem ProzeB der Auflösung und Bildung der Klassen ...diese latenten oder offenen Gegensätze und Widersprüche aber durch die Aktionen der Klasse zum Ausbruch bringt oder verstäkt. D a s ver lang $\mathrm{d}$ e $n$ a $\mathrm{d}$ a $\mathrm{u}$ 
Staat als den Hauptadressaten ihrer Forderungen gelenkt worden ist, daß ihre Selbsttätigkeit von der SPD und der Gewerkschaftsbürokratie, oft in Zusammenarbeit mit der Bourgeoisie, immer wieder unterdrückt worden ist, und nicht zuletzt: daß solches Bewußtsein der Arbeiterschaft (träfe die Beschreibung wirklich zu) auch das Resultat dieser historischen Erfahrung u nd ihrer theoretischen Bestätigung durch die Arbeit der sozialdemokratischen Theoretiker seit Bernstein ist. Sie fühlen sich von der Arbeiterklasse verlassen und weben doch eifrig an der Legitimierung und Ideologie des bürgerlichen Staates. Die Ideologie vom Sozialstaat und die Unterdrückung der Arbeiterklasse als handelndes Subjekt der Geschichte durch ihre Organisationen hängen in der Geschichte der Arbeiterbewegung eng miteinander zusammen.

Indem der 'Wohistand für alle' zur Legitimationsbasis der Staatsgewalt und ihrer Institutionen wird, erscheint er als etwas, über das die Staatsgewalt im Verein mit der ökonomisch herrschenden Klasse, der 'Wirtschaft', verfügen kann, das den Massen zu gewähren ist und das umgekehrt die Massen von der Staatsgewalt erwarten und fordern. Die Massen erscheinen hier als fordernde, mit Rechtsansprüchen ausgestattete Objekte staatlicher Daseinsvorsorge, der Staat als gewährendes Subjekt - die 'Güter' fallen sozusagen vom Himmel. Doch eine Gesellschaftstheorie, die wissenschaftlich vorgeht, muß davon ausgehen, daß die Masse der Produkte, bevor sie verteilt werden kann, von denen, an die sie (und zwar nur zum Teil) verteilt wird, von den Massen insgesamt produziert worden sind. Die Massen sind also nicht erst als Behandelte, allenfalls Fordernde in die Theorie einzuführen, sondern bereits als unter bestimmter Form der Produktion arbeitende und produzierende, und das heißt, konkret: vom Kapital angewendete Subjekte, also, oder vielmehr, Objek te des Subjekts Kapital. Und der Staat kann nicht erst als 'Verteiler' --, 'Wohlfahrts' - und 'Sozialstaat' untersucht werden, sondern seine Funktionen müssen unter dem Gesichtspunkt betrachtet werden, daß die Waren, bevor sie verteilt werden, zunächst einmal produziert werden müssen, daß also der Staat gerade auch als 'Sozialstaat' für den Reproduktionsprozeß des Kapitals aufgrund seiner widersprüchlichen geschichtlichen Entwicklung in bestimmten historischen Entwicklungsstufen jeweils besondere Funktionen übernimmt. Eine marxistische Analyse muß daher die 'Verteilung des Volkseinkommens' als in den Produktions- und Zirkulationsprozeß des Kapitals eingeschlossenes Momen' betrachten und die Funktionen des Staates von da aus zu begreifen suchen.

\section{Einkommensverteilung und Kapitalkreislauf}

Wir haben gesehen, daß die Verselbständigung der Verteilung der Einkommen als eigenständige Sphäre neben der Produktion, d.h. neben der in dieser vorausgesetzten Verteilung der Produktionsmittel, eine entscheidende theoretische Annahme ist, die in den revisionistischen Staatsauffassungen gemacht werden muß, um grundlegende Eingriffsmöglichkeiten des Staates in die Verteilung der Einkommen begründen zu können. Die Vorstellung vom 'Kuchen des Sozialprodukts' (75),

ernden Angrift aufdie einzelnenstaatlichen Organe, die die A ufgabe der Lenkung vongesellschaftlichen Teilbereichen h a be $n$ (Ausbildung, Erziehung, Gesundheitswesen, Justiz, Polizei, Armee etc.), um die Funktion des Staates $z u$ entlarven und zu verhindern, daß er sich als konterrevolutionäres Machtmittel konsolidiert." (S. 106; Hervorhebung: M/N) Wenn die Widerspruchsebene auf der Ebene der kapitalistischen Produktion zu orten ist, d.h. in bezug auf die Beteiligien: auf der Ebene des Widerspruchs zwischen Lohnarbeit und Kapital, wird nicht einsichtig, warum die Betroffenen vor allem gegen den kapitalistischen Staat und nicht gegen das Kapital selbst ihre Aktionsstrategie entfalten sollen. Diese negative Fixierung auf den Staat (statt auf das Kapital und erst dadurch vermittelt auf den Staat, der ihm zu helfen $v$ e $\mathrm{r}$ s $\mathrm{ch} t$ ) trägt die Gefahr in sich, den richtigen Gegner aus dem Auge zu verlieren. Das zeigt sich z.B. daran, daß die Illusion einer grundsätzlichen Veränderung entsteht, sobald die staatliche Gewaltausübung oberflächlich gemildert wird (Amnestie, Verminderung von Polizei- und Justizterror; überhaupt die Illusionen über die SPD-Regierung). Das zeigt sich auch in den rein politischen Organisationsvorstellungen, die von dieser Staatsvorstellung bestimmt sind und die Notwendigkeit einer Fundierung in 'ökonomischen' Klassenkämpfen höchstens verbal zugestehen. Vgl. dazu auch Teil V.

75 Es handelt sich bei der Kuchenvorstellung um eine äußerst beliebte und populäre Betrachtungsweise, der sich auch die 'Großen' der bürgerlichen Okonomie gern hingaben. So z.B. Keynes: DIE WIRTSCHAFTLICHEN FOLGEN DES FRIEDENSVERTRAGES, München und Leipzig 1921, S. 14: "... Einerseits begnügten sich die arbeitenden Klassen aus Ungewiß- 
der nach dem Ergebnis der Kämpfe der Interessenten stückweise und losgelöst von den Produktionsbedingungen verteilt wird, setzt voraus, daß das Kapital, nachdem es die Waren produziert hat, diese der Gesellschaft 'zur freien Verfügung' überläßt, daß es in interesselosem Wohlgefallen dem Kampf der Interessenten um die Kuchenstücke zuschaut und sich damit zufrieden gibt, was ihm seine eigenen Interessenvertreter, also die Kapitalistenverbände (BDI, BdA, DIHT Usw.) erkämpfen. Danach besteht keine ökonomische, sondern nur eine politische Verbindung zwischen der kapitalistischen Produktion ais Produktion von Waren und Kapital einerseits und der Verteilung der daraus'entspringenden' Einkommen andererseits.

\section{Primäryerteilung und staatiiche Umverteilung}

So einfach allerdings machen es sich die bürgerlichen ökonomischen Verteilungstheorien doch nicht. Nach ihnen ist der Zusammenhang zwischen Verteilung und Umverteilung durchaus ökonomisch bestimmt und nicht nur durch politische Gesetzmäßigkeiten geregelt. Die staatliche Umverteilungspolitik erscheint dabei als sekundä re Korrektur der primä $r$ sich ergebenden Verteilung aufgrund von 'Faktorentlohnungen'. Die nachträgliche Korrektur der primären Verteilung kann nicht mehr willkürlich oder nach den politischen Gesetzen des Machtausgleichs, sondern nur auf der Basis der primär erfolgten Verteilung durchgeführt werden. Die Macht könne, wie Preiser schreibt (76), innerhalb der Primärverteilung nur noch als Bestandteil des 'Datenkranzes' des ökonomischen Systems einwirken, da in den die Verteilung bestimmenden ökonomischen Gesetzen der Einfluß der Macht enthalten sei. Diese Bedeutung der ökonomischen Gesetze bei der Verteilung der Einkommen erscheint in dezidierter Form in den Kreislauftheorien der Verteilung, in denen "die Lohnzahlungen und die Gewinne... die einkommensmäßige Grundlage der Konsum- und Investitionsausgaben (bilden), die wiederum die Erlöse darstellen, aus denen in der nächsten Runde die Löhne gezahlt werden und die Gewinne entstehen." (77) Damit wird die Verteilung tatsächlich als ein Moment in den allgemeinen Kreislaufzusammenhang der Reproduktion gestellt; sie verliert also ihren Charakter als selbständiger und politisch zu manipulierender Vorgang. (78)

heit oder Machtlosigkeit mit einer Lage, in der sie nur ein ganz kleines Stück des Kuchens ihr eigen nennen konnten, den sie, die Natur und die Kapitalisten zusammen herstellten (!) ...Auf der anderen Seite durfte die Kapitalistenklasse den besten Teil des Kuchens ihr eigen nennen..." Und auch heute, in der "modernen Industriegesellschaft", werden von einern Volk von Konditoren Kuchen gebacken: "Dieses Volkseinkommen ist die tatsächliche Wertschöpfung der westdeutschen Volkswirtschaft. Das ist der 'große Kuchen', die Summe, die für Arbeits- und Kapitaleinkommen, für Grundrenten und Staatsausgaben zur Verfügung steht. - Jeder versucht von diesem Kuchen ein möglichst großes Stück zu ergattern..." (Kurt Walter und Amold Leistico: ANATOMIE DER WIRTSCHAFT - EINE EINFUHRLNG IN DIE VOLKSWIRTSCHAFTSLEHRE, Reinbeck bei Hamburg 1969, S. 42. An diesem Buch ist bemerkenswert, daß es (1) im dritten Fernsehprogramm gesendet worden, also doch immerhin breitgetreten worden ist, (2) von dem 'fortschrittlichen' Dr. Gerhard Szcesny herausgegeben wurde, (3) von dem Leiter der Kammergemeinschaft Offentlichkeitsarbeit der nordrhein-westfälischen Industrie- und Handelskammern und dem wissenschaftlichen Berater des Generals für das Erziehungs- und Bildungswesen im Heer geschrieben worden ist und (4) im 'linken' Rowohlt-Verlag seinen Verbreiter fand). Um diese Kuchenvorstellung auf die dritte Welt zu übertragen, müßte man zu Grimms Märchen greifen: “Knusper knusperknäuschen, wer knuspert an meim Häuschen?" - "Der Wind, der Wind - das Imperialistengesind"!"

76 Erich Preiser: "Distribution: (1) Theorie", in: HANDWORTERBUCH DER SOZIALWISSENSCHAFTEN, Band 2, S. 624. Damit wird von Preiser die Auffassung zu bezeichnen versucht, daß 'Macht' zwar eine politische und soziale Kategorie aber auch okonomisch relevant sei, da ja die ökonomischen Kategorien und 'reinen' Gesetze die politische und soziale Mlacht notwendig auch reflektierten. Auf diese formale Weise wird auszudrücken versucht, daß Macht eine 'ökonomische Potenz' ist. Vgl. Karl Marx: DAS KAPITAL, Bd. I, S. 791/799.

77 Wilhelm Krelle: VERTEILUNGSTHEORIE, Tübingen 1962, S. 110.

78 Es wird hier darauf verzichtet, die verschiedenen Verteilungstypen (personelle, funktionelle, sektorale Verteilung) zu diskutieren (wenn einfach von 'Verteilung' die Rede ist, ist stets 'Verteilung von Einkommen' zu verstehen). Vgl. dazu Erich Preiser, a.a.O., und Leo Kowalski: EINKOMMENSVERWENDUNG, EINKOMMENSVERTEILUNG UND VERMOGENS VERTEILUNG, Tübingen 1967, wo die neueren Ansätze der bürgerlichen Óonomie referiert werden. Im vorliegenden Aufsatz geht es nicht um Verteilung an sich, sondern um den $\mathbf{Z u}$ sammenhang von Verteilung und Kapitalverwertungsprozeß. 
Oder anders ausgedrückt: Politische Umverteilungsmaßnahmen haben mit bestimmten angebbaren Gegenwirkungen zu rechnen. Dies drückt sich wiederum politisch als Zielkonflikt aus, da nun die ökonomischen Gegenwirkungen die Verwirklichung anderer politischer Ziele gefährden.

Ein solcher 'Zielkonflikt' zwischen Wachstum und Verteilung stellt sich folgendermaßen dar: Man kann "von einer Untergrenze der Kapitalverzinsung (ausgehen), bis zu der Investition und Beschäftigung gerade noch erhạlten bleiben, bei deren Überschreiten jedoch der marktwirtschaftliche Wachstumsprozeß nicht mehr funktioniert. Diese Untergrenze der Kapitalverzinsung ist gleichzeitig die Obergrenze für den Reallohn. Wird die Obergrenze der Kapitalverzinsung, die mit der Untergrenze des Reallohns identisch ist, überschritten, so wird eine 'soziale Revolution' ausgelöst, und das marktwirtschaftliche Wirtschaftssystem bricht zusammen." (79) In solchen politischen Zielkonflikten drücken sich an der Oberfläche die zugrundeliegenden ökonomischen Widersprüche zwischen Lohnarbeit und Kapital aus, die nun allerdings als die bewegenden Momente dieser Konflikte von der bürgerlichen Okonomie nicht begriffen werden. So zeigt sich auf der einen Seite ein typischer Unterschied zwischen ökonomischer und politischer Einschätzung staatlicher Einkommensumverteilung. Während die revisionistischen und politologischen Theoretiker eine sehr große staatliche Manipulationsfähigkeit annehmen, sind die nationalökonomischen Theorien grundsätzlich sehr viel skeptischer. Auf der anderen Seite bleiben aber auch die ökonomischen Verteilungstheorien im Anschein staatlicher Manipulierungsfähigkeiten verhaftet. Sie sind deshalb auch ledig. lich in der Lage, mögliche Zielkonflikte zu beschreiben und Methoden anzugeben, wie bei widersprüchlichen Zielen optimale Verwirklichungskomplexe in der 'rationalen' Wirtschaftspolitik zu gestalten seien. Information über solche Konflikte und Erkenntnis der Zusammenhänge zwischen widersprüchlichen Zielen erscheinen der bürgerlichen Okonomie als Methoden, mit Konflikten fertigzuwerden. Voraussetzung für eine solche idealistische Annahme bleibt natürlich, genau wie in den revisionistischen und politologischen Theorien, ein Staat, der sich als übergreifendes Subjekt ökonomischen Bezugssystem konstituiert und wirklich nur der immer weiter verbesserten Informationen (gerade über Konfliktsituationen) und Manipulationsinstrumente bedarf, um der Anforderung an eine rationale Wirtschaftspolitik gerecht werden zu können: "Rationale Politik muß zielbewußt und sachgerecht sein." (80)

Aus der Beobachtung ökonomischer Gesetzmäßigkeiten ergibt sich folglich der Realismus ökono. mischer Verteilungstheorien in bezug auf politische Umverteilungsmöglichkeiten. Krelle kommt in seiner "Verteilungstheorie" zu dem desillusionierenden Ergebnis, daß kurzfristige Umverteilungsmaßnahmen innerhalb einer "Marktwirtschaft" aufgrund langfristiger Gegenwirkungen "korrigiert" werden (81). Auch im Gegensatz zu gewerkschaftlichen Gesundpredigern der kapitalistischen Vermögensverteilung mit Placebos wie der 'Vermögensbildung in Arbeitnehmerhand' kommt die bürgerliche Ökonomie zu dem konkreten Ergebnis, daß eine Umverteilung durch Vermögensbildung gar nicht möglich ist. Wie Föhl und Hennies das Blatt auch drehen und wenden: als Ergebnis ihrer Abhandlung finden sie wieder das, was bisher durch alle Gutachten bestätigt worden ist: daß eine "echte Umverteilung" des Vermögens nicht zu erreichen ist. (82) Entweder sinken als Folge von Umverteilungsmaßnahmen Einkommen, Beschäftigung und Wachstumsrate, oder es findet Kapitalflucht statt, oder es erfolgt nur eine Umverteilung zwischen "staatlichem Sektor" und "Privatwirtschaft", nicht aber zwischen Kapital und Arbeit, wenn versucht wird, die Vermögensund Einkommensverteilung zugunsten der Lohnarbeit zu verändern. Kurz gesagt: "Wer hat, dem wird gegeben!" (83) Im Akkumulationsprozeß des Kapitals, und daran kann die bürgerliche Ókono.

79 Georg H. Küster: UNTERSUCHUNGEN ZUR EINKOMMENSVERTEILUNG IM WIRTSCHAFTSWACHSTUM, Berlin 1969, S. 15. Hierbei beruft sich Küster auf Wilhelm Krelle: "Bestimmungsgründe der Einkommensverteilung in der modernen Wirtschaft", in: W.G. Hoffmann (Hrsg.): EINKOMMENSBILDUNG UND EINKOMMENSVERTEILUNG, Berlin 1957.

80 H. Giersch: ALLGEMEINE WIRTSCHAFTSPOLITIK, Grundlagen, Wiesbaden 1960, S. 23.

81 "Uberblicken wir das Ergebnis (der Verteilungstheorie -- Verf.) als Ganzes, so zeigt sich eine ganz unerwartete Stabilität eines marktwirtschaftlichen Systems. Fast alle Änderungen kurzfristiger Art rufen langfristige Gegenwirkungen hervor, die sie wieder rückgängig machen..." (Wilhelm Krelle: VERTEILUNGSTHEORIE... a.a.O., S. 257).

82 Carl Föhl und Manfred Mennies: VERMOGENSBILDUNG IN ARBEITNEMMERHAND, Pfullingen 1966.

83 Carl Föhl: KREISLAUFANALYTISCHE UNTERSUCHUNGEN DER VERMÖGENSBILDUNG IN DER BUNDESREPUBLIK UND DER BEEINFLUSSBARKEIT IHRER VERTEI- 
mie nicht vorbei, polarisiert sich auf der einen Seite der gesellschaftlich produzierte Reichtum als privater in Kapitalform und auf der anderen Seite die Armut des Lohnarbeiters, der auch in der 'modernen Industriegesellschaft' immer noch nicht mehr auf den Markt zu tragen hat als seine Arbeitskraft. Wer hat, dem wird gegeben und wer nichts hat, der muß arbeiten, um zu leben, mit der Folge, daß denen, die haben, noch mehr gegeben wird.

Der Realismus allerdings, der in einem solchen Ergebnis liegt, ist nichts anderes als der Realismus des 'gesunden Menschenverstandes', der auch ohne Rückgriff auf ökonomische Zusammenhänge einfach festzustellen in der Lage ist, daß denen, die haben, und nicht denen, die nicht haben, gegeben wird. Daher hört der Realismus der ökonomischen Theorien sofort auf, wenn sie in Empfehlungen für die staatliche Politik ausmünden. Denn wird nicht gerade Vermögensbildung von dem ökonomischen 'Sachverstand' seit Jahren empfohlen (84)? Dies kann man doch schließlich nur. wenn man mit der Möglichkeit einer solchen Umverteilung rechnet. Die Konsequenz aus den ökonomischen Kreislaufbetrachtungen, daß Umverteilung im Kapitalismus längerfristig oder gar dauerhaft eine pure lllusion ist, und die Erkenntnis, daß der im Kapitalismus auf immer enweiterter Stufenleiter wiederhergestellte Klassengegensatz zwischen Lohnarbeit und Kapital den für die störungsfreie Erneuerung des Kapitals absolut notwendigen Klassenfrieden gefährdet, geraten in W: derspruch zueinander. Auf zwei Weisen kann sich der bürgerliche Wissenschaftler nun aus der Affäre ziehen: Erstens kann er sich aus dem Entscheidungsprozeß auf staatlicher Ebene zurückziehen und dem politischen Dezisionismus das Feld überlassen, und zweitens kann er Umverteilung von Einkommen und Vermögen vorschlagen, wenn sie "behutsam" (das heißt im Klartext: im Ganzen wirkungslos) vorgehe, und zwar mit dem Ziel, die Lohnarbeiter über ihre wirkliche Lage hinwegzutäuschen. (85)

LUNG, Tübingen 1964, S. 40. Es handelt sich bei dieser Aussage um nichts anderes als eine Verballhornung des Akkumulationsgesetzes. Karl Marx: DAS KAPITAL, Band I, S. $680 \mathrm{f} /$ 674 f: "Aber alle Methoden zur Produktion des Mehrwerts sind zugleich Methoden der Akkumulation und jede Ausdehnung der Akkumulation wird umgekehrt Mittel zur Entwicklung jener Methoden. Es folgt daher, daß im Maße wie Kapital akkumuliert, die Lage des Arbeiters, we $\mathrm{l} \mathrm{ch}$ e s i m m e r s e i n e $\mathrm{Z}$ a hl u $\mathrm{ng}$, hoch oder niedrig, sich verschlechtern

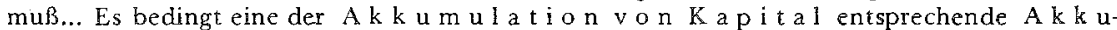
$\mathrm{mul}$ a $\mathrm{t}$ i o $\mathrm{n}$ v o n Ele $\mathrm{nd}$. Die Akkumulation von Reichtum auf dem einen Pol ist also zugleich Akkumulation von Elend, Arbeitsqual, Sklaverei, Unwissenheit, Brutalisierung und moralischer Degradation auf dem Gegenpol, d.h. auf Seite der Klasse, die ih r e ig ene s Produkt als Kapital produziert."

84 Vgl. dazu als Beispiel für viele die gesammelten Stellungnahmen der bürgerlichen Wissenschất in: Georg Leber: VERMOGENSBILDUNG IN ARBEITNEHMERHAND, Wissenschaf thiche Beiträge, Dokumentation, Frankfurt/Main 1965, die alle auf das hinauslaufen, was Georg Leber im Vorwort von ihnen erwartet: "Schritte zur Veränderung einer ungerechten und überholten Einkommensstruktur auch auf dem sicheren Boden wissenschaftlicher Erkenntnisse (unternehmen zu können)".

85 Die beiden Autoren, die im HANDWORTERBUCH SOZIALWISSENSCHAFTEN die beiden Teile des Artikels zur Distribution geschrieben haben, nämlich Erich Preiser und Gerhard Weisser, polarisieren sich auf den beiden Vorgehensweisen, nach denen sich bürgerliche Wissenschaftler aus der Affäre ziehen: Erich Preiser stellt die Konsequenz in einem Aufsatz gleich dreimal klar: "Wenn wir das Problem (der Vermögensbildung - Verf.) überhaupt diskutieren wollen, so müssen wir also annehmen, beide Parteien (die 'Tarifpartner' - Verf̂.) seien guten Willens, wobei für die Unternehmer zwar eine Gewinneinbuße, nicht aber eine Existenzgefährdung herauskommen dürfte..." Und: "Die Aussichten der Investivlohnpolicik (bzw. der Vermögenspolitik) sind umso besser (!), je behutsamer sie vorgeht." Erich Preiser: "Theoretische Grundlagen der Vermögenspolitik", abgedruckt in Georg Leber, a.a.O, \$. 34, 38, 41. Wie sieht aber 'Behutsamkeit' praktisch aus? Gerhard Weisser: "Distribution: (II) Politik" (in: HaSW, Bd. 2, 5. 645) hat eine Antwort: "...Aber die verteilungspolitischen Korrekturen stehen zum Teil in Spannung mit der Kompatibilitätsregel. Extreme Maße dürften zu groß sein, als daß dabei die Marktwirtschaf optimalen Autonomie der Wirtschaftsteilnehmer willen für eine grundsäizlich mark twirtschất liche Ordnung entscheidet, muß also irgendwelche Grenzen für die Verteilungskorrekturen anerkennen. Selbstverständlich kann an dieser Stelle nicht versucht werden, diese Grenze generell oder für die gegenwärtige Situation in der Bundesrepublik Deutschland zu bestim. men. Die Wissenschaft dürfte auch in diesem Bereich nicht dahin kommen können, daß der 
Der Zielkonflikt enthüllt sich auf diese Weise als innerer Widerspruch der Gesellschaft, der sich im Realismus ökonomischer Verteilungstheorien $u n d$ in der Erkenntnis von der Notwendigkeit der Umverteilung gleichermaßen darstelit. Dieser auf theoretischer Ebenereproduzierte gesellschaftliche Widerspruch zwischen Lohnarbeit und Kapital wird allerdings als bloße Folge von Verhüllungs. absichten nicht auf den Begriff gebracht, sondern seine Verhüllung ist in der Realität kapitalistischer Warenzirkulation selbst verankert. Der kapitalistische Produktionsprozeß ist Warenproduktion, d. h. es werden Waren für die Zirkulation produziert. In der Zirkulation kann man es der einzelnen Ware nicht ansehen, aus sweichen Wertbestandteilen sie sich zusammensetzt; und das heißt: welchen Verteilungsnotwendigkeiten der durch den Verkauf der Waren realisierte Wert unterliegt. Woher stammt aber das Geld, gegen das die Ware ausgetauscht und in dem der Warenpreis realisiert wird? Ein Teil dieses Geldes stammt aus den Händen der Arbeiter, die ihren Lohn im Austausch gegen Waren verausgaben. Hier, in der Zirkulation sind die Arbeiter nur Konsumenten, die mit Geld ausgestattet sind, um deren Kaufkraft die Warenverkäufer, die Unternehmer, konkurieren. Der Lohn erscheint bloß als nachfragewirksames Einkommen, das gegen Waren ausgetauscht wird, denen man ihre Herkunft aus kapitalistischer Produktion und damit ihre Wertzusammensetzung, nämliç daß in innen variables Kapital (für den Arbeiter sich darstellend als Lohn), Mehrwert und konstantes Kapital enthalten ist, nicht ansieht. In dieser Sphäre sind die lliusionen von den Verteilungsmöglichkeiten begründet; im Rahmen solcher lllusionen gibt es die Möglichkeit, der als Folge von Umverteilungsmaßnahmen sich ergebenden Kaufkraftumverteilung und deren negativen Auswirkungen staatlichen gegenzusteuern.

Diesen aus dem Zirkulationszusammenhang begründeten $1 / 1$ u s i o $\mathrm{n}$ e $\mathrm{n}$ steht auf der anderen Seite durch die Hereinnahme der Produktionssphäre in die ökonomische Analyse von Verteilungsvorgängen die $\mathrm{realist}$ is che $\mathrm{E}$ insicht in die engen Grenzen staatlicher Umverteilungsmaßnahmen entgegen. So kornmt aufgrund dieses ökonomischen Zusammenhangs von Produktion und Zirkulation der oben bezeichnete Widerspruch zustande. Seine Lösung kann nur in der genauen Analyse der doppelten Funktion jenes Wertteils liegen, der für den Kapitalisten variables $K$ a $p$ it a l, für den Arbeiter E i n k o m m e n (Lohn) ist. (86) Wenn wir dies vereinfacht als 'Doppelcharakter des Lohns' ausdrücken, so können wir sagen: Der Widerspruch zwischen Lohnarbeit und Kapital ist schon in der Kategorie des Lohns enthalten und daher schon in der Verteilungstheorie impliziert, wenn sie die einzelnen Einkommenskategorien (Lohn, Gewinn, Rente) diskutiert, aiso schon bevor sie sich dem $\mathrm{V}$ e $\mathrm{rh}$ ä I t $\mathrm{n}$ i s von Löhnen und Gewinnen zuwendet. In den ökonomischen Verteilungstheorien kehren also die beiden Seiten bürgerlicher Kapitalismusanalyse wieder: einerseits wird die kapitalistische Produktion von Waren als einfache Produktion von Gütern aufgefaßt, die wesentlich den natürlichen Bedingungen des industriellen Arbeitsprozesses unterliegt und keine gesellschaftlichen Widersprüche einschließt ('moderne Industriegesellschaft'); andrerseits beruht

politischen Praxis das Wagnis abgenommen wird..." (Ähnliche Äußerungen finden sich übri. gens auch in der SOZIALENQUETE, a.a.O.) Wie gehabt: Behutsam überläßt der bürgerliche Wissenschafúler das Feld dem Politiker, wohl wissend, daß nun die Funktionsfähigkeit der 'Marktwirtschaft' sicherlich erhalten bleibt.

Daß das eigentliche Ziel der Vermögenspolitik die Befriedung der Lohnarbeiter ist, wird von zahllosen Vertretern "unserer demokratischen Ordnung" unverhüllt ausgesprochen, vgl. z.B. Georg Leber, nach dem sie die Aufgabe hat, "Freiheit und Eigentum als tragende Elemente unserer demokratischen Ordnung zu sichern..." (Leber, "Die Gretchenfrage ist gestellt", in: DIE ZEIT, 2,10.1964, abgedruckt in ders., VERMOGENSBILDUNG IN ARBEITNEHMERHAND, Dokumentation Bd. 2, Frankfurt/Main 1965, S. 63). Weitere Außerungen dieser Art bei E. Altvater: "Gewerkschaften und Vermögenspolitik", in: HEIDELBERGER BLATTER Nr. 12/13, April-Oktober 1968, S. $61 \mathrm{ff}$, und bei W. Müller: "Grenzen der Sozia'politik in der Marktwirtschaft", in: DER CDU-STAAT, hrsg. Nedelmann/Schäfer, Frankfurt $1969^{2}$.

86 Karl Marx: DAS KAPITAL, Bd. III, S. 940/890: "Die sogenannten Verteilungsverhältnisse entsprechen alsq, und entspringen aus historisch bestimmten, spezifisch gesellschaftlichen Formen des Produktionsprozesses und der Verhälınisse, welche die Menschen im Reproduktionsproze $\beta$ ihres menschlichen Lebens untereinander eingehn. Der historische Charakter die. ser Verteilungsverhältnisse ist der historische Charakter der Produktionsverhältnisse, wovon sie nur eine Seite ausdrücken. Die kapicalistische Verteilung ist verschieden von den Verteilungsformen, die aus andren Produktionsweisen entspringen, und jede Verteilungsform ver. schwindet nit der bestimmten Form der Produktion, der sie entstamme und entspricht." 
ihre Theorie wesentlich auf der Zirkulation der Waren und Geldeinkommen ('Güter- und Geldströ$\left.m e^{\prime}\right)$; dadurch erhält sie einen Eindruck von den Rückwirkungen der Widersprüche innerhalb der Produktionssphäre, wie sie sich in den Zirkulationsbewegungen manifestieren. Nur in dieser verkehrten Form ist sie fähig, richtige Voraussagen über die Schranken von Umverteilungsmaßnahmen auf der Ebene von Einkommen zu machen. Soll die bürgerliche Wissenschaft aber sachvor ständige Empfehlungen erteilen, so wird sie sich auf Behutsamkeit oder auf politische Dezisionismus zurückziehen müssen. Der Widerspruch in den ökonomischen Verteilungstheorien ist in der kapitalistischen Wirklichkeit selbst verankert.

Der Schlüssel zur Aufdèckung der Verteilungsverhältnisse auf der Ebene der 'Einkommen' liegt in der Analyse der historisch gesellschaftlichen Bestimmtheit der Verteilungsverhältnisse auf der Ebene der Produktion, also in der Analyse des Kapitalverhältnisses, (87) wo die Produktionsmittel als Kapital der 'freien', nämlich von Produktionsmitteln freien Lohnarbeit gegenübertreten. Wir müssen also der Frage nachgehen: Wie sieht der Zusammenhang beider Verteilungsverhältnisse aus? Inwiefern ist das eine bloß ein Moment des anderen? Hier kann diese Frage nur in Umrissen beantwortet werden; in ihrer ausführlichen Gestalt wäre sie Kern der Analyse des Kapitals und der von $\mathrm{ihm}$ produzierten Fetische sowie der ihnen entsprachenden Bewußtseinsformen in der ökonomischen Theorle.

\section{Netto- und Bruttosozialprodukt: Volkseinkommen und Kapitalerhaltung}

In der bürge rlichen The or ie stellt die Summe der verschiedenen Einkommensarten ('Einkommen aus unselbständiger Arbeit'; 'Einkommen aus Unternehmertätigkeit und Vermögen') das 'Volkseinkommen' dar. (88) Danach entspricht das Volkseinkommen der Gesamtheit der Ko. stern für die drei Produktionsfaktoren Arbeit, Boden und Kapital, die im Verlauf eines Jahres von den Unternehmen aufgewendet worden sind. Daher wird auch das Volkseinkommen dem Nettosozialprodukt zu Faktorkosten gleichgesetzt. Was für die Unternehmer Kosten sind, stellt sich demnach in gleicher Höhe für die 'Besitzer der Produktionsfaktoren' als Einkommensstrom dar. (89) Der geleisteten Arbeit entspringt der Arbeitsiohn, dem zur Verfügung gestellten Boden die Grundrente (Pacht und Z.T. Mieten) und dem Kapital der Profit. Gegenstand der funktionellen Vertei. lungstheorie ist demzufolge auch "die Verteilung des Volkseinkommens auf die volkswirtschaftli. chen Produktionsfaktoren Arbeit, Boden, Kapital, denen die Einkommensarten Lohn, Grundrente und Profit entsprechersd ihrem produktiven Beitrag und ihrer wirtschaftlichen Macht zufließen." (90) Monsieur le Capital und Madame la Terre (91) treten also in den bürgerlichen Theorien im. mer noch, ungeachtet aller Modernisierungsversuche, in schöner Eintracht mit 'der' Arbeit als die Schöpfer des 'Reichtums der Nation' auf. Was als Volkseinkommen in der Hand der Besitzer dieser 'Faktoren' gezählt wird, erscheint in den Unternehmen als jolkswirtschaftliche Wertschöpfung. Dem Volkseinkommen als der Summe aller Wertschöpfung entspricht das Nettosozialprodukt (zu Faktorkosten) als der Summe von Konsumtion und Nettoinvestitionen.

87 Vgl. im II. Band des KAPITAL insbes. S. $443 \mathrm{ff} / 437 \mathrm{ff}$.

88 Von der durch die spezifischen Formen staatlicher Verteilertätigkeit infolge der Erhebung indirekter Steuerrourad der Zahlung von Subventionen bedingten statistischen Unterscheidung von Nettosozialprodukt zu Marktpreisen und Volkseinkommen wird hier abgesehen, da dies für den Gang der Argumentation nicht von Bedeutung ist.

89 "Das Entgelt für die in Unternehmungen erbrachten Faktorleistungen stellt für die Empfänger ('Faktorhaushalte') Einkommen dar." A. Paulsen: VOLKSWIRTSCHAFTSLEHRE, Bd. III, Berlin 1965, S. 9.

90 Dr. Gablers WIRTSCHAFTSLEXIKON, Taschenbuchausgabe, Band 6, Frankfurt/Main 1969, Spalte 2955.

91 "Im Kapital - Profit oder noch besser Kapital - Zins, Boden - Grundrente, Arbeit - Arbeitslohn, in dieser ökonomischen Trinität als dem Zusammenhang der Bestandteile des Werts und des Reichtums überhaupt mit seinen Quellen ist die Mystifikation der kapitalistischen Produktionsweise, die Verdinglichung der gesellschaftlichen Verhältnisse, das unmittelbare Zusammenwachsen der stofflichen Produktionsverhältnisse mit ihrer geschichtlich-sozialen Bestimmtheit vollendet: die verzauberte, verkehrte und auf den Kopf gestelite Welt, wo Monsieur le Capital und Madame la Terre als soziale Charaktere, und zugleich unmittelbar als bloße Dinge ihren Spuk treiben." Karl Marx: DAS KAPITAL, Bd. III, S. 884/838. 
Bis hierher haben wir es nur mit den Definitionen der bürgerlichen Ökonomie zu tun. In ihnen werden die Einkommen, da sie allesamt 'Leistungen' der drei 'Produktionsfaktoren' entspringen, gleichgesetzt. Bei näherem Hinsenen entdecken wir allerdings in dieser Gleichsetzung einen Zirkelschluß. Dieser Zirkelschiıß resultient aus der doppelten Betrachtung der Einkommen, nämich einma! vôn ihrem 'Pezieher' her, und zum zweiten von ihrem 'Schöpfungsprozeß' her. Alle EinKornmen werde'n ja in den Produktionsstätten der Volkswirtschaft geschöpft. Sie sind demnach in erster In'stanz bloße Einkommen. Erst danach werden sie auf verschiedene 'Beziehergruppen' verteilt: Arbeiter - Lohn; Kapitalisten - Gewinn. Dies ist zunächst die offensichtliche Tatsache in der kapitalistischen Wirtsch-ft (von der Bodenrente wollen wir hier absehen). Was wird aber daraus gefolgert? Das Kapital ist produktiv, weil es ein Einkommen erhält und es erhält ein Einkommen, weil es produktiv ist. Alle weitere Begründung wird lediglich zur Vervollkommnung dieser Taurologie, sei es mit Hilfe der Grenzproduktivitätstheorie der Verteilung odier irgendeiner anderen theoretischen Variante. (92) Es bietet sich daher als Vorgehensweise die Betrachtung dieses Zirkels nach seinen beiden Seiten hin an; nach der Seite der 'Wertschöpfung' und nach der Seite des 'Bezugs von Einkommen'.

Wenden wir uns zunächst der Seite der Wertschöpfung zu, d.h. der Frage, in welchen Formen die Begründung der Annahme von der Produktivität des Kapitals liegt. Das Grundproblem besteht darin, daß die zu verteilenden Werte produziert werden müssen, bevor sie überhaupt irgendwelchen 'Faktoren' als Einkommen zugerechnet werden können; daher muß auch die Analyse der Verteilung beim Produktionsprozeß beginnen. Dieser Produktionsprozeß ist in seiner kapitalistischen Form von doppeltem Charakter, d.h. zugleich Arbeits- und Verweriungosprozeß. Die erzeugten Produkte sind für den kapitalistischen Leiter des Produktionsprozesses nur insoweit allerdings von Bedeutung, als sie als Gebrauchswerte auch Träger von Wert sind, d.h. auf dem Markt gegen Geld ausgetauscht werden können. Als zusätzliche Bestimmung muß nun aber noch hinzutreten, daß der Kapitalist das von ihm für den Produktionsprozeß vorgeschossene Kapital und einen Öberschuß darüber hinaus zurückerhält. Da dieser Uberschuß nicht aus dem Warenaustausch stammen kann - der Überschuß, den der Verkäufer erhält, ist ein Abzug beim Käufer; und da jeder sowohl als Käufer als auch als Verkäufer auftritt, saldieren sich Überschüsse und Abzüge zu null -, muß er im Produktionsprozeß selbst produziert worden sein. Die Frage ist nun, auf welche Weise. Die Antwort der bürgerlichen Ökonomie ist eindeutig: durch die produktiven Beiträge der Produktionsfaktoren Arbeit, Kapital und Boden. Sie stützt sich dabei auf die Tatsache, die bei oberflächlichster Betrachtung irgendeines Betriebes zutagetritt: daß Grund und Boden, Maschinen, Arbeiter zur Produktion von Waren kombiniert sind. Die natürlichen Notwendigkeiten des Arbeitsprozesses, daß Arbeit nur in Kombination mit Produktionsmitteln, bei historisch gegebenem technischem Entwicklungsstand, produzieren kann, werden in die Theorie umgemünzt, daß infolgedessen den beteiligten Faktoren 'Einkommen' zufließen muß. Dabei wird von der bürgerlichen Ökonomie nicht beachtet, daß durch diese Art der Faktorenkombination zwar Produkte entstehen, aber noch lange nicht ein kapitalistischer Produktionsprozeß, dessen Ergebnis in $W$ a $r$ e $n$, und - wenn der Verkauf der Waren gelingt - in $G$ e I d besteht. Zum zweiten fällt bei dieser Betrachtungsweise unter den Tisch, daß Maschinen und Rohstoffe sich nicht von selbst in neue Produkte verwan. deln - und dies ist ja der Sinn des Produktionsprozesses -, sondern als unnütze Dinge liegenbleiben, werden sie nicht von der lebendigen Arbeit in Bewegung gesetzt und verwandelt. Demgegenüber hat die Betriebswirtschaftslehre, die sich intensiv mit dem Produktionsprozeß selbst befaßt, immerhin einen wenn auch verschwommenen Begriff vom Doppeicharakter des Produktionsprozesses, wenn sie zwischen Betrieb und Unternehmung, zwischen Produktivität (im technischen Sinne) und Rentabilität (im Sinne der Verwertung des eingesetzten Kapitals) unterscheidet. Dies alles fällt aber aus der Produktionsfaktorentheorie heraus loder wird noch um einige Grade un. schärfer reflektiert, wenn nämlich bei der Untersuchung 'optimaler Faktorkombinationen' deren technisches Verhältnis wie auch deren Preisrelation auf der gleichen Ebene behandelt werden).

Betrachten wir zuerst den vom Kapitalisten vorgeschossenen Kapitalteil. Er wird verausgabt zum Kauf von Produktionsmitteln (Maschinen, Rohstoffe usw.) und zum Kauf der Ware Arbeitskraft auf dem Arbeitsmarkt. Wie alle Waren wird auch der Wert der Ware Arbeitskraft (im Durchschnitt, über einen Zyklus hinweg, jedenfalls) vom Arbeiter realisiert, also vom Kapitalisten bezahlt wer.

92 Vgl. zur Darstellung dieser Theorien Erich Preiser: "Distribution: (I) Theorie", a.a.o. 
den müssen. Der Arbeiter "realisiert ihren Tauschwert und veräußer t ihren G e bra u c hswert". (93) Dieser Gebrauchswert der Arbeitskraft, die Arbeit selbst, aber gehört nun nicht mehr dem Arbeiter, sondern dem Kapitalisten, der ihn gekauft hat; folglich gehört dem Kapitalisten auch das Ergebnis der Anwendung des Gebrauchswerts der Arbeitskraft des Arbeiters. Aufgrund der Tatsache, daß z.B. "ein halber Arbeitstag nötig, um ihn während 24 Stunden am Leben zu erhalten", ist die Bedingung erfüllt, die Mehrwertproduktion überhaupt erst möglich macht: "Der W e $r \mathrm{t}$ der Arbeitskraft und ihre $V$ e $r$ w e $r t u n g$ im Arbeitsprozeß sind also zwei verschiedne Größen. Diese W e r t d if f e re n z hatte der Kapitalist im Auge, als er die Arbeitskraft kaufte. Ihre nützliche Eigenschaft, Garn oder Stiefel zu machen, war nur eine conditio sine qua non, weil Arbeit in nützlicher Form verausgabt werden muß, um Wert zu bilden. Was aber entschied, warder spezifische Gebrauchswert dieser Ware, Quelle von Wert zu sein und von mehr Wert als sie selbst hat..." (94) Nun erfolgt zwar die Wertbildung bei der Kombination von Produktionsmitteln mit der Arbeit, aber die "verschiednen Faktoren des Arbeitsprozesses nehmen verschiednen Anteil an der Bildung des P r o d u k t e n w e r t s." (95) Während der Wert der Produktionsmittel im Arbeitsprozeß lediglich erhalten wird durch die bloße Ubertragung des Werts auf den Wert des gerade produzierten Produkts, "bildet jedes Moment ihrer (der Arbeitskraft - Verf.) Bewegung 2 us ätzlich en Wert, Neuwe rt." (96) Es ist alsonicht so, daß in der Arbeit zuerst der Wert der Produktionsmittel übertragen, und dann erst der Neuwert gebildet wird, sondern dies geschieht zugleich, vermöge des Doppelcharakters der Arbeit als konkreter, nützlicher und abstrakter, wertbildender. Denn soll die Arbeit ihre wertbildende Kraft wirklich entfalten können, dann muß sie zugleich konkret, als Verausgabung konkreter Qualifikationen des Arbeiters und unter konkreter Verwendung der Produktionsmittel verrichtet werden. So wird notwendig im Wertbildungsprozeß durch den dabei erfolgenden Gebrauch der Produktionsmittel deren Wert auf das Produkt übertragen. "Der Arbeiter k a n n n e u e Arbe it $n$ i ch t $z$ u se t$z$ e $n$, also nicht neuen Wert schaffen, o h ne alte Werte $z$ u e rh alte $n$, denn er muß die Arbeit immer in bestimmter nützlicher Form zusetzen, und er kann sie nicht in nützlicher Form zusetzen, ohne Produkte zu Produktionsmitteln eines neuen Produkts zu machen, und dadurch ihren Wert auf das neue Produkt zu übertragen. Es ist also eine $\mathrm{N}$ a t u r g a b e der sich betätigenden Arbeitskraft, der lebendigen Arbeit, Wert zu erhalte $n$, indem sie Wert $z u-$ se tz t ..." (97)

Der Kapitalist muß Kapital sowohl für den Ankauf der Arbeitskraft als auch der Produktionsmittel vorschießen. Der Teil des vorgeschossenen Kapitals, dessen Wert lediglich übertragen, nicht aber größenmäßig verändert wird, wird von Marx $k$ o $n$ s t a n t e s $K$ a p it a I (c) genannt; im Gegensatz zu dem für Arbeitskraft verauslagten Kapital, das seinen Wert im Produktionsprozeß sehr wohl verändert und $v$ a $r$ i a b le $s K$ a $p$ it a I $(v)$ genannt wird. Während der Kapitalist also $\mathrm{c}+\mathrm{v}$ für den Produktionsprozeß vorschießt, kommt am Ende Ware heraus, deren Gesamtwert größer als $c+v$ ist, nämlich $c+v+m$, wobei $m$ den im Verwertungsprozeß vom Arbeiter produzierten M e $\mathrm{h} \mathrm{rwert}$ vorstellt. Die im Produktionsprozeß geschaffenen Werte, und von dieser Problemstellung sind wir ausgegangen, sind Produkt der lebendigen Arbeit. Die 'produktive Funktion' des Kapitals besteht lediglich darin, Arbeitskraft und Produktionsmittel anzukaufen, um beide im Arbeitsprozeß zu kombinieren, damit Werte und vor allem Mehnwert, also ein Oberschuß über den Kapitalvorschuß, produziert werde.

Wenn in der Produktionsfaktorentheorie dem toten Kapital und der lebendigen Arbeit gleichermaBen produktive Kraft zugesprochen wird, so eben auch deshalb, weil in der Tat der von allen Produktionsmitteln entblößte Arbeiter darauf angewiesen ist, daß der Kapitalist seine Ware Arbeitskraft kauft und sie mit dem toten Kapital, den Produktionsmitteln kombiniert, will er überhaupt produktiv tätig werden. Auf Grund der antagonistischen Verteilungsverhältnisse - dem Kapitali-

93 Karl Marx: DAS KAPITAL, Bd. 1. S. 202/208.

94 Ebenda.

95 Karl Marx: DAS KAPITAL, Bd. 1, S. 207/214.

96 Karl Marx: DAS KAPITAL, Bd. I, S. 216/223.

97 Karl Marx: DAS KAPITAL, Bd. 1, S. 215/221. 
sten gehören die Produktionsmittel, dem Arbeiter seine Arbeitskraft - (98) entsteht der Schein, als sei die Arbeit eine produktive Kraft neben anderen: neben Boden und Kapital. Zwar kann der Kapitalist keine Waren produzieren ohne den Arbeiter, aber auch der Arbeiter ist zu produktiver Tätigkeit unfähig, stellt ihn der Kapitalist nicht an seine Produktionsmittel. Und es ist auch deutlich geworden, daß der in Produktionsmitteln angelegte Kapitalwert durchaus nicht wertbildend ist, sondern nur im Arbeitsprozeß als Wert auf das Produkt übertragen wird. "Eine Maschine, die nicht im Arbeitsprozeß dient, ist nutzlos. Außerdem verfäilt sie der zerstörenden Gewalt des natürlichen Stoffwechsels. Das Eisen verrostet, das Holz verfault. ... Die lebendige Arbeit muß diese Dinge ergreifen, sie von den Toten erwecken, sie aus nur möglichen in wirkliche und wirkende Gebrauchswerte verwandeln. Vom Feuer der Arbeit beleckt, als Leiber derselben angeeignet, zu ihren begriffs- und berufsmäßigen Funktionen im Prozeß begeistert, werden sie zwar auch verzehrt, aber zweckvoll, ais Bildungselemente neuer Gebrauchswerte, neuer Produkte..." (99) "Diese Naturkraft der Arbeit erscheint als $S$ elbsterhaltungskraft des $K$ a $p i t a \mid s$, dern sie einverleibt ist, ganz wie ih re gesell s $\mathrm{ch}$ a f $\mathrm{tl}$ ichen Produktivkräfte als se in e Eigenschaften, und wie die beständige Aneignung der Mehrarbeit durch den Kapitalisten als beständige $S$ e I b st verwe rtu ng des $\mathrm{K}$ a p it a Is. Alle Kräfte der Arbeit projektieren sich als Kräfte des Kapitals..." (100)

Indem das Geheimnis der Wert- und Mehrwertbildung aufgedeckt wird, wird zugleich auch gezeigt, warum sich dies notwendig verkehrt darstellt, nämlich als 'produktiver Beitrag des Faktors Kapi\&al' zum Wertschöpfungsprozeß. Die Bestandteile des jeweiligen Neuwerts - d.h. des Produktenwerts $(c+v+m)$ abzüglich des bloß übertragenen Wertteils $c$ - erscheinen demnach im bürgerlichen Bewußtsein als Beiträge der 'Faktoren' und werden in unbewußter Verhüllung als 'Volks'einkommen (101) bezeichnet. Daß die Wertschöpfung alleiniges Resultat der Arbeit ist, entgeht diesem Klassen. bewußtsein, das eben nicht allein aufgrund 'ökonomischer Interessen' sich konstitujert, sondern durch die besondere Form der Produktion selbst.

Nachdem wir also den oben bezeichneten Zirkelschluß von der 'Wertschöpfungsseite' her betrachtet haben, wollen wir ihn jetzt von der 'Einkornmenseite' her untersuchen. Wenn nämlich die Naturkraft der Arbeit im Produktionsprozeß als Selbsterhaltungskraft des Kapitals erscheint (und diesem zudem die Fähigkeit zur 'Einkommensschöpfung' zugesprochen wird), so wird zu analysieren sein, wie die Gratisgabe der lebendigen Arbeit auf der Ebene der Einkommen erscheint und wie die Erfahrung solcher Erscheinungen von der bürgerlichen Ökonomie verallgemeinert und 'wissenschaftlich' systematisiert wird.

Der Kapitalist zeichnet sich gegenüber dem Arbeiter dadurch aus, daß er über die Produktionsmittel verfügt, mit denen allein der Arbeiter unter den gegenwärtigen technologischen Bedingungen zu produzieren vermag. Sie sind innerhalb des Gesamtkapitals (102) also ein wichtiger Aktivposten,

98 "Allerdings kann gesagt werden, daß das Kapital... selbst schon eine Verteilung voraussetzt: die Expropriation der Arbeiter von den Arbeitsbedingungen, die Konzentration dieser Bedingungen in den Händen einer Minorität von Individuen..." Diese Verteilungsverhältnisse "bestimmen den ganzen Charakter und die ganze Bewegung der Produktion." Karl Marx: DAS KAPITAL, Bd. III, S. 935/886.

99 Karl Marx: DAS KAPITAL, Bd. I, S. 191/198.

100 Karl Marx: DAS KAPITAL, Bd. I, S. $637 \mathrm{f} / 633 \mathrm{f}$.

101 Um der Illusion vorzubeugen, $v+m$ sei der marxistische Audruck für die bürgerliche Kategorie 'Volkseinkommen', sei darauf hingewiesen, daß die bürgerliche Statistik und Theorie alles als Einkommen zählt, was irgendeiner natürlichen oder juristischen Person zufließt. In $v+m$ ist jedoch nur der neu geschaffene Jahreswert bezeichnet, der statistisch schon dadurch aufgebläht werden kann, daß die Lohn- und Gewinneinkommen gezählt werden und diesen die Beamteneinkommen hinzugefügt werden, obwohl der Anteil des Staates aus v+m stammt. Zu diesem Problemkreis, der so schwierige Komplexe wie das Verhältnis von produktiver und unproduktiver Arbeit enthält, wäre eine eigenständige Arbeit notwendig. An dieser Stelle sei daher Itdiglich darauf verwiesen, daß es nicht möglich ist, einfach für 'Volkseinkommen' $v+m$ zu setzen.

102 Das Gesamtkapital des Kapitalisten schließt auch den für den Ankauf der Arbeitskraft verausgabten Teil ein. Auch die Käufe von Rohstoffen, Hilfsstoffen usw. stellen Verausgabung von Geldkapital und seinen Formwechsel in Produk tivkapital dar. Der Unterschied zwischen dem länger als eine Produktionsperiode fungierenden Produktivkapital und dem anderen, nur 
dessen kontinuierliche Erhaltung und Ausdehnung für den Kapitalisten lebenswichtig ist. Für die Produktionsmittel gilt genau wie für die anderen Teile des konstanten Kapitals (Rohstoffe, Hilfs. stoffe usw.), daß ihr Wert im Arbeitsprozeß lediglich übertragen wird, daß sie zwar ganz in den Arbeitsprozeß eingehen (der Arbeiter arbeitet immer mit der ganzen Maschine), aber nur zum Teil in den Verwertungsprozeß eingehen, nämlich nur mit dem Teil, der anteilig im Arbeitsprozeß ver. schlissen wird durch den Gebrauch des Produktionsmittels. Dieser Teil wird nun aus Gründen der Kapitalerhaltung in Gestalt der Abschreibungen zuerst einmal in Abzug gebracht.

Vom Nettosozialprodukt bzw. dem größengleich gesetzten Volkseinkommen unterscheidet sich innerhalb der bürgerlichen Kategorienbildung - das Bruttosozialprodukt in diesem entscheidenden Punkt. Es schließt auch die Summe der Abschreibungen ein, die den Wert des Verschleißes der dauerhaften (länger ais eine Produktionsperiode, d.h. ein Jahr, gebrauchten) Produk tionsmittel während eines Jahres ausdrücken. Die Abschreibungen sind daher auch gleich der Summe aller $\mathrm{Er}$ satzinvestitionen in einem Jahr, die dazu dienen, das fixe Kapital, die kapitalistische Gestalt der dauerhaften Produktionsmittel, zu erhalten. Während also das Nettosozialprodukt nur den während eines Jahres neu geschaffenen Wert umschreibt, schließt das Bruttosozialprodukt auch die 'Kosten' ein, die im Verlauf des Jahres zur Erneuerung des im Produktionsprozeß verbrauchten Anlagekapitals entstehen. Anders ausgedrückt: Das Nettosozialprodukt, das schließlich als Volkseinkommen verteilt wird, enthält nicht die Aufwendungen zur Erneuerung des verbrauchten fixen Kapital teils. Im bürgerlichen Begriff der jährlichen Wertschöpfung als Resultat der 'Leistung der drei Faktoren' ist der Wert der abgenutzten und ersetzten Produktionsmittel nicht enthalten, obwohl doch auch dieser Wert produziert werden muß. Und jeder Kapitalist, der Produktionsmittel produziert, weiß erstens gar nicht, ob diese für den Kapitalersatz oder für die Kapitalakkumulation verwendet wer. den, und zweitens würde er die Produktion sehr bald einstellen, wenn dabei nicht auch Werte 'geschaffen' würden. Während als Schöpfer des Nettosozialprodukts und des Volkseinkommens die drei Produktionsfaktoren erscheinen, wird die Erzeugung des Ersatzes der verbrauchten Produktionsmittel aber ais quasi-naturbedingte Begleiterscheinung des Produktionsprozesses vorausgesetzt. Die Gratisgabe der Arbeit, 'Wert zu erhalten, indem sie Wert zusetzt', wird in der bürgerlichen Theorie reflektiert, indem diese Gratisgabe tatsächlich nicht im Volkseinkommen, im Nettosozialprodukt aufgeführt wird.

Seinen Ausdruck findet dies in den Definitionen des Kapitals, der Investitionen und des Einkom. mens innerhalb der bürgerlichen Ökonomie. Von A.C. Pigou, dessen Bedeutung als einer der Väter der Wohlfahrtsökonomie auch heute noch unbestritten ist, wird das Kapital einem See verglichen, "in den eine mannigfaltige Vielzahl von Dingen, die die Früchte von Ersparnis sind, kontinuierlich hineingeworfen werden. Wenn diese Dinge einmal in den See gelangt sind, überleben sie dort für verschiedene Perioden, ganz entsprechend ihrer jeweils verschiedenen Natur und dem jeweiligen Schicksal, das sie erleiden." (103) Aber alles, was in den See hineinfließt, verläßt ihn auch wieder. Um nun den 'Wasserspiegel' zu halten, müssen folglich die Zuflüsse zum Kapitalsee eine bestimmte Größe haben. Sie müssen mindestens so groß sein, wie die Abflüsse, wie der Verbrauch von Kapital. Was aber ist Kapitalverbrauch? Pigou rechnet dazu nur "die gewöhniliche Abnutzung, der Maschi. nen und Fabrikgebäude im Prozeß ihres Funktionierens unterliegen." (104) Die Notwendigkeit

kurzfristig vorzuschießenden Kapitalteil ist für den fungierenden Kapitalisten von großer praktischer Bedeutung und drängt daher zur begrifflichen Fixierung in den Kategorien des fixen und des zirkulierenden Kapitals. Diese Unterscheidung entspricht ungefähr der Unterscheidung von Anlage- und Umlaufvermögen in der Betriebswirtschaftslehre. Dagegen spielen die Kategorien des konstanten und variablen Kapitals keine solche praktische Rolle und tauchen folglich auch in der bürgerlichen Ókonomie nicht auf. Sie können es auch nicht, da sie den Klassencharakter der kapitalistischen Produktion aussprechen, nämlich die Produktion des Mehrwerts.

103 A.C. Pigou: THE ECONOMICS OF WELFARE, London 1932, repr. 1960, \$. 43 (Uberset zung d. Verf.).

104 A.C. Pigou, a.a.O.; vgl. S. 46: "Maintenance of capital intact in our sense is thus equivaleni to maintenance in an absolute sense save only that provision must not be made against destruction by 'act of God or the King's enemies." So etwas schrieb Pigou im Jahre 1932, als Kapitaldestruktion größten Ausmaßes im Verlauf der Weltwirtschaftskrise stattfand. Aber wahrscheinlich war die Wirtschaftskrise ein vom lieben Gott und dem Proletariat in unheiliger Allianz angezettelter 'Notstand'. 
der Erhaltung des Kapitals wird mit der Öberlegung begründet, daß im Falle der Nicht-Ersetzung des 'abfließenden' Kapitals nicht nur der Kapitalstrom salbst nach und nach versickern und der See austrocknen würde. "Vielmehr wird an diesem Ereignis die Menschheit kein Interesse mehr nehmen, da dem Abgang der letzten Kapitaleinheit ganz sicherlich der Abtritt des 'letzten Menschen' vornergegangen sein wird." (105) Daher, so schlußfolgent Pigou, muß erst einmal der Went zum Ersatz des 'abgeflossenen' Kapitals in Abzug gebracht werden, bevor die "national dividend" an die Produktionsfaktoren verteilt werden kann. Zur Verteilung steht also nur das Volkseinkommen, nicht ater das Bruttosozialprodukt. Oas Brutrosozialprodukt wird verwendet, aber nicht ver Teilt. So kann es kommen, daB im Jahre 1968 in der BRD zwar 404,91 Mrd. DM vert e ilt werden konnten, aber 530,80 Mrd. DM verwen d e $t$ worden sind.

'vor jeder Varteilung von 'Einkommen' aufgrund spezifischer 'Leistungen' der einzelnen Faktoren (106) findet die Reproduktion des verbrauchten, in Produktionsmitteln ausgelegten Kapitals statt. Das Kapital hat also das Recht, zumindest mit ungeschmälerter Substanz aus jeder Produktionsrunde hervorzugehen. (107) Nur das was darüber hinausgeht, kann daher als "Wohlfahrtssteigerung" bestimmt werden. "Das Sozialeirkommen (oder Sozialprodukt) ist definitionsgemäß der Nettoausstoß einer Wirtschaft. Aber 'netto' hat zwei unvermeidliche Implikationen. Die eine ist die, daßs das Kapital funktionsfähig bleibt. Die zweite ist die daB 'Kapital' klar von Endprodukten unterschieden werden kann $_{i}$ so daß die Konsumtion von Produkten im Verlauf eines Jahres in letzter Verwendung nicht mit Konsumtion innerhalb des Produktionsprozesses verwechselt werden kann. Definitionsgemäß ist dann das Sozialeinkommen ein Maß des Ausstoßes des gesamten Nettoausstoßes und nicht der letzten Verwendung oder irgendeiner anderen größeren oder kleineren Summe.... Wir müssen in Begriffen der gegenwärtigen Wohlfahrt auch solche Teile bewerten, die einen Nettozuwachs zum Kapital des Landes repräsentieren..." (108) Nur das Nettoergebnis der Jahresarbeit dient der Wohlfahrt. Da jedoch auch die verbrauchten Produktionsmittel produziert werden müssen, wird auf diese Weise eine Zweiteilung der Jahresarbeit einer konkreten Gesellschaft vorgeñommen. Der Teil der Arbeit, der dazu verwendè wird, das verbrauchte Kapital zu ersetzen, steiger die Wohlfahrt nicht. Der andere Teil der Jahresarbeit jeçoch, der Konsumtionsmittel und Nettoinvestitionsmittel herstellt, dient gerade diesem Zweck. Das Kapital kann nach dieser Kategorienbildung also verlangen, erst einmal seinen Anspruch auf Ewigkeit befriedigt zu bekommen, seinen Anspruch, ewig wie die Natur (aus der daher Pigou und Samuelson ihre Analogien beziehen) nicht nur zu gelten, sondern auch zu sein. Die Erhaltung der $A r$ b e i t jedoch figuriert bereite unter der Konsumtion in der Kategorie des 'Sozialeinkommens'.

So erweist sich die Unterscheidung zwischen Brutto- und Nettosozialprodukt nicht nur als eine statistisch-technische, sondern als die Form, in der die Gratisproduktivkraft der Arbeit, im ProzeB der Neuwertbildung den Wert der Produktionsmittel durch Übertragung auf das Produkt zu erhalten, als Natureigenschaf́t des Kapitals zurückgespiegelt wird. Gleichzeitig bedingt diese Unterscheidung, daß der Verteilung des Nettosozialprodukts zuerst einmal die Kapitalerhaltung vorausgesetzt wird. So wird in jedem Produktionsprozeß zunächst einmal die einfache Reproduktion sichergestelit, die daher auch logisch der erweiterten Reproduktion vorangeht (weshalb von Marx am Ende des 2. Bandes des "Kapital" auch die einfache und die erweiterte Reproduktion getrennt dargestellt

105 A.C. Pigou, a.a.O., S. 49

106 "Die Unternehmerleistung besteht in der faktischen Leistung des Unternehmens (!) und jedenfalls in einem Familienbetrieb (!) - in der Bereitstellung von Kapital, Grundstücken und Gebäuden..." Aus Walter und Leisticos Schatzkästlein, S. 44, vgl. oben Anm. 75.

107 Daß die gesellschaftliche und historische Bedingtheit dieser Prozesse absolut nicht in den mit bürgerlichen Vorstellungen gefüllten Kopf gehen kann und folglich als Naturnotwendigkeit ihm erscheinen muß, macht auch der groBe Paul A. Samuelson (VOLKSWIRTSCHAFTSLEHRE, Bd. I, Köln 1967, S. 242) deutlich: "Was würde man von einem Statistiker halten, der das Bevölkerungswachstum schätzt, ohne dabei die Todesfalle in Rechnung zu stellen? Sicherlich nicht allzu viel. Denn zählte er nur die Geburten zusammen, ohne die Sterbefälle abzuzichen, käme er zu übertriebenen Vorstellungen, was die Nettozunahme der Bevölkerung betrifft. Dasselbe gilt aber auch von Ausrüstungs- und Bauinvestitionen. Auch ihre Nettoveränderung ergibt sich aus Kapitalgeburt (!) und tod (!) (in diesem Falle Abschreibung)...".

108 Simon Kuznets: "On the Valuation of Social lncome - Reflections on Professor Hicks Article", Part I, in: ECONOMICA, N.S., Vol. XV, 1948, S. 13. Kuznets gilt als einer der führenden Einkommenstheoretiker in der bürgerlichen Okonomie. (Ubersetzung d. Verf.) 
werden). Erstes Resultat des Produktionsprozesses, wie es sich in dieser Unterscheidung herstellt, ist die Reproduktion des Kapitals; zweites Resultat ist das Nebeneinander von Lohn und Kapital. einkommen; das eine dient der Reproduktion der lebendigen Arbeitskraft - womit die Reproduktion der beiden Seiten des Kapitaiverhältnisses, des Kapitals und der Lohnarbeit vollendet ist -, das andere dient der ständigen Erweiterung der Kapitalproduktion, der Akkumulation. Dies alles erscheint nun aber als 'Selbstverständlichkeit', die nur noch technische Probleme der Abgrenzung zwischen 'brutto' und 'netto' aufwirft - womit denn auch die nationalökonomischen Lehrbücher vollgestopft werden. (109)

Die Gratisgabe der Arbeit, im Prozeß der Wertbildung auch den Wert des konstanten Kapitels zu erhalten, was auf der Ebene der Wertbildung als Selbsterhaltungskraft des Kapitals erscheint, drückt sich also auf der Ebene des Bezugs der Einkommen als aller Einkommensverteilung vorausgehender Ersatz des verbrauchten Kapitals aus.

Daß die Unterscheidung von Brutto- und Nettosozialprodukt nicht eine bloß technische, sondein von fundamentaler Bedeutung ist, wenn es um den Konjunkturzyklus geht, wird nur allerdings wieder in die bürgerliche Ökonomie hereingenommen. In der Keynes'schen Theritie spielt bekanntlich die Konsumneigung ("propensity to consume") eine entscheidende Folle für die kurzfristige Höhe von Einkommen und Beschäftigung. Je mehr die Konsüunenten aus ihrem Einkommen konsumieren, desto größer die effektive Nachfrage, desto besser die Auftragslage, desto größer auch die Beschäftigung und folglich das Gesamteinkomman - so lautet verkürzt die Argumentationskette. Wenn nun aber nur aus dem $N$ e t to sozialprodukt, dem 'Volks'einkommen konsumiert werden kann, dann gewinnt plötzlich die Größe der Ersatzinvestitionen zur Wiederherstellung der verbrauchtén dauerhaíten Produktionsmittel höchste Bedeutung. Denn nun hängt der tatsächliche Konsum bei gegebener Konsumneigung auch von der Größe der Abschreibungen ab. "...Es ist wichtig, die Größe des Abzugs zu betonen, der vom Einkommen einer Gesellschaft gemacht werden muß, die bereits einen großen Kapitalstock besitzt, bevor wir das Nettoeinkommen erhalten, das gewöhnlich für die Konsumtion verfügbar ist. Denn wenn wir dies übersehen, könnten wir den schweren Druck auf die Konsumneigung unterschätzen, der auch unter Bedingungen vorhanden ist, unter denen das Publikum einen sehr großen Teil seines Nettoeinkommens zu konsumieren bereit ist." (110) Und Keynes beklagt daher (ebenda, S. 100) die Erfahrungen der Weltwirtschaftskrise, in der sich die Tendenz jedes Einzelkapitalisten zum Aufschub von Erneuerungsinvestitionen als krisenverschärfendes Moment für das Gesamtkapital auswirken mußte. Nicht nur, daß der Investitionsmultiplikator mangels Masse geringer wurde, auch die Tatsache, daß die Abschreibungsbeträge vom fungierenden Kapital in Gestait von Geldkapital bis zur Erneuerung der Produktionsmittel zurückgehalten werden, wirkte als krisenverschärfendes Moment, "Sie verringern die laufen. de Effektivnachfrage und heben sie erst in dem Jahr an, in dem der Kapitalersatz tatsächlich vorgenommen wird. Wenn der diesbezügliche Effekt noch durch 'finanzielle Klugheit' verschlimmert wird, d.h. dadurch, daß es ratsam erscheint, die Anfangskosten schneller 'abzuschreiben' als die Ausrüstungen tatsächlich abgenutzt werden, dann wird das kumulierte Ergebnis wahrhaft sehr ernst sein." (111) So führt nach Keynes die "finanzielle Klugheit" der E i n z e I kapitalisten, indem sie höhe:e, vorsichtige Abschreibungsbeträge ansetzen, zur Krise der kapitalistischen Ökonomie insgesamt. Denn Abschreibungen ohne Ersatzinvestitionen verringern die Gesamtnachfrage, indem die Produktionskosten steigen (Abschreibungen sind schließlich Kosten, die der Kapitalist im Preis erstattet haben will), ohne daß neue Einkommen infolge der Investitionstätigkeit geschaffen würden. Je höher nun diese Abschreibungen, desto niedriger auch die für die Konsumtion 'zur Verfügung stehenden' Einkommen. So führt der Zwang zur Erhaltung jedes $E$ in z e | kapitals zur Verschärfung der Krise des $G$ e s a $m$ t kapitals.

Was der Verteilungstheoretiker nicht begreifen kann, wenn er sich auf die Nettogrößen bezieht, wird nun voll sichtbar. Seine Verteilungstheorie hängt in der Luft und wird durch das Abschreibungs- und Investitionsverhalten der Kapitalisten immer wieder auf den 'Boden der Tatsachen' gezogen. Die Verteilung wird tangiert, wenn die Kapitalverwertung es erfordert. Die Größe des 'zur

109 Vgl. dazu auch Erich Schneider: EINFUHRUNG IN DIE WIRTSCHAFTSTHEORIE, Tübirgen 1958, vor allem Band I: THEORIE DES WIRTSCHAFTSKREISLAUFS.

110 John Maynard Keynes: THE GENERAL THEORY OF EMPLOYMENT ${ }^{6}$ INTEREST AND MONEY, London (repr.) 1964, S. 104.

111 John Maynard Keynes, a.a.O., S. 100. 
Verfügung gestellten Kuchens' hängt davon ab, inwieweit die Voraussetzungen der Kapitalverwertung gewährleistet sind. Insofern übersehen alle Verteilungstheorien, die davon ausgehen, daß durch eine gleichmäßigere Verteilung der Einkommen die Konsumneigung steige (aus größeren Einkommen wird ja prozentual mehr gespart als aus kleineren Einkommen) und daher auch die effektive Nachfrage zunehme, gerade das Moment der Kapitalverwertung. Nicht die effektive Nachfrage ist entscheidend, sondern die Kapitalverwertung ausgedrückt in der Größe der Profitrate auf das vor geschossene Kapital. Und daher konstatiert Keynes zu Recht das Absinken der affektiven Nachfrage als Konsequenz der "finanziellen Klugheit" der Kapitalisten; sie müssen sich eben klug, d.h. als Charaktermasken des Kapitals verhalten, gleichgültig, was aus der effektiven Nachfrage und der Verteillung wird.

Dies geht auch aus den betriebswirtschaftichen, also den einzeikapitalistischen Abschreibungsregeln hervor, die vom 'ehrbaren Kaufmann' gerade die sich gesamtkapitalistisch so verheerend auswirkende "finanzielle Klugheit" verlangen. "Oberstes Prinzip bei der Bewertung in der Bilanz ist der Grundeatz kaufmännischer Vorsicht. Er soll verhindern, daß der Gewinn zu hoch ausgewiesen und durch Ausschüttung des Gewinns die betriebliche Substanz vermindert wird..." (112) Daher wird das Niederstwertprinzip aufgestellt, das besagt, daß von zwei möglichen Wertansätzen - dem Tageswert und dem Anschaffungswert - stets der niedrigere verwendet werden muß. Vor allem gilt es also, die betriebliche Substanz, das Kapıtal, zu erhalten. Solange keine tatsächlichen Verluste gemacht werden und ein Mindestkonsumtionsstandard der Kapitalistenklasse gehalten werden kann, sind vorsichtige, d.h. überhöhte Aurwendungen zur Kapitalerhaltung und als 'Residuum' ausgewiesene Gewinne zwar nicht in der Statistik, wohl aber für den Einzelkapitalisten verschiedene Summanden einer gleichbieibenden Sumne. Ob die Gewinne ausgewiesen oder gieich als Rücklagen oder Rück. stellungen verbucht werden, ist wirklich nur eine Frage der jeweiligen "finanziellen Klugheit". Ab. schreibungen richten sich auch nach der Preisentwicklung der Produktionsmittel. Steigen die Wiederbeschaffungskosten, so müssen die Abschreibungen höher, sinken sie, so können sie niedriger als die Anschaffungskosten sein, wenn eine tatsächliche Wiederbeschaffung mit Hilfe der durch Abschreibungen amortisierten Geldbeträge möglich sein soll (112). Und in der amtlichen Statistik wird diesem Prinzip Rechnung getragen, indem bei der Berechnung des Netrosozialprodukts die "zu Wiederbeschaffungspreisen bewerteten Abschreibungen" vom Bruttosozialprodukt abgezogen werden (113). So wird vom Einzelkapitalisten in seiner Kalkulation bereits die Unterscheidung zwischen Kapitalerhaltung und Wertschöpfung, zwischen Kapitalersatz und Verteilung vollzogen, oh. ne daß damit irgendeine Bosheit beabsichtigt wäre. Er verhält sich lediglich als Kapitalist, "finanziell klug". Und als Kapitalist kümmert inn die Verteilung der Einkommen a Is E rge b n is sei. nes Handelns nicht, wohl aber a is $V$ or a u s s e $\mathrm{z}$ u $\mathrm{ng}$ seiner Dispositionen zur Kapitalvenvertung.

Kapitalverwertung drückt sich nun aus in quantitativer Steigerung des vorgeschossenen Kapitals. Der Kapitalist will den Wert, den er in Geldform verauslagt hat, vergrößert zurückerhalten, und nur wenn dies der Fall isš, wird er den Produktionsprozeß aufrechterhalten. Die Höhe des Lohnes ist für den Kapitalisten entscheidend. Denn davon wird die Höhe des von ihm für den Ankauf der Arbeitskraft vorzuschießenden variablen Kapitalteils bestimmt. Die 'Produktionskosten' steigen mit steigenden Lohnkosten, und folglich sinkt bei sonst gleichbleibenden Umständen die Profitrate. Weil also die Verteilung der Einkommen für den E i $n z$ e I kapitalisten als Voraussetzung seiner Kapitalvervuertung höchst relevant ist, kann überhaupt erst der schon diskutierte Widerspruch von Umverteilung und Wirschaftswachstum auftauchen. In diesem Schluß, der sich in der bürgerlichen Ökonomie zum Zielkonflikt kristallisiert, ist allerdings als vermittelndes Glied die Annahme impliziert, daß der Profit dazu da sei, um akkumuliert zu werden. Denn wie könnte ein Wider. spruch zwischen Umverteilung der Einkommen und Wirtschaftswachstum formuliert warden, wenn nicht unter der Bedingung, daß das Wachstum gerade aus den Profiten getragen würde? Diese Annahme begründet sich aus dem kapitalistischen Produktionsverhältnis selbst. Das Kapital als ununterscheidbare Qualität kann sich nur in quantitativer Hinsicht verändern, durch Wachstum. Alle

112 Gïnter Wöhe: ALLGEMEINE BETRIEBSWIRTSCHAFTSLEHRE, Berlin und Frankfurt 1962, S. 389

112 Günter Wöhe, a.a.O., S. 403.

113 STATISTTISCHES JAHRESBUCH für die Bundesrepublik Deutschland 1969, Vorbemerkung zu den Statistiken der volkswirtschaf tlichen Gesamtrechnung, S. 485. 
Zwänge der Konkurrenz drängen dem Kapitalisten als Charaktermaske des Kapitals die Notwen. digkeit auf, diesem Imperativ gerecht zu werden: "Akkumuliere! Das ist Moses und die Propheten." Akkumulation aber geht über die bloße Kapitalerhaltung hinaus; sie wird aus dem Wertprodukt, das wir zur Vereinfachung dem Nettosozialprodukt bzw. Volkseinkommen gleichsetzen (vgl. Anm. 101), getätigt, also aus dem Nettosozialprodukt, das als 'Volkseinkommen' angeblich der Varteilung offensteht. Der in der bürgerlichen Ökonomie als Zielkonflikt zwischen Verteilung und Wachsıum formulierte Widerspruch ist also nichts anderes als unbegriffener Reflex der Widersprïche des Akkumulationsprozesses selbst. Für die sogenannte Verteilung ergibt sich allerdings daraus die Konsequenz, daß nicht nur der Zwang zur Kapitalerhal tung, der sich als jeder Verteilung schon immer vorausgegangener Abzug der Abschreibungen vom zu verteilenden Kuchen darstellt, sondern auch der Akkumulationszwang des Kapitals die Vorstellung von der Verteilung als einer Sphäre, in der ein Kuchen zu verteilen ist, geradezu lächerlich macht. Wenn also der Abzug der Abschreibun. gen überhaupt schon jeder Verteilung vorausgeht, wenn die Verteilung des Öbriggebliebenen, nämlich des Lohns und des Profits, nicht nach Gesetzen der verselbständigten Verteilungssphäre, sondern nach den Gesekzen der Akkumulation des Kapitals vollzogen wird - was bleibt dann von Vor. stellungen über eine mögliche Umverteilung überhaupt noch übrig?

Der sogenannte Sozialstaat hat demnach gar nicht "zur Verfügung", was er $z$ w is c h e n den Klassen urnverteilen könnte. Seine Möglichkeiten und Maßnahmen bewegen sich - dies ist bereits aus. geführt worden, bedürfte aber sehr konkreter Analysen - in der Sphäre der Umverteilung i $n$ n e r$\mathrm{h}$ a $\mathrm{l} \mathrm{b}$ der Klassen. Nur in den Fällen, wo die Reproduktion der Arbeitskraft wirklich nicht mehr gesichert ist, wenn das Maß des Lohns den Akkumulationsgesetzen allein überlassen bleibt, wird der Staat, aus Gründen der Erhaltung der Arbeitskraft als Basis kapitalistischer Ausbeutung, auch eine Umvertailung zwischen Lohnarbeit und Kapital erzwingen können. (Vgl. dazu Teil IV). Das Prinzip, daß die Gesetze der Verteilung die Gesetze der Akkumulation und Zirkulation des Kapitals sind, wird dadurch nicht berührt. Wir sind damit aus der Konsequenz der Sache an dem Punkt angelangt, wo die Untersuchung der verteilenden Macht des Sozialstaats in die Analyse der erweiter. ten Reproduktion des Kapitals mündet. Im vorliegenden Zusammenhang, der Kritik der Illusionen der Sozialstaats- und Verteilungstheorien, müssen wir an diesem Punkt abbrechen.

Der illusorische Charakter der revisionistischen Sozialstaatstheorien wird also erst durch die Zurückführung der Verteilungsverhältnisse in der Einkommensebene auf die Verteilung in der kapita listischen Produktion wirklich klar. Es wird damit auch klar, daß die revisionistische Staatstheorie direkt aus jenen verkehrten Formen abgeleitet ist, die der kapitalistische Produktionsprozeß selbst. im Bewußtsein der Kapitalagenten und der darauf beruhenden ökonomischen Wissenschaft erzeugt. Sowohl die bürgerlichen wie die revisionistischen Auffassungen sind nicht einfach Verhüllun. gen oder Ideologien im landläufigen Sinn, sondern notwendige Produkte der Erscheinungsformen des Kapitalverhältnisses. Dieses we se $\mathrm{n} t \mathrm{i}$ c h e Grundverhältnis, das die gesellschaftliche Pro. $d u k t i o n$ (in ihrer kapitalistischen Form) bestimmt, e r s ch e in t eben nicht als solches, sondern ganz verkehrt in der Sphäre der $Z$ irk u a c i o $n$, von der die Verteilung der Einkommen ein Moment ist. Hier ist der Ursprung der bürgerlichen Freiheitsillusionen, angefangen von der Freiheit des Individuums als 'Einkommenbezieher' und 'Konsument' bis hin zur Fähigkeit der 'neuen Wirtschaftspolitik' zur 'Globalsteuarung der Wirtschaft' oder zur 'Umverteilung durch Vermögenspolitik'.

Das Ziel der Veränderung der bestehenden (wie verbal zugegeben wird, immer noch kapitalistischen Gesellschaft ist auch heute noch für die revisionistischen Organisationsen eine 'humane' oder 'huma. nere Gesellschaft, und mit diesem Ziel wird die Beteiligung am bestehenden bürgerlichen Staat be. gründet. Wie sehr dieser Staat überhaupt erst auf der Grundlage kapitalistischei Produktion entsteht und neue Funktionen übernimmt, wie sehr andrerseits diese Grundlage die Eingriffe dieses Staates in 'die Wirtschaft' bis ins einzeine bestimmt und begrenzt, wird in der revisionistischen Theoria aus den aủsgeführten Gründen nicht begriffen. Die Beteiligung am bürgerlichen Staat, der mehr oder weniger starke Arischluß der historischen Organisationen der Arbeiterschaft bedeutế zunächst eine enorme Stärkung der Autorität dieses Staates (vgl. zuletzt die Illusionen vieler Linken über die SOP.FDP-Pegierung). Antererseits ist der $v 0 \|$ a Anschluß an die bürgerlichen Ullusionen zugleich der erste Schritt zur Zerstörung dieser Illusionen. Ein wichtiger Schritt bei dic ser Desibusionierung ist die theoretische Kritik dieser lllusionen, der Aufweis des inneren Zusammenhengs mit der Grundlage, aut der sie beruhen, mit der kapitalstischen form der Produktion. 
Diese Kritik kann dazu beitragen, die Beschränktheit jenes 'staatlichen Handelns', das auf der Grundlage jener notwendigen lllusionen einzig möglich ist und das die revisionistischen Hoffnun. gen und Versprechungen nicht erfüllen kann, nicht einfach bloß zu konstatieren, sondern zu begreifen und daraus praktische Folgerungen zu ziehen, die auf eine wirkliche, nicht scheinbare Veränderung hinzielen.

\section{Die Notwendigkeit von Staatseingriffen zur Erhaltung dep kapitalistischen Gesellschaft}

\section{Die Durchsetzung der Arbeitersehutzgesezgebung nach Marx}

Wir haben gesehen, daß die revisionistischen Theorien eines gemeinsam haben: sie begreifen den Staat in seinen verschiedenen Funktionen, insbesondere aber der Sozialpolitik, als "selbständiges Wesen", losgelöst vom Produktionsprozeß als kapitalistischem Verwertungsprozeß. Dagegen ist nach der marxistischen Auffassung die "Grundlage des bestehenden Sta a t s" "die bestehende Gesellschaft", (114) ist aus dieser und ihrem widersprüchlichem Grundverhältnis ihre "Zusammenfassung... in der Form des Staates" (115) zu entwickeln, und zwar jeweils in ihren konkreten historischen Erscheinungsformen. Nur in einem solchen Sinn könnte man von einer marxistischen Staatsiehre sprechen; im Sinne eines feststehenden Lehrgebäudes ist sie also nicht möglich. Es ist daher nicht zu fällig, daß Marx in sämtlichen Planskizzen seiner Untersuchung der kapitalistischen Gesellschaft insgesamt vom Grundverhältnis ausgeht, das die Sphäre der Produktion kennzeichnet, also vom Kapitalverhältnis, und daß erst für eine etwaige Fortsetzung der Analyse dieser Basis unter anderen auch ein Buch über den Staat vorgesehen war (das er allerdings für so wichtig hielt, daß er sich seine Ausführung im Unterschied zu anderen Büchern selbst vorbehielt). Jedoch überschreitet er schon im ersten Band des KAPITAL an verschiedenen Stellen die hier wie im zweiten Band beibehaltene Abstraktionsebene des 'Kapitals im allgemeinen' und entwickelt aus grundlegenden Widersprüchen des Arbeits- und Verwertungsprozesses bestimmte Formen, in denen der bürgerliche Staat tätig wird. Als eine solche Entwicklung einer bestimmten staatlichen Funktion soll Marx' Darstellung der Entstehung und Durchsetzung der Fabrikgesetzgebung im ersten Band des KAPITAL im folgenden resümiert und charakterisiert werden. Es soll also die Ableitung des "bestehenden Staats" aus der "bestehenden Gesellschaft" an einem konkreten Beispiel vorgeführt werden, um zu zeigen, was Marx unter "Zusammenfassung der bürgerlichen Gesellschaft" verstanden hat.

Es kann sich allerdings nicht darum handeln, die von Marx gegebene (teilweise sehr detaillierte) "historische Skizze" einfach als solche aus der Darstellung des KAPITAL herauszulösen und ohne Bezeichnung ihres systematischen Ortes zu referieren. Die bloße Übernahme der isolierten historischen Tatsachen und die brutale Desinteressiertheit für ihren Stellenwert (d.h. ihren Zusammenhang mit der Darstellung der Bewegung des 'Kapitais im allgemeinen') ist nämlich gerade charakteristisch für die revisionistische Marx-Rezeption - nicht zuletzt auch bei der Einschätzung der Fabrikgesetzgebung und des staatlich begrenzten Normalarbeitstags. Wenn Marx bei der Einführung des Zehnstundentags von einem "Sieg des Prinzips" sprach, so wurde dieser Satz in der Sozialdemokratie immer wieder so verstanden, daß damit eine schrittweise Durchsetzung sozialistischer Prinzipien innerhalb der kapitalistischen Gesellschaft eingeleitet worden sei. Nach Bernstein stellten die Fabrikgesetze ein Stück "gesellschafticher Kontrolle" und damit ein Stück Sozialismus dar (116), für Sering eine "Regulierung der Gesellschaft nach menschlichen Notwendigkeiten statt nach automatischen Marktgesetzen." (117) Zunächst muß also wenigstens angedeutet werden, an weicher Stelle der systematischen Entwicklung des Kapitalbegrififs Marx auf die gesetzliche Beschränkung des Arbeitstages zu sprechen kommt.

114 Marx, "Kritik des Gothaer Programms", MEW Bd. 19, S. 28.

115 GRUNDRISSE, a.a.O. S. 29.

116 Vgl. R. Luxemburg, "Sozialreform oder Revolution?" A.a.O. S. 72.

117 P. Sering, JENSEITS DES KAPITALISMUS, a.a.O. S. 50 f. Vgl. KAPITAL Bd. I, S. 309/312, sowie weiter unten in diesem Abschnitt. Vgl. auch F. Naphtali, WIRTSCHAFTSDEMOKRATIE, a.a.O. S. 19, wo von einer bedeutenden Einschränkung der kapitalistischen Willkür (!) die Rede ist. 
Marx beginnt die dialektische Darstellung des Kapitals von jener Grundkategorie aus, von der sich alle übrigen Kategorien (und damit alle Erscheinungen der kapitalistischen Gesellschaftsform) ableiten lassen, nämlich von der widersprüchlichen Form, die das Arbeitsprodukt beim Ausiausch erhält: der Ware. Er entwickelt, wie sich der in der Ware gesetzte Widerspruch von Gebrauchswert und Went; und damit der Doppelcharakter der warenproduzierenden Arbeit, in der Form des Geldes darstellt. Noch im 1. Abschnitt des 1. Bandes entwickelt er auch die verschiedenen Funktionen des Geldes. Erst im II. Abschnitt wird der Ubergang vom Geld zum Kapital volizogen; as wird herausgearbeitet, daß die Zirkulation des Geldes a is $K$ a $p$ i $t$ a l sich von der e in $f$ a $\mathrm{c}$ hen Zirkulation (Abschnitt // grundsätzlich unterscheidet. Während die einfache Zirkulation in der Konsumtion der Waren endet, im Gebrauchswert der Waren also ihr Ziel findet, liegt der Zweck der Kapitalzirkulation in ihr selbst; ihr Zweck liegt in der Vermehrung des Kapitals, der Selbstverwertung des Werts, der Auspressung von mehrWert aus der Arbeitskraft. Die Quelle des Mehrwerts kann nicht in der Zirkulation selbst liegen, wenn man den Austausch von ungleichen Werten ausschließt und sich jede Ware zu ihrem Wert ausgetauscht vorstellt. Sie kann nur in der Produktion selbst stattfinden. Dazu mu allerdings eine Voraussetzung erfüllt sein: der Geldbesitzer muß auf dem Markt die Ware Arbeitskraft und die übrigen Produktionsbedingungen kaufen können; vorausgesetzt ist also der von den Produktionsmitteln 'befreite', der freie Lohnarbeiter. (Dieses Verhältnis unterscheidet die kapitalistische von allen anderen Gesel Ischaftsformen; entweder sind die sachlichen Produktionsbedingungen in der Hand der Produzenten, oder diese Produzenten sind bloßes Zubehör zu diesen Produktionsbedingungen - 'an die Scholle gebundener Leibeigener' 2.B. - und zusammen mit diesen in der Hand einer Herrenklasse.) Der We $r \mathrm{t}$ der Ware Arbeitskraft ist gleich dem aller andren Waren, nämlich gleich der Summe der in seine Produktion eingehenden Arbeitszeit (was die Erhaltung der "Arbeiterrasse" (118) insgesamt, ihre Ausbildung und für die Kulturstufe eines Landes normale Existenz einschließt). Ihr $\mathrm{G}$ e b $\mathrm{r}$ a u c h s we $r \mathrm{t}$, ihre Anwendung im Produktionsprozeß selbst (dies der Gegenstand des ersten Bandes) gehört rechtmäßig dem Käufer, der als Werkzeug des Kapitals aus der Arbeitskraft möglichst viel Mehrwert herauszupressen versucht. Für den Kapitalisten ist der Sinn des Produktionsprozesses die Produktion von Mehrwert, nicht die Befriedigung von Bedürfnissen lobwohl die Ware nicht nur Wert, sondern auch Gebrauchswert im Hinblick auf bestimmte Bedürfnisse hat - ohne Gebrauchswert taugt sie nicht zum Träger von Wert). F ï $r$ i h $n$ ist der Gebrauchswert der Ware Arbeitskraft, mehr Wert zu schaffen als in sie bei ihrer Produktion an Wert eingegangen ist. Dazu stehen dem Kapitalisten zwei Möglichkeiten zur Verfügung. Er kann die Arbeitskraft möglichst lange über die Zeit hinaus in der Produktion anwenden, die zur Ersetzung ihres von ihm vorgeschossenen Wertes notwendig ist. Diese Verlängerung des Arbeitstages über das notwendige Maß hinaus schafft den a b s o l u te $\mathrm{n} \mathrm{Mehrwert;} \mathrm{er} \mathrm{wird} \mathrm{im} \mathrm{111.} \mathrm{Abschnitt} \mathrm{des} \mathrm{er-}$ sten Bands des KAPITAL behandelt. Die Produktion des $r$ elativen Mehrwerts andrerseits ist das Resultat der Verkürzung der notwendigen Arbeitszeit durch die Steigerung der Produktivkraft der Arbeit, d.h. durch die Revolutionierung der technischen Prozesse der Arbeit und ihrer Organisation im Betrieb, außerdem auch das Resultat einer Steigerung der Intensität der Arbeiž $z$. B. Erhöhung der Bandgeschwindigkeir; MTMSystem). Die relative Mehnwertproduktion wird im IV. Abschnitt des ersten Bandes des KAPITAL behandelt. Absolute und relative Mehrwertproduk. tion bilden natülich im Verwertungsprozeß immer schon eine Einheit; sie werden getrennt behandeft, um ihre Besonderheit rein herausarbeiten zu können. Die Reihenfolge der Behandlung ist aber nicht willkürlich; bis zur gesetzlichen Beschränkung des Arbeitstages ist die absolute Mehrwertproduktion die Hauptform. Sie wird vom Kapital derart extrem betrieben, daß das Eingreifen des Staates unvermeidlich wird, worauf sich dann das Kapital mit umso größerem Heißhunger auf die relative Mehrwertproduktion wirft, die nun zu seiner eigentlichen, aber nicht einzigen Form wird. (Immer wieder und vor allem in den Phasen der Hochkonjunktur sucht das Kapital den Arbeitstag nach seinem Bedürfnis zu verlängern.)

Die maximale Verlängerung des Arbeitstages ist natülicher Trieb des Kapitals und daher auch des Kapitalisten als des personifizierten Kapitals; sie ist sein natürliches Recht, da er ja die Arbeitskraft für den Gebrauch während eines Tages nach den Gesetzen des Äquivalententauschs zu ihrem Wert gekauft hat und daher über ihren Gebrauchswert wie über den jeder andren Ware verfügen darf. Die Verkürzung des Arbeitstags, z.B. durch Ausruhen, ist Diebstahl am Eigentum des Kapitalisten. Der

118 Dieser von Marx häufig gebrauchte Begriff meint im Unterschied zu Arbeiterklasse die Gesamtheit der Arbeiter als einzelner Verkäufer der Ware Arbeitskraft. 
Arbeiter als Verkäufer seiner Ware, der Arbeitskraft, erkennt das Gesetz des Warenaustauschs an, jedoch hat es für ihn einen andren Inhalt: die übermäßige Verlängerung des Arbeitstages über ihr normales Maß hinaus verhindert die normale Regeneration seiner Arbeitskraft, hat also die vor. $z$ e i t i ge Abnutzung des einzigen Vermögens des Arbeiters zur Folge. Für den Arbeiter ist daher die über den Normalarbeitstag hinaus verlängerte Arbeitszeit Diebstahl. Das Recht des Verkäufers steht gegen das Recht des Käufers. "... von ganz elastischen Schranken abgesehn, ergibt sich aus der Natur des Warenaustausches selbst keine Grenze des Arbeitstags, also keine Grenze der Mehrarbeit. Der Kapitalisê behauptet sein Recht als Käufer, wenn er den Arbeitstag so lang als möglich und womöglich aus e i n e m Arbeitstag zwei zu machen sucht. Andrerseits schließt die spezifische Natur der verkauften Ware eine Schranke ihres Konsums durch den Käufer ein, und der Arbeiter behauptet sein Recht als Verkäufer, wenn er den Arbeitstag auf eine bestimmte Normalgröße beschränken will. Es findet hier also eine $A \mathrm{n} t$ i $n$ o $\mathrm{m}$ i e statt, Recht wider Recht, beide gleichmäßig durch das Gesetz des Warenaustausches besiegeit. Zwischen gleichen Rechten entscheidet die $\mathrm{G}$ e w al t. Und so stellt sich in der Geschichte der kapitalistischen Produktion die Normie rung des Arbeitstags als Kampfum die Schrankendes Arbeitstags dar - ein Kampf zwischen dem Gesamtkapitalisten, d.h. der $K$ las se der $K$ a pitalis te $n$, und dem Gesamtarbeiter, oder der A r be iterklas se." (119)

Der Kampf zwischen den beiden Klassen ist in der Natur des Verhältnisses selbst angelegt, das diese Klassen konstituiert (einerseits die Eigentümer des bloßen Arbeitsvermögens, andrerseits die Eigentümer der gegenständlichen Produktionsbedingungen). In diesem Verhältnis gibt es keine "rationale Lösung", sondern nur vorläufige Entscheidungen nach gewaltsamer Auseinandersetzung. Dieser Widerspruch erzwingt den Klassenkampf (unabhängig von den politischen Formen, in denen er et* wa ausgetragen oder in denen seine Formierung versucht wird; Marx charakterisiert an keiner Stel. le diesen Klassenkampf als bloß "ökonomisch"; vgl. dazu den letzten Abschnitt dieses Aufsatzes). Das Verhältnis zwischen Lohnarbeit und Kapital enweist sich also als ein Verhältnis innerhalb der warenaustauschenden Gesellschaft, das der normalen Form der Regulierung in dieser Gesellschaft nicht unterliegt, nämlich der den Austausch der Waren, des Privateigentums regelnden allgemeinen Gesetze. Die Arbeiterklasse, gerade indem sie auf dem Gesetz des Warenaustauschs besteht, fälit aus dem durch Gesetze regulierbaren gesellschaftlichen Zusammenhang heraus.

Wie diese Antinomie sich historisch gel tend macht, wird von Marx dann ausführlich an der Geschichte des Kapitals in England belegt. $Z$ w e i B e we gu nge $n$ sind dabei zu unterscheiden. (120) Der maßlose Trieb des Kapitals zur Verlängerung des Arbeitstags setzt sich gegen vielfache hergebrachte Schranken und vor allem gegen den Widerstand der Arbeiter selbst durch. Eine wesentliche Unterstützung sind dem Kapital dabei von ihm durchgesetzte $Z w$ ang sge set $z$ e d e s $S t$ a $a$ tes zur Verlängerung des Arbeits tages, wie sie die Epoche seiner Entstehung und Durchsetzung seit dem späten Mittelalter begleiten (ursprüngliche Akkumulation); hier wird der Staat von der Kapitalistenklasse unmittelbar als Instrument gebraucht. "Aber in seinem maßlos blinden Trieb, seinem Werwolfs-Heißhunger nach Mehrarbeit, überrennt das Kapital $n$ ich t $n u r$ die moralischen, sondernauch dierein physischen Maximalschranken des Arbeitstags." (121) Die kapitalistische Produktion produziert also "die vor. zeitige Erschöpfungund Abtötung der Arbeitskraftselbst" (122), und damit beseitigt sie auch tendenziell die Quelle der Verwertung. Sie gerät also zu sich selbst in Widerspruch. Das Kapital und der Kapitalist verhalten sich nach dem Prinzip 'Nach mir die Sintflut'. Aber andrerseits ruft diese. Bewegung der Selbstzerstörung eine Gegenbewegung zur Erhaltung der Bedingungen weiterer Kapitalverwertung hervor, und zwar wesentlich durch den Widerstand der in ihrer Existenz als besondre Sorte von Warenbesitzern bedrohten Arbeiter. Uber komplizierte Vermittlungen allmählich und immer wieder von Rückschlägen bedroht, setzt sich eine "bewußte und planmäßige Rückwirkung der Gesellschaft auf die naturwüchsige Gestalt ihres Produktionsprozesses" (123) durch. Als n e gat i ver Ausdruck des Heißhungers nach Mehrarbeit werden die Fabrikge.

119 KAPITAL Bd.1, S. 243/249.

120 KAPITAL Bd. 1, S. 282 ff/286ff.

121 KAPITAL Bd. 1, S. 276/280.

122 KAPTTAL Bd. 1, S. $277 / 281$.

123 KAPYTAL Bd. 1, S. 505/504. Selbstverständlich ist hier nicht di e Gesellschaft an sich, sondern die kapicalistische gemeint. Vgl, das folgende Zitat. 
setze eingeführt; sie "zügeln den Drang des Kapităls nach maßloser Aussaugung der Arbeitskraft durch gewaltsame Beschränkung des Arbeitstags von Stats wegen, und zwar von seiten eines Staats, den Kapitalist und Landlord beherrschen." (124)

Marx vergleicht diese Gegenbewegung mit der Notwendigkeit, die die englischen kapitalistischen Pächter zwang, die durch blinden Raubbau erschöpfte natürliche Produktivkraft des Bodens durch künstliche Düngung zu erneuern. Die Fabrikgesetzgebung ist nach ihm "ebensosehr ein notwendiges Produkt der großen Industrie, als Baumwollgarn, Selfactors und der elektrische Telegraph." (125) Aber diese Notwendigkeit setzt sich deshalb keineswegs automatisch durch, sondern die Fabrikgesetze sind das $R$ esultat eines langwierigen, mehroder weniger offenen Klassenk ampfes zwischen Kapitalistenklasseund Arbei$\mathrm{t}$ e $\mathrm{r} \mathrm{klas} \mathrm{s}$, vermittelt durch eine Vielzahl von politischen Auseinandersetzungen auch unter einzelnen Fraktionen der herrschenden Klassen selbst und unter Beteiligung relativ entfernter Gruppen. Erst die gewissermaßen politologische Darstellung (126), wie sich diese vom Interesse der Erhaltung der Kapitalverwertung selbst diktierte Notwendigkeit im einzelnen mehr oder weniger unbewußt auf der Ebene der Interessenkämpfe schließlich, und niemals wirklich endgültig durchsetzt, kann diese zunächst bloß abstrakt entwickelte Notwendigkeit konkret belegen. Andrerseits ist die dazu notwendige empirische Analyse erst dann marxistisch zu nennen, wenn sie sich bewußt und methodisch klar auf die widersprüchliche Bewegung des Kapitals selbst bezieht; andernfalls wäre sie eine politologische, soziologische usw. Untersuchung, wie sie gang und gäbe sind. (127) Im folgenden ist daher die auf diesem Hintergrund von Marx entworfene "historische Skizze" nachzuzeichnen. (Dem Leser wird die Lektüre im KAPITAL selbst empfohlen.) Sodann ist der Prozeß dieser Durchsetzung einer staatlichen Funktion aus dem Kapitalprozeß zusammenfassend zu charakterisieren.

Seit der Entstehung der großen Industrie war der Arbeitstag mit größter Gewaltsamkeit immer weiter verlängert worden, nachdem er in den Jahrhunderten bis zur Mitte des 18. Jahrhunderts bereits auf 12 Stunden und mehr ausgedehnt worden war. "Das Kapital feierte seine Orgien. - Sobald die vom Produktionslärm übertölpelte Arbeiterklasse wieder einigermaßen zur Besinnung kam, begann ihr Widerstand, zunächst im Geburtsland der großen Industrie, in England. Während drei Dezennien jedoch blieben die von ihr ertrotzten Konzessionen rein nominell. Das Parlament erließ fünf Arbeits-Akte von 1802 bis 1833, war aber so schlau, keinen Pfennig für ihre zwangsmäßige Ausfüh-

124 KAPITAL Bd. 1, S. 247/253.

125 KAPITAL Bd. 1, S. 505 f/504 f. Vgl. S. 247/253, 295 f/299. Ist der Vergleich der Arbeiter mit dem Boden nicht eigentlich falsch, da Erschöpfung seines Bodens jedenfalls den langfristiger kalkulierenden kapitalistischen Pächter zur Einsicht zwingt (wie die Zugrunderichtung seiner Sklaven den Sklavenhalter, sofern nicht billiger Nachschub auf dem Sklavenmarkt dies erlaubte oder gebot)? Der Boden kann nicht selbst als handelndes Subjekt auftreten, auch gibt es keinen Bodennachschub wie bei der Arbeiterbevölkerung. Steht Marx hier nicht in Widerspruch zu seiner sonstigen Darstellung, in der er zeigt, wie diese Notwendigkeit sich eben gerade durch Klassenk ämpfe vermittelt durchsetzt?

126 Marx selbst bezeichnet seine Darstellung als "historische Skizze" (KAPITAL Bd. 1, S. 312 ) 315 ).

127 Vgl. Abschnitt III.4, sowie E. Altvater über die Probleme einer marxistischen Konjunkturanalyse, in: SOZIALISTISCHE POLITIK 5/70. Die politologische Lehre vom Pluralismus ist in Deutschland nicht zufällig von einigen jener revisionistischen Theoretiker begründet urid formuliert worden, die solche Interessenkämpfe innerhalb von Gewerkschaft und Partei miterlebt und mitvollzogen hatten. Von ihnen wurde zuerst die mehr oder weniger verselbständigte Untersuchung solcher 'Konflikte' zu einer Disziplin erhoben und theoretisch begründet . Sie zogen damit die ideologische Konsequenz aus dem praktischen Selbstverständnis ihrer "Interessenverbände" spätestens seit dem ersten Weltkrieg, freilich oft noch in marxistischer Terminologie. Sehr deutlich sagt Ernst Fraenkel: "Der Pluralismus ist die Staatstheorie des Reformismus." (Fraenkel, "Strukturanalyse der modernen Demokratie", in: AUS POLITIK UND ZEITGESCHICHTE, a.a.O. S. 23) Fraenkel hat te bereits 1928 die wesentlichen Elemente der pluralistischen Auffassung unter dem Titel "Kollek tive Demokratie" dargestellt (abgedruckt in: ARBEITSRECHT UND POLITIK, Quellentexte 1918-1933, hg. Th. Ramm, Neuwied u. Berlin 1966, S. 79-95). Vgl. auch etwa F.L. Neumann: BEHEMOTH. The Structure and Practice of National Socialism 1933-1944, Oxford 1944룰 ${ }^{2}$, S. $8 \mathrm{ff}, 13 \mathrm{ff}, 403 \mathrm{ff}$; sowie auch den bereits erwähnten Otto Kirchheimer, und insgesamt oben Teil I und II. 
rung, das nötige Beamtenpersonal usw. zu votieren. Sie blieben ein toter Buchstabe." (128) Erst das $F$ a b r i kgese tz v o n 1833 setzt einen Normalarbeitstag von 12 Stunden fest, freilich nur für Jugendliche. Für Kinder vơn 9 bis 13 Jahren wurde er auf 8 Stunden beschränkt; gegen die tatsächliche Durchsetzung dieser Bestimmung "eröffnete das Kapital ... eine mehrjährige und geräuschvolle Agitation" (129), mit dem Ziel, die Grenze zwischen Jugendlichen und Kindern zu seinen Gunsten zu verschieben. Jedoch unter dem drohenden außerparlamentarischen Druck verwe:gerte das Unterhaus eine Abänderung des Gesetzes. Das Kapital fand zahlreiche andere Möglichkeiten zu seiner Umgehung; "... die offiziellen Berichte der Fabrikinspektoren strotzten von Kla. gen über die Unmöglichkeit seiner Ausführung." (130) "Unterdes hatten sich aber die Umstände sehr geändert. Die Fabrikarbeiter, namentlich seit 1838, hatten die $Z$ ehnstunde n b ill zu ihrem ökonomischen, wie die $\mathrm{C}$ h a rte $r$ zu ihrem politischen Wahlaufruf gemacht. Ein Teil der Fabrikanten selbst, der den Fabrikbetrieb dem Akt von 1833 gemäß geregelt hatte, überwarf das Parlament mit Denkschriften über die unsittliche "Konkurrenz" der "falschen Brüder" (131), denen größere Frechheit oder glücklichere Lokalumstände den Gesetzesbruch erlaubten. Zudem, wie sehr immerhin der einzelne Fabrikant der alten Raubgier den Zügel frei schießen lassen mochte, die Wortführer und politischen Leiter der Fabrikantenklasse geboten eine veränderte Haltung und veränderte Sprache gegenüber den Arbeitern. Sie hatten den Feldzug zur A b s c h a f fung d ar Kornges e $\mathrm{z}$ e eröffnet und bedurften der Hilfe der Arbeiter zum Siege! Sie versprachen daher nicht nur Verdopplung des Laibes Brot" (d.h. Verbilligung des Brots durch Abschaffung der Getreideeinfuhrzölle, die den Großgrundbesitz schützten), "sondern Annahme der Zehnstundenbill unter dem tausendjährigen Reich des Free Trade. Sie durften also um so weniger eine Maßregel bekämpfen, die nur den Akt von 1833 zur Wahrheit machen sollte. In ihrem heiligsten Interesse, der Gru n d r e $n$ t e, bedroht, donnerten endlich die Torries entrüstet philanthropisch über die "infamen Praktiken" ihrer Feinde." (132)

Aufgrund von Klassenkämpfen, die in ihrer Wirkung durch die Kämpfe der Fraktionen der herr. schenden Klassen untereinander verstärkt wurden, kam 1844 der Zus at z z u m F abrik$g$ e $s$ e $t z$ zustande, durch den Frauen in der gleichen Weise wie bisher Jugendliche geschützt wur. den. "Zum ersten Mal sah sich die Gesetzgebung also gezwungen, auch die Arbeit Volljähriger direkt und offiziell zu kontrollieren." (133) Zur Verhinderung zukünftiger Umgehung traf das Gesetz zahlreiche Detailbestimmungen, die Marx teilweise genau referiert; darauf faßt er zusammen: "Man hat gesehn: diese minutiösen Bestimmungen, welche die Periode, Grenzen, Pausen der Arbeit so militärisch uniform nach dem Glockenschlag regeln, waren keineswegs Produkte parlamentarischer Hirnweberei. Sie entwickelten sich allmählich aus den Verhältnissen heraus, als $\mathrm{N}$ a $\mathrm{t} \mathrm{u} \mathrm{rg}$ es e $\mathrm{t}$ z e der modernen Produktionsweisè. Ihre Formulierung, offizielle Anerkennung und staatliche Proklamation waren Ergebnis langwieriger Klassenkämpfe." (134)

Die Jahre $1846 / 1847$ bringen einerseits die Einführung des Freihandels, zum anderen ein $\mathrm{n}$ e u e s F a b r i kgeset $z$, das wesentlich ein Ausdruck des Höhepunkts der Chartistenbewe. gung und der Zehnstundenagitation war, im Parlament auch die Unterstützung der über den Sieg der Freihändler erbosten Konservativen fand. Das Kapital versucht die tatsächliche Einführung des Zehnstundentags für Jugendliche und Arbeiterinnen durch einen Klassenfeldzug zu verhindern. Nach den Lohnausfällen als Folge der Krise von 1846/47 wurde zur Einleitung und Begleitung der allmählichen Arbeitszeitverkürzung der Lohn um insgesamt etwa $25 \%$ gekürzt. "Unter so günstig vorbereiteten Chancen begann man die Agitation unter den Arbeitern für Widerruf des Akts von 1847. Kein Mittel des Betrugs, der Verführung und der Drohung wurde dabei verschmäht, aber alles umsonst." (135) Dieser erste Feldzug mißglückte also, und am 1. Mai 1848 trat der Zehnstundentag in Kraft (nicht für männliche Arbeiter). "Unterdes hatte jedoch das Fiasko der Chartisten. partei, deren Führer eingekerkert und deren Organisation zersprengt, bereits das Selbstvertrauen der englischen Arbeiterklasse erschüttert. Bald darauf vereinigte die Pariser Juni-Insurrektion und ihre blutige Erstickung, wie im kontinentalen Europa so in England, alte Fraktionen der herrschenden Klassen, Grundeigentümer und Kapitalisten, Börsenwölfe und Krämer, Protektionisten und Freihändler, Regierung und Opposition, Pfaffen und Freigeister, junge Huren und alte Nonnen, un-

128 KAPITAL Bd. 1, S. 291/294.

129 KAPITAL Bd. 1, S. 293/296.

130 KAPITAL Bd. 1, S. 293/297.

131 Vgl. auch die unten zitierten Stellen.
132 KAPITAL Bd. 1, S. 294/297 f.

133 KAPITAL Bd. 1, S. 295/298.

134 KAPITAL Bd. 1, S. 295 f/299.

135 KAPITAL Bd. 1, S. 297/300 f. 
ter dem gemeinschaftlichen Ruf zur Rettung des Eigentums, der Religion, der Familie der Gesellschaft! Die Arbeiterklasse wurde überall verfemt, in den Bann getan, unter das ' $I 0 i^{\prime} d$ a s $s$. s p e c t s' "(Notstandsgesetz)" gestellt. Die Herren Fabrikanten brauchten sich also nicht zu genieren. Sie brachen in of $f \mathrm{n}$ e $\mathrm{F}$ evolt e aus nicht nur wider das Zehnstundengesetz, sondern

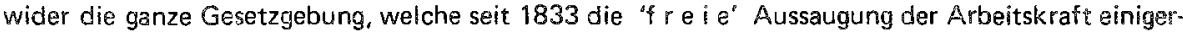
maßen zu zügeln suchte." (136) Marx schildert ausführlich (137), wie das Kapital im offenen Klassenkampf terroristisch und zynisch alle Mittel gegen die früheren Kompromisse mit der Arbeiterklasse anwendet, etwa die Entlassung großer Teile der unter das Gesetz fallenden Arbeiter, die Kürzung der gesetzlichen Essenspausen, die Aufsplitterung der täglichen Arbeitszeit der Kinder, aus* drücklich angekündigte Nichtbeachtung bestimmter Gesetzesklauseln. Unterstützung fanden die Fabrikanten bei den vielfach von ihnen selbst besetzten Gerichten. Dazu wies der Innenminister die Fabrikinspektoren an, bei Gesetzesübertretungen in bestimmten Fällen nicht einzuschreiten. Schließlich kam noch das Urteil eines Gerichts der höchsten Instanz, nach dem die Gesetzbrüche der Fabrikanten zwar gegen den Sinn des Fabrikgesetzes von 1844 verstießen, dieses Gesetz jedoch gewisse Worte enthalte, die es selbst sinnlos machten.

"Mit diesem scheinbar definitiven Sieg des Kapitals trat aber sofort ein Umschlag ein. Die Arbeiter hatten bisher passiven, obgleich unbeugsamen und täglich erneuten Widerstand geleistet. Sie protestierten in laut drohenden Meetings in Lancashire und Yorkshire... Die Fabrikinspektoren warnten dringend die Regierung, der Klassenantagonismus sei zu einer unglaublichen Höhe gespannt." (138) (Staatliche Uberwachungsbeamte erfüllen also hier direkt am Ort des Klassenkampfes die Funktion, die heute vielfach Funktionäre von Gewerkschaften ausführen - oder ausführen sollen). Selbst eim Teil der Fabrikanten beschwerte sich über die willkürliche Anwendung der Fabrikgesetzgebung, die die Gleichheit der Konkurrenzbedingungen authebe. "Unter 'diesen Umständen kam es zu einem KompromiB zwischen Fabrikanten und Arbeitern, der indem neuen $z$ u. sätzlichen Fabrikakt vom 5. August 1850 parlamentarisch besiegelt ist." (139) Dieses Gesetz hatte zum Inhalt einerseits eine gewisse Verlängerung des Zehnstundentags, andrerseits beseitigte es die besonders verbreitete Umgehung des Gesetzes durch das Relaissystem. (140)

Mit der Durchsetzung in den großen Industriezweigen hatte nach Marx "das Prinzip gesiegt" (141), nämlich die Gegenbewegung gegen die Zerstörung der "Arbeiterrasse" (und damit der Quel. le des Mehrwerts, der Kapitalverwertung) durch die maßlose und zerstörerische Verlängerung des Arbeitstags. Das Ergebnis war im Aufschwung von 1853-1860 und in der "physischen und moralischen Wiedergeburt der Fabrikarbeiter" (142) offensichtlich, und zwar auch den Fabrikanten

136 KAPITAL Bd. 1, S. 298/302.

137 Vgl. KAPITAL Bd. 1, S. 298/302 bis $305 / 308$.

138 KAPITAL Bd. 1, S. 305/309.

139 KAPITAL Bd. 1, S. 306/309.

140 Das Gesetz galt nur für Frauen und Jugendliche, und nur im Bereich der kapitalistisch voli entwickelten "großen Industrie". Das Relaissystem: die Verteilung des gesetzlichen Arbeitstags von z.B. 10 Stunden auf eine viel längere Zeit durch $Z$ wischenschiebung zahireicher $\mathrm{Pau}$. sen, die für den Arbeiter ganz, willkürlich, für seinen Anwender aber durchaus sinnvoll waren. Vgl. KAPITAL Bd. 1, S. 292/296, $293 \mathrm{f} / 297,300 \mathrm{ff} / 303 \mathrm{ff}$.

I41 KAPITAL Bd. 1, S. 309/312. Marx versteht also diese Gegenbewegung keineswegs im Sinne der späteren revisionistischen Deutung (vgl. den Anfang dieses Abschnitts mit Anmerkungen 3 und 4) als "Regulierung d e r Gesellschaft nach m e n s ch lic h e n Notwendigkeiten" (P. Sering, JENSEITS DES KAPITALISMUS, a.a.O. S. 50 f; Hervorhebung durch W.M./Ch.N.). Er spricht in diesem Zusammenhang auch von der "politischen Okonomie der Arbeiterklasse" (im Rahmen einer politischen Debatte in der Internationalen Arbeiterassoziation, vgl. F. Naphtali, WIRTSCHAFTSDEMOKRATIE, a.a.O. S. 19). Was damit gemeint ist, wird im Zusammenhang der Darstellung der Fabrikgesetzgebung erst wirklich deutlich: daß nämlich auch das Kapital als Herrschaft der toten Arbeit über die lebendige nicht umhin kann auf die Tatsache praktisch Rücksicht zu nehmen, daß es aus der lebendigen Arbeit Wert schöpft. Schließ. lich ist diese "der allgemeine Reichtum gegenüber dem Kapital" (GRUNDRISSE, S. 302). Gewisse Rücksichtnahme auf den 'Leistungsfaktor Mensch', eine Beschränkung des ver. schwenderischen Umgehens mit der Arbeitskraft wird dem Kapital, vermittelt über die Klassenk ̈̈mpfe, als Bedingung seiner eigenen Weiterexistenz aufgezwungen.

142 KAPITAL Bd. 1, S. 309/312. 
selbst samt ihren wissenschaftlichen Apologeten, die sich nunmehr mit der Unvermeidlichkeit einer gesetzlichen Beschränkung des Arbeitstages abfanden. Zum Sieg des Prinzips gehört auch die allmähliche Ausdehnung der Fabrikgesetzgebung auf alle Industriezweige, nämlich in dem Maß, in dem diese sich von den Vorformen Handwerk, Manufaktur, Hausarbeit zur großen Industrie entwickeln. Zwei Umstände vermitteln die Notwendigkeit dieser Verallgemeinerung von einem Ausnahmegesetz für einzeine, industriell besonders entwickelte Branchen zu einem "Gesetz aller gesellschaftlichen Produktion": "erstens die stets neu wiederholte Erfahrung, daß das Kapital, sobald es der Staatskontrolle nur auf einzelnen Punkten der gesellschaftlichen Peripherie anheimfällt, sich um so maßloser auf den andern Punkten entschädigt, zweitens der Schrei der Kapitalisten seibst nach Gleichheit der Konkurrenzbedingungen, d. h. gleichen Schranke n der Arbeitsexploitation." (143) Diese Verallgemeinerung des Schutzes der Arbeiterklasse beschleunigt zugleich die Vernichtung der Vorformen der großen Industrie und die Konzentration des Kapitals bzw. die Alleinherrschaft des Fabrikregimes, damit aber auch die damit verbundene Herausbildung des Klassenantagonismus. (144)

Durch die maßlose Verlängerung des Arbeitstags produziert das Kapital die vorzeitige Erschöpfung der Arbeitskraft, die Zerstörung der Gesundheit der lebenden und der kommenden Arbeitergeneration; es ist die Ursache seelischer Verkrüppelung und Brutalisierung, verkürzter Lebensdauer, ja von Epidemien, die die gesamte Bevölkerung einschließlich der herrschenden Klassen bedrohen. Das Kapital droht seine eigene Existenzgrundlage zu vernichten; zumindest aber erhöht es den Wert der Arbeitskraft und damit die Kosten des variablen Kapitalteils durch zu schnellen Verschleiß. "D e r We rt der A rbeitskraft schließt ... den Wert der Waren ein, weiche zur Reproduktion des Arbeiters oder zur Fortpflanzung der Arbeiterklasse erheischt sind. Wenn also die naturwidrige Verlängrung des Arbeitstags, die das Kapital in seinem maßlosen Trieb nach Selbstverwertung notwendig anstrebt, die Lebensperiode der einzelnen Arbeiter und damit die Dauer ihrer Arbeitskraft verkürzt, wird rascherer Ersatz der verschlissenen nötig, also das Eingehen größerer Verschleißkosten in die Reproduktion der Arbeitskraft, ganz wie der täglich zu reproduzierende Wertteil einer Maschine um so größer ist, je rascher sie verschleißt. Das Kapital scheint daher durch sein eignes Interesse auf einen Nor m a l a r be it s t a hingewiesen." (145) (Zum Wert der Ware Arbeitskraft gehören natürlich nicht nur die Lebensmittel im eigentlichen Sinn, die der Arbeiter mit seiner Fa. milie von seinem Nettolohn kauft, sondern auch jene "Bildungskosten" (146), die der Qualifikation der Arbeitskraft dienen, weiter die Kosten für die Reparatur erkrankter Arbeitskraft und schließlich die Aufwendungen für die (meist sehr erbärmliche) Lebendigerhaltung der nicht mehr venwertbaren Arbeitskraft bis zu deren natürlichem Tod. Dieser Teil des Wertes der Arbeitskraft wird von öffentlichen Institutionen wie staatlichem Volks- und Berufsschulsystem, Kranken- und Rentenversicherung umverteilt; es ist dies wesentlicher Bestandteil der sozialpolitischen Umverteilungstä. tigkeit des Staates - einer Umverteilung in n e r h a l b der Lohneinkommen.)

Das Kapital $\mathrm{s} \mathrm{ch}$ e i n t aiso durch sein eignes Interesse auf einen Normalarbeitstag hingewiesen. Diesem Schein entspricht der $f i k t$ i ve, nämlich nicht wirkliche Gesamtkapitalist. Denn "in seiner praktis ch en Bewegung" wird das Kapital "durch die Aussicht auf zukünftige Verfaulung

143 KAPITAL Bd. I, S. $516 / 514$ f.

144 "Wenn die Verallgemeinerung der Fabrikgesetzgebung als physisches und geistiges Schutzmittel der Arbeiterklasse unvermeidlich geworden ist, verallgemeinert und beschleunigt sie andrerseits, wie bereits angedeutet, die Verwandlung zerstreuter Arbeitsprozesse auf Zwerg. maßstab in kombinierte Arbeitsprozesse auf großer, gesellschaftlicher Stufenleiter, also die Konzentration des Kapitals und die Alleinherrschaft des Fabrikregimes. Sie zerstört alle altertümlichen und Übergangsformen, wohinter sich die Herrschaft des Kapitals noch teilweise versteckt, und ersetzt sie durch seine direkte, unverhüllte Herrschaft. Sie verallgemeinert damit auch den direkten Kampf gegen diese Hertschaft. Während sie in den individuellen Werkstätten Gleichförmigkeit, Regelmäßigkeit, Ordnung und Ókonomie erzwingt, vermehrt sie durch den ungeheuren Sporn, den Schranke und Regel des Arbeitstags der Technik aufdrücken, die Anarchie und Katastrophen der kapitalistischen Produktion im großen und ganzen, die Intensität der Arbeit und die Konkurrenz der Maschinerie mit dem Arbeiter. ..." KAPITAL Bd. 1, S. $528 / 525 \mathrm{f}$.

145 KAPITAL Bd. 1, S. 277/281.

146 Vgl. etwa KAPITAL Bd. 1, S. 206/212, oder schon "Lohnarbeit und Kapital", MEW Bd. 6 , S. $406 \mathrm{f}$. 
der Menschheit und schließlich doch unaufhaltsame Entvölkerung so wenig und so viel bestimmt als durch den möglichen Fall der Erde in die Sonne." (147) Der einzelne Kapitalist, als Kapitalist bloß Personifizierung des Kapitals $\mathrm{s}_{\mathrm{g}}$ kann sich den immanenten Gesetzen der kapitalistischen Produktion nicht entziehen; in der Konkurrenz zwingen sie sich ihm von außen als Zwangsgesetze auf. "im großen und ganzen" hängen "physische und geistige Verkümmerung, vorzeitiger Tod, Tortur der Überarbeit" "nicht vom guten oder bösen Willen des einzeinen Kapitalisten ab. D i e fr e i e Konkurrenz macht die immanenten Gesetzederkapitalistischen Produktion dem einzelnen Kapitalisten gegenüber als äu $B$ e $r$ liches $Z$ wangsgeset $z$ geltend." (148) Es hängt al'so nicht vom Kapitalisten als moralischem Individuum ab, in welchem Grad er die Arbeiter ausbeutet, wie sehr er an der Zerstörung der Geselischaft und seiner eigenen Existenzgrundlage mitarbeitet bzw. die Mitarbeit verweigert. Daher ergibt sich aus dem Kapitalverwertungsprozeß selbst auch keine moralische Schranke. Als Kapitalist, als personifiziertes Kapital ist er zur maßlosen Ausbeutung gezwungen. Ein Handeln als moralisches Individuum ist für ihn nur möglich, wenn er seine Existenz als Kapitalist aufgibt. Wenn ein Kapitalist bei gesellschaftlicher Durchschnit tsarbeitszeit von 12 Stunden nur 6 Stunden arbeiten läßt, macht er pleite, d.h. er hört auf Kapitalist zu sein. (149)

Wie kommt es trotzdem zum allgemeinen Zwangseingriff "der Gesellschaft", der allein dieser Tendenz einen Riegel vorschieben kann? Wie kommt es zur gewaltsamen und mehr oder weniger wirksamen Beschränkung des Arbeitstages durch den von Kapitalist und Grundeigentümer beherrschten Staat, wenn der vernünftige Gesamtkapitalist, wie Marx gründlich darstellt, eine Fiktion ist? "Die Schöpfung eines Normalarbeitstags ist... das Produkt eines langwierigen, mehr oder minder ver. steckten Bürgerkriegs zwischen der Kapitalistenklasse und der Arbeiterklasse" (150) (also nicht dem $v$ e reinz elt e n Arbeiter, dem Arbeiter als Verkäufer seiner Arbeitskraft - wieweit auch das Ausbleiben solchen $\mathrm{k}$ o $\mathrm{l}$ l e k $\mathrm{t} i$ v e $\mathrm{n}$ Widerstands als historische Möglichkeit im Einzelfall zu erwägen ist, welche Folgen dies für die Fortexistenz bzw. die Verfaulung der kapitalistischen Produktion hat, wäre noch zu erörtern). Zunächst: de $r$ Widerstand der Arbeite $r$ a Is $\mathrm{K} I$ a s se gegen ihre eigene Zerrüttung und Vernichtung entsteht aus der "maßIosen B ew e gu ng des $K$ apitals selbst. Die Arbeiterbewegung ist nach Marx "instinktiv aus den Produktionsverhältnissen selbst" (151) erwachsen; der Arbeiter $\mathrm{m} \mathrm{u} B$ in dieser Form um seine Existenz als Arbeiter kämpfen. In diesem Sinn, und nicht als moralischer Aufruf, ist der berühm. te Satz am Ende des Kapitals über den Arbeitstag zu verstehen: "Zum 'Schutz' gegen die Schlange ihrer Qualen müssen die Arbeiter ihre Köpfe zusammenrotten und a / $\mathrm{S} K$ I a s s e ein Staatsgesetz erzwingen, ein übermächtiges $\mathrm{g}$ es e ll s $\mathrm{ch}$ aft liches $\mathrm{Hinder} \mathrm{nis}$, das sie selbst verhindert, durch freiwilligen Kontrakt mit dem Kapital sich und ihr Geschlecht in Tod und Sklaverei zu verkaufen." (152) Die Erhaltung der kapitalistischen Produktionsweise selbst erfordert die Organisation der Arbeiter als Klasse, denn als vereinzelte Verkäufer der Ware Arbeitskraft könnten sie ihre Existenz nicht sicherstellen. Von diesem Punkt aus ist sowohl die

147 KAPITAL Bd. 1, S. 281/285 (keine Hervorhebung im Original).

148 KAPITAL Bd. 1, S. 282/286, vgl. dort Anmerkung 114, sowie "Brief an Kugelmann" vom 17.3.1868, MEW Bd. 32 , S. 541 .

149 Auch die bisher von 'Wirtschaftswunder' und 'Sozialpartnerschaft' verbrämte Ausbeutung in der BRD wird zunehmend an die 'internationalen Maßstäbe' erinnert. Das innere Gesetz des Kapitals, das erst in seiner Aktion auf dem Weltmarkt ganz hervortritt, macht sich in der BRD immer mehr geltend, vermittelt z.B. durch die Agenten des eindringenden US-Kapitals.In einer vom US-Kapital übernommenen großen westdeutschen Elek trofirma schlug der amerikanische Direktor in der letzten Krise der deutschen Geschäftsleitung zu deren Entsetzen vor, ein Drittel der Belegschaft zu entlassen. Damit würde ein Drittel der Lohnliosten eingespart und durch gesteigerte Arbeitsmoral (d.h. Angst vor weiteren Entlassungen) die gleiche Leistung wie bisher erbracht. In der nächsten Krise (bzw. 'Talsohle' in Schillers Beschwörungsdeutsch) wird das Überleben für viele Einzelkapitale davon abhängen, ob sie auf solche Weise 'energisch eine Kostensenkung durchführen'. Die Konkurrenz diktiert so das Verhalten der Kapitalagenten.

150 KAPITAL Bd. 1 , S. 313/316.

151 KAPITAL Bd. 1, S. 315/319.

152 KAPITAL Bd. 1, S. $316 / 320$. 
Entstehung sozialpolitischer Funktionen des Staates wie die Ausbildung und die Anerkennung von Gewerkschaften wie auch die Entstehung des Reformismus in der Arbeiterbewegung zu begreifen." (153)

Das Kapital "in seiner praktischen Bewegung", bei der Mehrwertproduktion, ist jedoch weit entfernt, diese Notwendigkeit der Organisation der Arbeiter als Klasse einzusehen; sie wird ihm vielmehr in langwierigen Kämpfen aufgezwungen. Die maßlosen Ausschreitungen des Kapitals gegen Gesundheit und Lebenskraft der Arbeiter rufen die gesetzliche Kontrolle in Gestait der Fabrikgesetze zunächst jahrzehntelang bloß als Ausnahmegesetzgebung hervor, die bloß für die voll ins Fabriksystem eingetretenen Industriezweige gilt. Sie wird zunächst so ungenau formuliert, daß ihre Umgehung durch die Fabrikanten bereits vorgesehen scheint. (154) Erst nach und nach werden in die Fabrikgesetzgebung Klauseln eingefügt, die die amtliche Kontrolle über ihre Einhaltung durch bezahlte staatliche Inspektoren vorsieht; zunächst jedoch ist deren Zahl ganz ungenügend. Die wirkliche Überwachung der Einhaltung der gesetzlichen Vorschriften wird ebenfalls erst allmählich durchgesetzt; jedoch erweisen sich z.B. die vorgesehenen Strafandrohungen als unwirksam, weil die Gerichte von den Vertretern der angeklagten Klasse besetzt sind; auch sind die angedrohten Sanktio. nen vergleichsweise schwach. Aber auch die bereits bestehenden Gesetze sind vor dem Gegenangriff der Kapitalistenklasse nicht sicher, besonders in Zeiten politischer Schwäche der Arbeiter als Klasse. Und umgekehrt ist die relative Stärke der Arbeiterklasse zu bestimmten Zeiten Grund Für Zugeständnisse des Kapitals.

Die praktische Durchsetzung der Fabrikgesetzgebung, die Anerkennung des Arbeiterschutzes als Funktion des Staates ist in der historischen Wirklichkeit also nicht das Resultat eines ununterbrochenen, kontinuierlichen Prozesses, in dem die Arbeiterklasse der Kapitalistenklasse ihren Willen einfach aufzwingt (noch weniger natürlich das Ergebnis 'sozialpolitischer Eingriffe' 'des' Staates). Vieimehr ist dieser Prozeß durch vielfältige Auseinandersetzungen vermittelt, durch Fortschrit . te und Rückschläge, durch Koalitionen und Kompromisse usw. Die ökonomische und politische Kampfkraft der Arbeiterklasse gegen die Kapitalistenklasse ist dabei von verschiedenen Momenten bestimmt. Eine wichtige Rolle spielen die Konflikte mit den Resten vorkapitalistischer Herrenklassen, die nicht unbedingt schon ganz ins Kapitalverhältnis einbezogen und damit zu einer bloßen Fraktion der Kapitalistenklasse geworden sein müssen: vor allem die Grundeigentümer ("Landlords"). Bekanntich macht sich ihr Gewicht besonders im Staatsapparat geltend (vgl. den Doppel. charakter des Bismarck-Staates). Bedeutender sind die Auseinandersetzungen unter verschiedenen Fraktionen innerhaib des Kapitals, z.B. über die Frage der Abschaffung von Zöllen auf bestimmte Waren. Privilegien für bestimmte Gruppen, etwa zur Nichtbeachtung gesetzlicher Bestimmungen, werden von den andren Gruppen abgelehnt, die die Einhaltung im Interesse gleicher Konkurrenzbedingungen verlangen. Solche Konflikte innerhalb der herrschenden Klassen können das Gewicht der Arbeiterklasse zeitweise erheblich verstärken. Abgeschwächt gilt entsprechendes für das Kleinbürgertum (Kleinwarenproduzenten, Händler, auch Ärzte usw.); sofern die Ideologieproduzenten ("Pfaffen, Professoren", Lehrer, Wissenschaftler, Journalisten usw.) nicht direkt von den herrschenden Klassen in Dienst genommen sind, folger sie meist kleinbürgerlicher Bewußtseinsausrichtung. Im Zusammenhang mit der Fabrikgesetzgebung spielen diese Gruppen eine nicht unbedeutende Rolle, etwa durch Stellungnahmen in der Presse oder Ausarbeitung von Gutachten und Untersuchungsberichten im Rahmen von 'Königlichen Kommissionen' (155). Sie haben diese 'Unabhängigkait' freilich nur soweit die Auseinandersetzungen zwischen den entscheidenden Klassen ihnen einen Spielraum gewähren - damit ist zugleich die von Liberalen regelmäßig überschätzte (156) und

153 Vgl. dazu Teil V.

154 Entsprechendes gilt heute für die gesetzlichen Unfallvorschriften in den Betrieben, für das Jugendarbeitsschutzgesetz, das Mutterschutzgesetz und andere Schutzbestimmungen für die Lohnarbeiter gegenüber dem Kapital.

155 Vgl. z.B. KAPITAL Bd. 1, S. 520 f/519: "Die Untersuchungskommission von 1840 hatte so schauderhafte und empörende Enthüllungen gemacht, und einen solchen Skandal vor ganz Europa hervorgerufen, daß das Parlament sein Gewissen salvieren mußte durch den Mining Act von 1812, worin es sich darauf beschränkte, die Arbeit unter Tag von Weibern und Kindern unter 10 Jahren zu verbieten."

156 Vgl. J. Habermas. STRUKTURWANDEL DER OFFENTLICHKEIT. Untersuchungen zu einer Kategorie der bürgerlichen Gesellschaft. Neuwied U. Berlin-West 1962. 
zum bewegenden Moment der Geschichte des bürgerlichen Staates erhobene Bedeutung der bürgerlichen Öfentlichkeit anerkannt un d eingeschränkt. Zahllose der von Marx herangezogenen Berichte der Fabrikinspektoren sind jahrzehntelang ohne Wirkung in den Archiven verschwunden; die Aufklärung hatte keine Konsequenz in der Wirklichkeit. Diese Öffentlichkeit hat eine wichtige Funktion: es kann sich in ihr ein bürgerlich-kritisches Bewußtsein entwickeln, das auf die Probleme aufmerksam macht, die dem Kapital in seiner praktischen Geschäftigkeit notwendig entgehen müssen. Dieser über den direkten Interessen stehenden öffentlichen Meinung tritt auf dem gleichen Terrain aber auch die Tätigkeit der einfach gekauften Auftragsforscher und Meinungsmacher einzelner Fraktionen des Kapitals gegenüber, die deren Interessen durch Pressekampagnen, Gutachten für Parlamentsausschüsse usw. vertreten. Die Wirkung aller der hier aufgezählten Momente auf die Kampfkraft der Arbeiterklasse ist immer vor dem Hintergrund zu sehen, daß die Fabrikgesetzgebung im damaligen England einerseits notwendig war, um die Arbeiterrasse als Quelle der Kapitalverwertung zu erhalten, und daß sie andrerseits dem Kapital auf seinem damaligen Entwicklungsstand erträglich war, also seine Existenz nicht ernsthaft gefährdete. (157)

Eine besonders wichtige Funktion der unabhängigen Öffentlichkeit ist es, auf die Bedrohung der Existenzgrundlagen der Gesellschaft, d.h. ihrer kapitalistischen Form, und auf drohenden offenen Klassenkarnpf aufmerksam zu machen. Marx erwähnt die Warnungen über den "unglaublich gespannten Klassenahtagonismus", die die Fabrikipspektoren an die Regierung übermitteln; sie haben damit eine ähnliche Aufgabe wie heu te die Gewerkschaftsfunktionäre, die die Stimmung unten nach oben weitergeben sollen, um etwa erforderliche Zugeständnisse einzuleiten. Die Befriedung durch Sozialpolitik ist eine wichtige Seite bei der Erhaltung der Arbeitskraft als Wertquelle; bekanntlich hat Bismarck ganz bewußt neben der Peitsche der Sozialistengesetze das Zuckerbrot der Sozialversicherung verordnet und damit, gegen den Willen der politischen Vertreter des Kapitals, wesentlich zu der folgenschweren Orientierung der deutschen Arbeiterklasse auf den Staat beigetragen. (158) Jedoch ist hier vor der verbreiteten Auffassung zu warnen, der Staat greife als weiser Vertreter der Interessen des Kapitals in seine unerschöpfliche Zaubertasche, um nach Belieben das Proletariat durch Sozialpolitik zu manipulieren. Die Schranken der sozialpolitischen Eingriffe des Staates sind eng gezogen, und selbst die auf einer bestimmten historischen Entwicklungsstufe möglichen Eingriffe (so weise sie an sich wären) werden im allgemeinen erst nach langwierigen Auseinandersetzun. gen und angesichts tatsächlicher oder drohender Klassenkämpfe durchgeführt.

Die oben erwähnte Antinomie zwischen dem Recht des Kapitalisten als dem Käufer und dem Recht des Arbeiters als dem Verkäufer der Ware Arbeitskraft wird nach Marx durch Gewalt entschieden; sie konstituiert zugleich den Staat in einem doppelten Charakter. Einerseits werden die sozialpolitischen Funktionen des Staates überhaupt erst durch die wirklichen oder drohenden Kämpfe der Arbeiter als Klasse durchgesetzt (159); ohne sie wäre seine Existenz als ideeller Gesamtkapitalist und

157 Vgl. dazu auch den Anfang des letzten Teils.

158 So war die Begründung zum Unfallversicherungsgesetz, es sollten "die bedenklichen Erscheinungen, welche den Erlaß des Gesetzes gegen die gemeingefährlichen Bestrebungen der Sozialdemokratie" notwendig gemacht hätten, auch "durch positive, auf die Verbesserung der Lage der Arbeiter abzielende Maßnahmen" bekämpft werden. Vgl. O. Vossler: BISMARCKS SOZIALPOLITIK, Darmstadt 1961, S. 17. Sozialpolitik "drainiert die Ziele der Arbeiterbewegung, indem sie eine Alternative zu radikalen Lösungen entwickelt hat", ist nach wie vor die Auffassung der bürgerlichen Wissenschaft. Vgl. Ch. Ferber: SOZIALPOLITIK IN DER WOHL: STANDSGESELLSCHAFT, Hamburg 1967, S. 46. Gegenüber den bürgerlichen Parteien stellte Bismarck im Reichstag (26.11.1884) fest: "Wenn es keine Sozialdemokratie gäbe und wenn nicht eine Menge von Leuten sich vor ihnen fürchtete, würden die mäßigen Fortschritte, die wir überhaupt in der Sozialreform bisher gemacht haben, auch noch nicht existieren." (Diese und andere Äußerungen bei P. Peschke: GESCHICHTE DER DEUTSCHEN SOZIALVERSICHERUNG. Der Kampf der unterdrückten Klassen um soziale Sicherung. Berlin (DDR) 1962; hier S. 278.).

159 Vgl. die in der vorigen Anmerkung zitierte Außerung Bismarcks. An historischen Beispielen fehlt es nicht: der größte sozialpolitische Schub fand in Deutschland 19I8/1919 angesichts der drohenden Revolution statt; in Italien wurden 1969 nach zwei Generalstreiks usw. die Renten von 65 auf $74 \%$ des Endverdienstes erhöht, bis 1976 sollen sie auf $80 \%$ steigen (BRD: ca. $45 \%$ ). Die Frage ist aber, wie weit Zugeständnisse auf dem einen Gebiet durch 
scheinbar selbständige Instanz nicht möglich. Andrerseits konstituieren diese Klassenkämpfe immer auch die Arbeiter als Klasse im Sinne eines handelnden Subjekts, damit aber auch die Tendenz zur Aufhebung des Kapitalverhältnisses und seines Staates; dieser Tendenz entspricht wiederum die militärische Unterdrückungsaufgabe des Staates. Wäre nicht die Arbeiterklasse von Zeit zu Zeit gezwungen, für ihr Recht als Warenverkäufer zu kämpfen oder damit zu drohen, so wäre Polizei usw. überflüssig. Andererseits würde die 'sozialpolitische Aufgabe' des Staates (nämlich die Aufgabe der Befriedung) 'unglaubwürdig', wenn dieser immer vorhandene Zwangscharakter des Klassenstaates zur Unzeit offenbar würde. Das Janusgesicht des Staatsapparates, 'Fürsorge' und Unterdrückung, ist notwendiger Ausdruck der Antinomie des kapitalistischen Verwertungsprozesses selbst, wie sie als Recht gegen Recht beim Tausch der Ware Arbeitskraft auftritt. (160)

\section{Das Kapital als Bedingung der Besonderung des Staates (161)}

Es ist die besondere Eigenart der auf dem Verhältnis von Kapital und Lohnarbeit beruhenden Form der gesellschaftlichen Produktion, daß hier die Menschen ihren eigenen Lebenserhaltungsprozeß nicht $v$ o $n$ vor $n h$ e re i $n$ überschauen und planmäßig gestalten können, sondern daß die im Ka. pitalverhältnis angelegte widersprüchliche innere Tendenz, und zwar durch das Handeln der Kapitalagenten vermittelt, zu Folgen führt, die die einzelnen Funktionäre des Kapitals selbst nicht bewußt wollen und gegen die sie als Einzelkapitalisten nichts unternehmen können. Zwar ist der Staat um des Privateigentums, um des Kapitals willen da, zwar ist er "weiter Nichts als die Form der Organisation, welche sich die Bourgeois sowohl nach Außen als nach innen hin zur gegenseitigen Garantie ihres Eigentums und ihrer Interessen notwendig geben." (162) Aber damit ist der Staat eben nicht einfach mit dem Kapital, mit dieser besonderen Form der gesellschaftlichen Produktion i d e $\mathrm{n} \mathrm{i} \mathrm{s} \mathrm{c} \mathrm{h.} \mathrm{Vielmehr} \mathrm{charakterisiert} \mathrm{den} \mathrm{bürgerlichen} \mathrm{Staat} \mathrm{gerade} \mathrm{die} \mathrm{Tatsache,} \mathrm{daß}$ er auf der Loslösung des Eigentums als Privateigentum aus der ursprünglichen Einheit des Gemeinwesens beruht (163) und daß er a u f d i e se r G ru n d I a g e zu "einer besonderen Existenz neben und außer der bürgerlichen Gesellschaft geworden" ist (164).

Es ist wichtig hervorzuheben, daß diese Besonderung zur Existenz "n e be n und a u $B$ er" der bürgerlichen Gesellschaft auf deren Grundlage stattfindet, also aufder in s i ch wide rsprü $c h$. I i ch e $\mathrm{n}$ Basis der kapitalistischen Produktion. Die wirkliche B e so nde ru ng auf dem Grund dieses Widerspruchs führt dann zu der "verkehrten", "mystifizierten", idealistischen (165) Auffassung, nach der der Staat 'der' Gesellschaft s e I b s tä n d i g gegenübersteht, das w i rk l i c h e $\mathrm{S} \mathrm{u} \mathrm{b} \mathrm{j} \mathrm{e} \mathrm{k} \mathrm{t} \mathrm{ist,} \mathrm{dessen} \mathrm{Objekt} \mathrm{'die} \mathrm{Gesellschaft'} \mathrm{ist;} \mathrm{Marx} \mathrm{kritisiert} \mathrm{diese} \mathrm{Auffassung} \mathrm{in} \mathrm{seiner} \mathrm{Kri-}$ tik des Hegelschen Staatsrechts. (Letzten Endes ist darin bereits, wenn auch in abstrakter Weise, die Kritik an der revisionistischen Staatstheorie enthalten, die zwar verbal am Primat der Gesellschaft, des Antagonismus von Lohnarbeit und Kapital festhält, aber die Fähigkeit des Staates zur Regulierung des gesellschaftlichen Widerspruchs behauptet, den Staat zum Subjekt erhebt.) Den Lesern des KAPITAL ist diese Entwicklung des Staates als "besondere Existenz neben und außer

Sozial- und Lohnabbau auf anderen Gebieten notwendig ihr Gegengewicht finden - notwendig infolge des Mechanismus der kapitalistischen Akkumulation, wie er über den Weltmarkt auf die einzelnen Kapitale wirkt. Es ist bekannt, wie die Zugeständnisse an die französische Arbeiterklasse im Sommer 1968 über Preiserhöhungen usw. teilweise wieder abgebaut wurden.

160 Vgl. auch P. Lapinski: "Der 'Sozialstaat'. Etappen und Tendenzen seiner Entwicklung." In: UNTER DEM BANNER DES MARXISMUS, II (1928) S. 380; vgl. Nachdruck in: GEGEN DEN STROM, Nr. 1, S. 36

161 Wir wählen diesen zunächst schwer verständlichen Titel, da sich in der Diskussion gezeigt hat, daß die scheinbar leichter verständliche Fassung "b e s on d e r e Ex is te n z des Staates" die Vorstellung der $\mathrm{S}$ e l b s t ä n d i g k i t des Staates hervorrufen kann. Was gemeint ist, wird sich in der Darstellung klären.

162 Marx, DEUTSCHE IDEOLOGIE, MEW Bd. 3, S. 62. Die Formulierung in dieser frühen Schrift schließt das Mißverständnis nicht völlig aus, daß die Bourgeois als Bourgeois etwas anderes als bloße Charaktermasken des Kapitals seien ( $\mathrm{da} B$ sie also sich diese Form der staatlichen Organisation bewußt gäben).

163 Dies wird weiter unten noch ausgeführt.

164 Marx, DEUTSCHE IDEOLOGIE, a.a.O. S. 62.

165 Diese Ausdrücke werden von Marx immer wieder gebraucht, vgl. weiter unten. 
der bürgerlichen Gesellschaft" leicht verständlich, wenn sie sich an die dialektische Entwickiung der Wertform, weiter der Geldform aus dem in der Ware gesetzten Widerspruch von Wert und Gebrauchswert erinnern (166). Dieser im Doppelcharakter des Arbeitsprodukts als Ware enthaltene Widerspruch kann nur dadurch erscheinen, daß er sich in einer besonderen Ware, der Geldware, darstellt; daß sich die Wertform der Ware, die sich in ihrer eigenen Gebrauchsform nicht ausdrükken kann, in der Gebrauchsform einer besonderen Ware ausdrückt und diese dadurch zum Geld macht. Das Geld e r s c h e i n t nun als selbständiges Ding, dem die besondere, historisch-gesellschaftliche Eigenschaft des Wertes als $n$ a $t \ddot{u} r l i c h$ e oder auch als von Menschen durch bewuß. te $\ddot{U}$ b e $r$ e i $\mathrm{ku} \mathrm{n} \mathrm{ft} \mathrm{definierte} \mathrm{Eigenschaft} \mathrm{anhafter.} \mathrm{Der} \mathrm{gleiche} \mathrm{'Fetischismus'} \mathrm{ist} \mathrm{beider}$ Form des Staates festzustellen. Nach der bürgerlichen Auffassung hat es entweder den Staat immer schon gegeben, ist der Mensch ' $v$ o n N a tu $r$ auf den Staat hin geschaffen', bzw. ist der Staat für ein menschliches (d.h. bürgerliches) Leben unentbehrlich, oder-aber er wird durch $\mathrm{V}$ e r trag s. s $c h \mid u ß$ bewußt begründet (167). Daß er bloß Besonderung dieser spezifischen, der kapitalistischen Produktionsweise ist, ist in dieser Verkehrung auf den Kopf gestellt. Diese Verdinglichung und Verselbständigung des Staates ist auf der Basis der bürgerlichen Produktionsweise eine ebenso notwendige Illusion, wie es die Formen des Geldes, des Kapitals, des Arbeitslohns, des Profits, der Produktionsfaktoren bzw. der Einkommen usw. sind, die sich durch den besonderen Mechanismus dieser Produktionsform ihren Agenten aufdrängen und deren Handeln wirklich bestimmen.

Daher ist der bürgerliche Staat eben auch nicht " $w$ i $r$ k l i c h e $r$ Gesamtkapitalist", sondern "ideeller", "fiktiver Gesamtkapitalist" (168). E r s t n a ch träg li c h und angesichts drohenden Untergangs der Grundlage dieser Produktionsweise kann sich das Interesse des Kapitals auf Erhaltung seiner Existenzbasis durchsetzen. Das wesentliche, für das wirkliche Verhalten des Kapitals bestimmende Verhältnis ist das Verhältnis des Einzelkapitals zu seiner individuellen Mehrwertquelle, den von ihm angewendeten Arbeitern. (169) "Was könnte die kapitalistische Produktionsweise bessercharakterisieren als die Notwendigkeit, ihr durch Zwangsgesetz von Staats wegen die einfachsten Reinlichkeits- und Gesundheitsvorrichtungen aufzuherrschen?" (170) Der Prozeß dieser allmählichen, durch Katastrophen und Auseinandersetzungen, Siege und Niederlagen vermittelten 'Aufherrschung' konstituiert jeweils erst den 'Sozialstaat', den 'Interventionsstaat' usw. als besondere, dem Kapital an sich äußerlich gegenübertretende Zwangsgewalt. Dieser Prozeß er-

166 Vgl. KAPITAL Bd. 1, I. Abschnitt, besonders 1. Kapitel.

167 Das ist bis heute die Fiktion bei jeder Verfassung, auch z.B. beim Grundgesetz, wo freilich diese Fiktion besonders durchsichtig ist, da alle die Gesellschaft betreffenden Grundentscheidungen dem Grundgesetz vorausgegangen waren, nämlich die Restauration der kapitalistischen Verhältnisse; vgl. oben II.4.

168 Vgl. z.B. Engels, ANTI-DÜHRING, MEW Bd. 20, S, 260: "Aber weder die Verwandlung in Aktiengesellschaften noch die in Staatseigentum, hebt die Kapitaleigenschaft der Produktivkräfte auf. Bei den Aktiengesellschaften liegt dies auf der Hand. Und der moderne Staat ist wieder nur die Organisation, welche sich die bürgerliche Gesellschaft gibt, um die allgemeinen äußern Bedingungen der kapitalistischen Produktionsweise aufrechtzuerhalten gegen Übergriffe, sowohl der Arbeiter wie der einzelnen Kapitalisten. Der moderne Staat, was auch seine Form, ist eine wesentlich kapitalistische Maschine, Staat der Kapitalisten, der ideelle Gesamtkapitalist. Je mehr Produktivkräfte er in sein Eigentum übernimmt, desto mehr wird er wirklicher Gesamtkapitalist, desto mehr Staatsbürger beutet er aus. Die Arbeiter bleiben Lohnarbeiter, Proletarier. Das Kapitalverhältnis wird nicht aufgehoben, es wird vielmehr auf die Spitze getrieben. Aber auf der Spitze schlägt es um. Das Staatseigentum an den Produktivkräften ist nicht die Lösung des Konflikts, aber es birgt in sich das formelle Mittel, die Handhabe der Lösung."

169 GRUNDRISSE, S. 322 f; vgl. oben Teil II, Anm. 24.

170 Marx, KAPITAL Bd. 1, S. 506 f/505 (keine Hervorhebungen im Original). Wie unverändert aktuell im wörtlichsten Sinn diese Charakterisierung ist, zeigen die umständlichen Versuche zur Durchsetzung von Gesetzen zur 'Reinerhaltung von Luft und Gewässern', die schwachen Regungen gegen die weitere Steigerung des Dauerlärms durch Autos, Flugzeuge usw. Kürzlich wurde von einem Gutachten berichtet, nach dem allein die bisher bereits projektierten Kernkraftwerke am Rhein dessen Temperatur bei vollem Betrieb auf 50 Grad Celsius steigern werden, nebst Zerśtörung von Klima und Uferlandschaften, Vernichtung der Fische, Luf tverpestung usw. Sind derartige 'Projekte' z.B. in der DDR vorstellbar? 
zeugt auch erst jene Kämpfe der verschiedenen Gruppen von 'Interessen' und ihre verfestigten institu. tionen im Staat selbst wie in seinem Vorfeld, der 'politischen Willensbildun'g' (als welche sie dann, aus ihrem Entstehungszusammenhang losgelöste Erscheinungen, das Objekt der politischen Wissenschaft bilden). Und weil die Eingriffe in den immanenten Zwang zur Kapitalverwertung dem Kapital als Zwangsgesetze, von einer ihm äußerlichen Institution aufgedrängt werden müssen, muß diese Institution mit Kontrollbefugnissen und einer wirksamen Sanktionsgewalt, kurz: mit einem ungeheuren und wachsenden bürokratischen Zwangsapparat ausgerüstet sein. Die bloße Tatsache dieses 'Staatsapparats' befestigt wiederum die Illusion der Selbständigkeit des Staates, seiner Fähigkeit zur 'Intervention' in 'die Wirtschaft'. Dabei besagt die Tatsache der Existenz dieses Apparats ja noch keineswegs, daß er wirklich wirksam eingreifen kann (ganz abgesehen von der systematischen Errichtung von Gegenapparaten zur Umgehung oder zum Widerstand gegen diese Zwangsgewalt - Unternehmerverbände und -lobbies, Steuer'beratungs'büros usw.).

Diese besondere Existenz des Staates ist also nicht selbstverständlich - nicht einmal für Klassengesellschaften. Erst die Privatisierung der in vorkapitalistischen Gesellschaftsformationen von vornherein umfassend-gesellschaftlichen Sphäre der Lebenserhaltung, erst die Herausbildung des privaten im Unterschied zum kommunalen Eigentum macht ïberhaupt diese besondere Existenz einer ausschließlich politischen Zwangsinstitution, des Staates, möglich und notwendig. Bereits in seiner Kritik des Hegelschen Staatsrechts (1843) beschrieb Marx den bürgerlichen "Mystizismus", der "das w i $r$ K I i c h e Verhältnis von Familie und bürgerlicher Gesellschaft", also der "eigentlich Tätigen zum Staat auf den Kopf stellt, die Voraussetzung zum Bedingten macht, das "Produzierende... als das Produkt seines Produkts" setzt. (171) "Es versteht sich, daß da erst die politische Verfassung als solche ausgebildet ist, wo die Privatsphäre", das "Eigentum, der Vertrag, die Ehe, die bürgerliche Gesellschaft", eine selbständige Existenz erlangt haben. Wo Handel und Grundeigentum unfrei, noch nicht verselbständigt sind, ist es auch noch nicht die politische Verfassung. ... Die Abstraktion des $S \mathrm{t}$ a a $\mathrm{t} \mathrm{s}$ a I $\mathrm{s}$ s o l c h e n gehört erst der modernen Zeit, weil die Abstraktion des Privatlebens erst der modernen Zeit gehört. ... Im Mittelalter gab es Leibeigene, Feudalgut, Gewerbekorporation, Gelehrtenkorporation etc., d.h., im Mittelaiter ist Eigentum, Handel, Sozietät, Mensch p o I i t i s c h; der materielle Inhalt des Staates ist durch seine Form gesetzt; jede Privatsphäre hat einen politischen Charakter oder ist eine politische Sphäre, oder die Politik ist auch der Charakter der Privatsphären. ... Im Mittelalter ist Volksleben und Staatsleben identisch." (172) Was Marx hier vom Mittelalter sagt, gilt für jede vorbürgerliche Geselischaftsformation, wie er danach für die antiken Stadistaaten andeutet und später in den Vorarbeiten zum 'Kapital' wiederholt ausführt. (173) In den alten 'Gemeinwesen', dem 'Stamm', der 'Gemeinde' oder 'commune', existiert der Staat nicht als "eine b e s o n d e re Wirklichkeit neben dem wirklichen Volksleben", sondern die'politische' Organisation, die Stammeszugehörigkeit z.B., ist Voraussetzung und Garantie für die Aneignung der objektiven Lebensbedingungen in der Arbeit. Diese Arbeit ist auf die Herstellung der Gebrauchswerte gerichtet, deren die Mitglieder der Gemeinschaft bedürfen (wobei Sklaven oder Leibeigne als eine besondere Art von Arbeitstieren nicht Gemeindemitglieder sind, jedoch als Arbeitsinstrumente mehr oder weniger viel vom Arbeitsertrag erhalten - werden sie von ihrem Herrn zugrundegerichtet, so weiß dieser, was er tut: er schadet sich selbst, nicht anders als wenn er sich in den Fuß hackt oder seinen Tragesel verhungern läßt (so begründet Aristoteles die Unmöglichkeit einer ethischen Beziehung zwischen Herr und Knecht). Das Verhalten der arbeitenden Individuen zum Boden, also ihrer Werkstatt und ihrem Rohstoffvorrat, den objektiven Bedingungen ihrer Arbeit, "ist sofort vermittelt durch das naturwüchsige, mehr oder minder historisch entwickel te, und modifizierte Dasein des Individuums als Mitglieds e in e r G e me ind e" (174) (ganz elementar zunächst in der friedlichen oder gewaltsamen Inbesitznahme dieses Bodens, die nur im Gemeindeverband möglich ist). 'Eigentum' an den objektiven Bedingungen der Arbeit existiert nicht als

171 Marx: "Kritik des Hegelschen Staatsrechts", MEW Bd. 1, S. 206 f. Vgl. auch die im I. Teil, oben Anm. 5 zitierten Stellen aus Marx' Randglossen zum Artikel eines Preußen.

172 Ebenda S. 233, 232. Vgl. insgesamt die Dissertation von A. Gurland: PRODUKTIONSWEISE - STAAT - KLASSENDIKTATUR, a.a.O.

173 Vgl ausführlich Marx: GRUNDRISSE, a.a.O. S. 375 ff; hier wird die ursprüngliche, durch das Gemeinwesen vermittelte $\mathrm{E}$ in he it der Arbeit mit ihren sachlichen Voraussetzungen ihrer Tren un $\mathrm{g}$ im Verhältnis von Lohnarbeit und Kapital gegenübergestellt.

174 GRUNDRISSE, a.a.O. S. 385. 
Privateigentum, sondern von vornherein nur als gesellschaftlich vermitteltes Eigentum. Die 'politische Gemeinsamkeit der Mitglieder solcher vorkapitalistischer Gemeinwesen äußert sich besonders in der gemeinsamen Organisierung der Aufgaben, die für die weitere Existenz im Verband der Gemeinde notwendig schienen: Flußregulierung, Wegebau, Anlegung von Vorräten, auch die Aneignung rieuen Bodens durch die gemeinschaftliche Arbeit des Krieges, Kult der die Einheit der Gemeinde darstellenden Götter usw. Diese Gemeinschaftsaufgaben sind hier nicht eine sich $\mathrm{n}$ a $\mathrm{ch}$. t $\mathrm{rag} / \mathrm{ich}$ als notwendig erweisende, von besonderen politischen institutionen und erst nach komplizierten Auseinandersetzungen in den von der Kapitalverwertung gesetzten Grenzen allmäh lich übernommene Aufgabe, sondern sie sind vo $n$ vor $n h$ e r e in Teil der gesellschaftlichen Lebenserhaltung durch Arbeit (zu dieser gehört hier auch die Produktion der nächsten Generation). (175)

Wie sehr in vorkapitalistischen Gemeinwesen der g e s a $\mathrm{m}$ t e Lebenserhaltungsprozeß einschließlich der Produktion der materiellen Gebrauchsgüter eine Einheit ist, läßt sich am anschaulichsten am selbstwirtschaftenden Bauernhof oder am adeligen Gut klarmachen. Die Grundstruktur solcher Einheiten der gesellschaftlichen Lebensproduktion vom Großer, Haus des Pharao bis zum Zeit des Erzvaters Abraham oder dem Hof des freien Bauern, ist die gleiche; unterschiedlich ist nur, ob das Gemeinwesen sich in einer einzigen Person oder in der Gemeinschaft einer mehr oder weniger gro. Ben Zahl Freier und Gleicher darstellt (Monarchie, Oligarchie oder Demokratie). Unterhalb des jeweiligen Herrn stehen die Mitglieder der 'Familie', darunter auch leibeigene Knechte usw. Unabhängig von den besonderen Formen beruhen alle diese Einheiten auf dem 'Grundeigentum', d.h. hier auf der Aneignung der Früchte der Erde durch gesellschaftliche Arbeit. (176) Die alten Handbücher der Hauswirtschaftslehre (= 'Ökonomie') lassen erkennen, was alles zu einem solchen 'Haushalt' oder 'Hof' gehörte.Ein solches Handbuch aus dem 17. Jahrhundert (177) leitet den Hausherrn u.a. zu folgenden Aufgaben an (die er natürlich delegieren kann, für die er jedoch die letzte Verantwortung trägt und die er also auch im voraus planen muß): zunächst das Verhältnis zu Gott (diese Aufgabe kann er einem Priester übertragen), zu Frau und Kindern, zum Gesinde und den Leibeigenen - dieses Verhältnis der Herrschaft schließt die Anleitung, Erziehung und Züchtigung ein; das Verhalten bei Seuchengefahr, die Beobachtung des Kalenders mit den Terminen für die verschiedenen Arbeiten ('Martini man die Gänse schlachtet'), die Wetterkunde; unter den besonderen Aufgaben der Hausherrin werden erwähnt: Erziehung vor allem der Töchter, Kochen, Backen, Herstellung von Lebensmittelvorräten durch Einmachen, Trocknen, Pökeln usw., Herstellung und Reparatur von Kleidung, die Apotheke und die Krankenversorgung, Küchen-, Arznei- und Biumengarten. Weiter werden genannt: Weinbau- und Kellerwirtschaft, Obstzucht, Ackerbau samt Brauerei, Müllerei usw., Pferde-, Rinder-und Schafhaltung; Bienen- und Seidenraupenzucht; Wasserversorgung, Bachregulierung (zum Antreiben der Mühlen), Fischzucht; Forstwirtschaft und Jagd; Mühlen, Ziegeleien, Steinbrüche und Minen. So disparat diese Aufzählung für die bürgerliche Wissenschaftsaufteilung erscheinen muß, nach der dieser Zusammenhang in die Einzeldisziplinen der Theologie, Ethik , Pädagogik, Medizin, Meteorologie, Soziologie, Betriebswirtschaftslehre usw. usw. aufgesplittert wird, so sehr kann diese Aufzählung einen Begriff von jener Tot a lität der ge sellschaftlichen $L$ e b e $n$ se $r h$ a I t ung geben, die erst nach der Abschaffung des Kapitalverhältnisses wieder als solche gestaltet und geplant werden kann. Eine Trennung von Gesellschaft und Staat, von Ökonomie und Politik gibt es hier nicht; der Hausherr übt die, allerdings durch Tradition genau festgeleg. te, totale Herrschaftsgewalt in abgestufter Rangfolge über Frau, Kinder und Knechte aus, bis zum Recht der körperlichen Bestrafung, ja der Todesstrafe (selbstverständlich hat sich diese Tradition allmählich aus den besonderen Bedingungen der Produktion des Lebens heraus entwickelt, nicht

175 Begriffe wie Gemeinschaft, Gemeinschaftswerk dienen ideologischen Zwecken, wenn sie aus ihrem vorbürgerlichen Zusammenhang umstandslos auf die vom Kapitalverhältnis beherrschte Gesellschaft übertragen werden ('Volksgemeinschaft', 'Deutsches Gemeinschaftswerk' und dgl.). Dagegen können sie in gewisser Weise beim Aufbau des Kommunismus ihren ursprünglichen Sinn wiedergewinnen.

176 Vgl. GRUNDRISSE, S. $375 \mathrm{ff}$ über die verschiedenen Formen, in denen sich dieses Grundverhältnis realisiert.

177 Hohberg: "Georgica curiosa", 1682; zitiert nach O. Brunner, Das "ganze Haus" und die alt. europäische "Ókonomik", in: ders., NEUE WEGE DER SOZIALGESCHICHTE, Göttingen 1956 , S. 33-61, bes. S. 35 . 
ohne ein gewisses Beharrungsvermögen). Wenn der Hausherr nicht der einzige Herr, der Herrscher ist (wie der Inka in Peru), so kann er einen Teil seiner Rechte und Pflichten an niederigere Herren. verleihen (Feudalsystem). Oder er übt einige dieser Rechte und Pflichten gemeinsam mit anderen, gleichberechtigten Herren aus, 2.B. im Senat oder auch der Volksversammiung (zum Volk gehören grundsätzlich nur die freien Hausherren auf eigenem Grund); wichtigste dieser Aufgaben ist die Kriegführung (vgl. das germanische Thing, wo zu diesem Zweck der 'Herzog', der Heerführer, gewählt wurde).

Katastrophen treten für solche vorkapitalistischen Gemeinwesen entweder als wirkliche Naturkatastrophen oder beim Zusammenstoß mit anderen Gemeinwesen auf, nicht jedoch als gesellschaftliche Naturkatastrophen wie in der verkehrten Welt des Kapitals. Und es ist notwendiger Ausdruck der im Kapital enthaltenen Konsequenz, wenn Marx im KAPITAL nach der Entwicklung der Kategorie des absoluten Mehrwerts sogleich zur Darstellung der Katastrophen kommt, die die Mehrwertproduktion für die lebendige Arbeitskraft zur Folge hat, und von daher die Besonderung des Staates in der Fabrikgesetzgebung ableitet. Solange die Arbeit auf die Produktion von Gebrauchswerten, auf die Lebenserhaltung der gesellschaftlichen Individuen gerichtet ist, wird keine gesonderte Kontroll- und Zwangsorganisation nötig, die zu verhindern sucht, daß die Individuen und die Gesellschaft sich durch ein Ubermaß an Arbeit selbst zugrunderichten. Erst die kapitalistische Warenproduktion zerreißt diesen Zusammenhang und erzeugt das Problem der Selbstzerstörung der Geselischaft. Die Zusammenfassung der bürgerlichen Gesellschaft in der Form des Staates, ihre Zusammenfassung also in einer Institution, die ihr selbst als äußerlich erscheint, die über ihr als 'besondere Existenz' zu schweben scheint, ist deshalb notwendig, weil nur so die Existenz der Gesellschaft (nämlich als kapitalistischer) überhaupt gewährleistet werden kann. Weil der direkte Zweck der Produktion nicht die gesellschaftliche Lebenserhaltung, sondern der Mehrwert ist, weil deshalb der Produktionsprozeß von Gesetzmäßigkeiten vorwärtsgetrieben wird, die dem bewußten Willen der Individuen verborgen sind und sich hinter ihrem Rücken, aber durch ihr eigenes Handeln durchsetzen, ist eine solche gesonderte gesellschaftliche Institution notwendig, die der Gesellschaft als produzierender gegenübertritt. Diese nachträgliche und notdürftige Kontrolle des Staates über die naturwüchsige Gestalt des gesellschaftlichen Produktionsprozesses ist notwendig zur Erhaltung der Produktion von Mehrwert, dieser besonderen Form der Aneignung der Mehrarbeit einer Klasse durch eine andere Klasse. Diese Kontrolle soll also den Klassencharakter dieser Gesellschaft erhalten; sie ist eine der Funktionen, die der Staat in dieser Klassengesellschaft übernehmen muß (die Funktion der d i r e k t e $\mathrm{n}$ Unterdrückung wird in unserem Zusammenhang nicht behandelt, da sie für diese besondere Gesellschaftsform gerade nicht in e r s t e r Linie typisch ist - die Verkennung dieser grundlegenden Tatsache verführt vielfach zu falschen Folgerungen im Hinblick auf die revolutionäre Umwälzung und ihre Organisation; vgl. Teil V). Bis in die alltäglichen Einzelheiten hinein hat daher die 'Sozialpolitik' (also eine Staatstätigkeit, die in die Gesellschaft nachträglich eingreift und deren 'soziale Frage' zu lösen versucht) den Charakter einer die Produzenten entmündigenden Überwachung, Kontrolle bzw. 'Fürsorge' (das spürt jeder Arbeiter, wenn er vor dem 'Vertrauensarzt', dem Sozialbürokraten hinter dem Schalter der AOK in der Schlange der Wartenden antritt, um seine Arbeitskraft möglichst schnell reparieren zu lassen). So sehr also einerseits die staatliche Sozialpolitik dem einzelnen Produzenten eine gewisse Sicherheit bei teilweisem oder vöiligem Verlust seiner Arbeitsfähigkeit bietet, so wenig hat die Sozialpolitik andrerseits mit einer bewußten und planvollen Vorsorge für die Erhaltung, Erneuerung und Erweiterung des gesellschaftlichen Arbeitsvermögens durch den Gesamtarbeiter, die assoziierten Produzenten selbst zu tun. Eine solche bewußte Vorsorge wird in der kommunistischen Gesellschaft von vornherein bloß ein Teil des gesamtgesellschaftlichen Produktionsprozesses sein; sie wird eine ö ffe $n t$ liche Aufgabe wie die übrige Lebenserhaltung der Gesellschaft und ihrer Glieder, nicht aber der Gegenstand der abstrakten bürokratischen Tätigkeit einer besonderen $\mathrm{p}$ o l i t i s c h e n Organisation sein. (178)

178 Vgl. Marx/Engels: KOMMUNiSTISCHES MANIFEST, Ende des M. Abschnitts, MEW Bd. 4, S. 482 ("Sind im Laufe der Entwicklung die Klassenunterschiede verschwunden und ist alle Produktion in den Händen der assoziierten Individuen konzentriert, so verliert die öffentliche Gewalt den politischen Charakter. Die politische Gewalt im eigentlichen Sinn ist die organisierte Gewalt einer Klasse zur Unterdrückung einer andern."). 
Elemente einer Zurücknahme der staatlichen Funktionen in die Gesellschaft sind 2.B. in der DDR bereits deutlich zu erkennen, obwohl dies dort vielfach durch den überlieferten Namen des Staates ('Staatliche Plankommission') verdeckt ist. Denn dieser Staat beansprucht die Entscheidung über a 11 e wesentlichen Fragen des gesamtgesellschaftlichen Reproduktionsprozesses. Für unseren Zusammenhang besonders interessant sind jene Bereiche dieses Prozesses, die im bürgerlichen Staat not:dürftig und unvollständig als Sozialpolitik am Rande der 'eigentlichen' Produktion besorgt werden Dazu gehört etwa die planmäßige Qualifikation der Arbeitskraft in Übereinstimmung mit der Entwicklung der gegenständlichen Produktionsbedingungen (die Erfolge der DDR auf diesem Gebiet, die keineswegs bloß Vorsprung, sondern qualitativ anders sind, brauchen nicht erläutert zu werden). Dazu gehör t auch die planmäßige Vorsorge für die Gesundheit des Gesamtarbeiters durch ein umfassendes Netz von Polikliniken und Ambulatorien, Beratungen, Vorbeugeuntersuchungen und Impfungen, aber auch durch die strenge Einhaltung der Unfallverhütungsvorschriften im Betrieb oder durch die Ermöglichung von Urlaubsreisen für alle Arbeiter (in der BRD kann bekanntlich nurein Bruchteil der Arbeiter im Urlaub auch wirklich verreisen); daß auch auf diesem Gebiet die DDR der BRD mit ihrem 'hohen Lebensstandard' überlegen ist, dafür lassen sich zahireiche statistische Angaben beiḅringen (179). Der Staat beansprucht hier, in dieser umfassenden Weise zu planen, und er hat auch die Macht dazu; insofern unterscheidet er sich grundsätzlich vom bürgerlichen Staat. Andrerseits ist er immer noch Staat, insofern nämlich, als diese gesamtgesellschaftliche Planung des Produktions- und Lebenserhaltungsprozesses den vereinzelten Produzenten noch weitgehend verselbständigt gegenübertritt. Das zeigt sich auch daran, daß die noch nicht wirklich assoziierten, sondern noch weitgehend einzelnen Produzenten mit individuellen materiellen Anreizen, wie bewußtlose Maschinenelemente durch Hebel, zu höherer Arbeitsleistung angetrieben werden. Wenn im Zusammenhang damit die Verfügung der Einzelbetriebe und 'VVBs über das Produkt der eigenen Mehrarbeit sogar soweit enweitert wird, daß sie damit auch ihren Produktionsmittelbestand ausbauen können, so liegt hier eine Möglichkeit zur Verselbständigung der Betriebe und damit der Schwächung der gesellschaftlichen Planung). Der Weg zum Aufbau des Kommunismus schließt aber die Revolutionierung des Bewußtseins der Produzenten, das Begreifen, aktive Beherrschen und Planen des gesellschaftlichen Produktionsprozesses durch die assoziierten Individuen ein. Erst dann kann der Staat seinen politischen Charakter verlieren und wirklich zur 'öffentlichen Gewalt' werden. Die Verwirklichung der kommunistischen Gesellschaft setzt die volle Entwicklung der gegen-

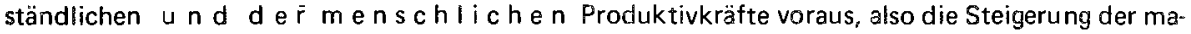
teriellen Produktivkraft ebenso wie die allseitige Entwicklung der Produktivkraft der gesellschaftlichen Individuen. Ja, die umfassende Weiterentwicklung der gegenständlichen Produktivkräfte erfordert gerade immer mehr ihre umfassende Beherrschung durch die assoziierten, selbstbewußten, voll entwickelten gesellschaftlichen Individuen; die größte Produktivkraft ist der Mensch selbst. Zu dieser umfassenden Beherrschung gehört auch die Seite des gesellschaftlichen Lebenserhaltungsprozesses, die das Kapital bei der Produktion von Mehrwert nicht interessiert und die von seiner Besonderung im Staat nur notdürftig und in den vom Kapital gesetzten Grenzen besorgt wird.

179 Nur einige Beispiele: 1968 gab es in der DDR auf je 10.000 Einwohner 6,9 Neuerkrankungen an Tbc (1950: 50,4), in der BRD 36,8. Im gleichen Jahr, also nur sieben Jahre nach der Schließung der Grenze nach Westdeutschland bzw. West-Berlin und damit dem Ende des Abwanderung von Ärten, lag die Zahl von Einwohnern pro Arzt in der DOR kaum noch unter der in der BRD (751 gegenüber 677); dabei ist zu berücksichtigen, daß in der BRD-Zahl eine große Zahl von Ärzten enthaiten ist, die sich als kosmetische, Kur-Modeärzte usw. vor allem mit der bequemen Versorgung der Bourgeoisie bzw. mit dem Ergattern eines Teils des Mehrwerts befassen. In den industriell teilweise 'unterentwickelten' Ländern des sozialistischen Lagers ist die ärztliche Versorgung wesnetlich besser als in Westeuropa. Daß die Zahl der Un:fälle am Arbeiţsplatz in der DDR wesentlich geringer ist als in der BRD (40\% der Fälle in der BRD), sagt einiges über die wirkliche Situation der Produzenten gegenüber den Produktionsmitteln aus: die dauernde Umgehung oder Nichtbeachtung der Vorschriften des Arbeiterschutzes' in westdeutschen Betrieben bestätigt immer noch die Marxschen Festscellungen im KAPITAL. Vgl. WO LEBT MAN BESSER? Lebensstandard in der DDR. Hrsg. Staatssekretariat für westdeutsche Fragen, Berlin-DDR $1970^{7}$, bes. S. 57 ; STATISTISCHES JAHRBUCH DER BRD 1969, S. 35; G. Tittel: DIE LEGENDE VON DER BONNER SOZIALSTAAT. LICHKEIT, Berlin-DDR 1967, S. 72 ff. 


\section{Zum Verhältnis von ökonomischem und politischem Kampf der Arbeiterklasse}

Im folgenden wollen wir einige Folgerungen darlegen, die sich für uns aufgrund der in $1-1 \mathrm{~V}$ entwickelten Uberlegungen ergaben, und die vor allem der Problematisierung einiger besonders verbreiteter Auffassungen über das Verhältnis von äkonomischem und politischem Kampf dienen sollen. Wenn dabei eine Seite besonders hervorgehoben wird, so liegt dies gerade an dieser Absicht der Problematisierung. Die Überlegungen haben insofern vorläufigen Charakter, als sie allein auf der Kritik der Sozialstaatsillusion basieren, während die Funktion des Staates für die Durchsetzung der expansiven Interessen des Kapitals, die imperialistische Politik des kapitalistischen Staates also, un. berïcksichtigt blieb. Da diese Staatsfunktion - wie sich in der !mperialismusauseinandersetzung in der deutschen Arbeiterbewegung vor, während und nach dem ersten Weltkrieg deutlich zeigt - eine wesentliche Rolle für das Verhältnis der Arbeiterklasse zum bürgerlichen Staat spielt, ble ibt die Frage offen, inwieweit die ausschließlich an der Sozialstaatsproblematik entwickelte Bestimmung des Verhältnisses Staat-Arbeiterklasse nicht wesentlich neue Gesichtspunkte durch die Hineinnahme der imperialistischen Staatsaufgaben erhalten würde. (180)

\section{Material istische Begründung der Staatsillusion}

Die Tendenz des Kapitals in seiner praktischen Bewegung zur Zerstörung der lebendigen Arbeitskraft, d.h. zur Zerstörung seiner selbst als Kapital durch die Zerstörung seiner Existenzgrundlage, wirkt der Kampf der Arbeiter um den Preis für den Verkauf ihrer Arbeitskraft und, dementsprechend, um den Normalarbeitstag, der die normale Erhaltung ihrer Arbeitskraft ermöglicht, entgegen. Die Klassenkämpfe der Arbeiter sind zunächst einmal Momente der Bewegung des Kapitals selbst und insofern auch seiner Existenzsicherung.

Klassenkämpfe können aiso dem Dilemma nicht entgehen, daß sie als Kämpfe der Arbeiterklasse um Erhaltung ihrer Arbeitskraft gleichzeitig "systemerhaltende Funktion" haben können. Dieses Moment der Klassenkämpíe können die Arbeiterklasse und ihre Organisationen nicht einfach voluntaristisch überspringen. Die Unterscheidung zwischen systemweitertreibenden und systemsprengenden Kämpfen der Arbeiterklasse ist auf dieser Ebene zunächst idealistisch. Ob ökonomische Auseinandersetzungen auf der Ebene subjektiver Forderungen systemerhaltenden oder systemsprengenden Charakter haben, das kann nur in dem Falf eindeutig entschieden werden, wenn wie bei der Konzertierten Aktion Gewerkschaften und Unternehmer sich von vornherein darüber einigen, auf welche Weise am besten der Profit zu sichern sei, wenn also die Organisationen der Arbeiterschaft nichts weiter anstreben, als die Venwertungsbedingungen des Kapitais zu sichern, das bedeutet, daß

180 Abgesehen von der Frage, wie sich der Imperialismus auf die Arbeiterklasse der kapitalisti. schen Länder auswirkt, ist im Zusammenhang der Frage nach dem Verhältnis zwischen ökonomischem und politischem Kampf für die Auswirkungen des Imperialismus auf die Völker der unterentwickelt gehaltenen Länder folgendes zu sagen: Auch die politischen Bewegungen in diesen Ländern beruhen auf den Bewagungen des Kapitals. Doch ergibt sich hier von vornherein ein anderes Verhältnis zwischen ökonomischem und politischem Kampí, als für die Arbeiterklasse der kapitalistischen Länder. Dies gilt vor allem für die Länder, die erst relativ kürzlich in den direkten Einflußbereich des Kapitals geraten sind, die also eine kaum gebrochene vorkapitalistische Tradition haben. Denn hier wird das Eindringen des Kapitals (wozu immer auch das Eindringen entsprechender Formen des Uberbaus gehört, z.B. die Erzeugung bürgerlicher Individuen in den Missionsschulen, die dann als 'zuveriässige', kalkulierfähige Agenten des Kapitals in der eigenen Umgebung wirken können) aufgefaßi als Angriff auf die alte Einheit dessen, was in der kapitalistischen Gesellschaft als Staat und Gesellschaft aus. einandergerissen ist, als Angriff auf die nationale Würde, die eigene Kultur, auf die Formen kollek tiver Lebenserhaltung usw. Daher beruht der antiimperialistische Kampf (der eben mehr ist als ein Kampf einer vom Kapital selbst erzeugten Klasse gegen die Klasse des Kapitaís) auf derAufnahme von Elementen dieser eigenen Geschichte, auf der 'nationalen Befreiung, des 'Volkes'. Diese Kämpfe sind daher von vornherein 'politischer', nämlich in dem Sinn, daß sie gar nicht auf der Trennung von Okonomie und Politik, kapitalistischer Produktion und besonderer Existenz des Staates beruhen. Dieser besondere Charakter politischer Kämpfe erlaubt es aber auch nicht, die in diesen Kämpfen gewonnenen Erfahrungen und die aus ihnen entwickelten Formen u $\mathrm{n}$ y e $\mathrm{r}$ m it $\mathrm{t}$ e I t auf die Gesellschaften zu übertragen, in denen das Verhältnis von Kapital und Lohnarbeiterklasse voll entwickelt ist. 
auch sie die Arbeitenden bloß als durch das Kapital angewendete Objekte behandeln. Doch selbst die Konzertierte Aktion ist Rest von institutionalisiertem Klassenkampf, dahinter droht der offene Kampf. Demgegenüber bewegen sich auch sogenannte 'ökonomistische' Forderungen, wie etwa: '15\% und kein Prozent weniger', auf der Ebene der von Marx bezeichneten Antinomie von Recht wider Recht, Recht der Lohnarbeit gegen Recht des Kapitals, die beide gleich durch die Gesetze des Warenaustauschs besiegelt sind. Diese Antinomie kann durch Gesetze nicht entschieden werden, sie bildet den Kern der Klassenkämpfe.

Der widersprüchliche Charakter der Klassenkämple - sie st a billis i er en möglicherweise vorübergehend die Verwertung des Kapitals - bringt in der Geschichte der Klassenkämpfe Veränderungen der Organisation der Arbeiterschaft selbst hervor. Da die Arbeiterklasse in ihren Kämpfen die Erfahrung macht, daß im Gefolge dieser Kämpfe de $r \mathrm{St}$ a a t sozialpolitische Funktionen übernimmt indem er dem Kapital Zwangsgesetze aufherrscht, also als 'besonderes Wesen' gegenüber dem Kapital in Erscheinung tritt, entsteht die IIlus ion der Klas se n neu trallität der Staatsgewalt und damit der bürgerliche Reformismus in der Arbeiterklasse und die revisionistische Theorfe. Das nachträgliche Zusammenfallen von Interessen des Kapitals und Interessen der Lohnarbeit (siehe Fabrikgesetzgebung), hergestellt durch staatliche Zwangsgesetze, und zwar entgegen der 'praktischen Bewegung des Kapitals', aber doch seine Existenz sichernd, bildet die Basis der Illusion von der möglichen Versöhnung der Klassengegensätze, von der allmählichen Transformation der Gesellschaft durch das Subjekt Staat.

Andererseits haben sich die Kapitalisten und der bürgerliche Staat, eben aufgrund ihrer in sich widersprüchlichen Interessen, auch dazu bereitgefunden, die Organisationen der Arbeiterklasse anzuerkennen und die Schlichtung der Antinomie zwischen Lohnarbeit und Kapital auf der Verhandlungsebene $z u$ versuchen. Die Bereitschaft dazu ist vor allem aufgrund der Erfahrung des Kapitals und seines Staats entstanden, daß die Bewegungsgesetze des Kapitals die Arbeiterklasse als Wider. spruch im Schoße der eigenen Gesellschaft erzeugen, und daß dieser Widerspruch, eben weil er durch die kapitalistische Produktion entsteht, nicht politisch, nicht terroristisch, auf die Dauer aufgehoben, sondern eben nur durch Institutionalisierung kontrolliert werden kann - in gewissen Grenzen, was sich besonders deutlich an der Entwicklung der Organisationen der Arbeiterklasse in der BRD zeigt.

Indem aber die Kapitalisten und der bürgerliche Staat zur Anerkennung der Organisation der Lohnarbeit als Verhandlungspartner neigen - für sie der einfachste Weg der politischen Konfliktregulierung - sind die Organisationen der Arbeiterklasse wiederum dazu veranlaßt, im Staat ein neutrales, ihnen nicht feindliches, sondern am Allgemeinwohl interessiertes Subjekt und zugleich Instrument zur weitgehenden Durchsetzung der Tagesforderungen der Arbeiterklasse zu sehen. Das revolutionäre Ziel muß dann allerdings zunächst zurückgestellt werden, was nur die Vorwegnahme seiner endgültigen Aufgabe ist (181). Sobald die Sozialdemokratie Sozialreform als Ziel ihrer Politik begreift, fixiert sie sich und die Arbeiterschaft notwendigerweise auch an das bestehende Staatswesen und an den Kapitalismus, da ja wie gesagt Sozialreformen nur durch den kapitalistischen Staat durchgeführt werden können. Damit ist auch das in den 'Versorgungsstaatstheorien' auf den Begriff gebrachte passive Verhältnis zwischen Bürger und Staat, die 'Konsumentenhaltung' im Kern schon in der frühen revisionistischen Theorie angelegt. Mit der revolutionären Zielsetzung, dem Ziel des Sturzes der alten Ordnung und der politischen Machtergreifung des Proletariats, wird auch der selbsttätige politische Kampf als Voraussetzung der Änderung der Lebensverhält́nisse aufgegeben. Ist das Ziel soziale Besserstellung, größere Gerechtigkeit in der Verteilung, Sozialreform, so kann dies auch stellvertretend von den Organisationen der Arbeiterschaft, von Gewerkschaften und politischer Partei wahrgenommen werden. Der Weg ist vorgeschrieben als der Weg der Zusammenarbeit der Klassen durch Zusammenarbeit ihrer gesellschaftlichen und politischen Organisationen. $j a$, es gibt gar keinen anderen Weg, da man ja die Hoffnung hat, den Kapitalisten und dem bürgerlichen Staat mit ihrem eigenen Einverständnis etwas von ihrer Macht und ihrem Reichtum abzuzwacken und an die arbeitende Klasse zu verteilen.

181 R. Luxemburg; “Sozialreform...", a.a.O., S. 114 f; vgl. oben Anfang von Teil I. 


\section{Politischer und äkonomischer Kampf}

Die Fabrikgesetzgebung war Ergebnis langwieriger Klassenkämpfe. Bei der Darstellung der Fabrikgesetzgebung trifft Marx keine Unterscheidung in der Weise, daß er nur solche Kämpfe als Klassenkämpfe bezeichnet, die unmittelbar die Staatsgewait zum Adressaten der Forderungen des Proletariats haben. Als Klassenkampf erscheint hier vielmehr zunächst der g e m e i n s a m e Kampf der Arbeiter gegen die Gewalttätigkeiten des Kapitals, in der sich die Forderung nach staatlicher, d.h. aligemeiner und durch Sanktionen verbindlich gemachter Beschränkung des Arbeitstags durch den Staat im Verlauf der Kämpfe selbst entwickelt.

Die Allgemeinheit der Forderung entspringt wiederum der Erfahrung des Proletariats, daß, wenn das Kapital nur an einer Stelle beschränkt wird, es sich an einer anderen doch wieder schadlos hält. Auch kann nicht behauptet werden, daß Marx hier nur ais Klassenkampf bezeichnet, was von einer bewußten politischen Organisation des Proletariats getragen ist. Die Fabrikgesetzgebung (Zehnstundentag) kam zu einer Zeit zustande, als die Chartistenbewegung zerschlagen und dennoch nach den Berichten der Fabrikinspektoren der "Klassenantagonismus zu einer unglaublichen Höhe gespannt" war. Es ist demnach ganz klar: Marx geht hier auf keinen Fall so weit zu behaupten, Klassenkampf finde nur dort statt, wo das Proletariat unter der Führung einer bewußten politischen Organisation steht. Vielmehr sind die Organisationen des Proletariats selbst wesentlich Ergebnis der Kämpfe, die sich aus dem antagonistischen Verhältnis von Lohnarbeit und Kapital im Kapitalverwertungsprozeß entwickeln.

In einem Brief an Bolte 1871 schreibt Marx noch einmal zusammenfassend zu dieser Frage: "Das political movement (die politische Bewegung) der Arbeiterklasse hat natürlich zum Endzweck die Eroberung der political power (politischen Macht) für sie, und dazu ist natürlich eine bis zu einem gewissen Punkt entwickelte previous organisation der working class (vorher vorhandene Organisation der Arbeiterklasse) nötig, die aus ihren ökonomischen Kämpfen selbst erwächst.

Andererseits ist aber jede Bewegung worin, die Arbeiterklasse als Klasse den herrschenden Klassen gegenübertritt und sie durch pressure from without (Druck von außen) zu zwingen sucht, ein political movement. Z.B. der Versuch, in einer einzelnen Fabrik oder auch in einem einzelnen Gewerk durch strikes etc. von den einzelnen Kapitalisten eine Beschränkung der Arbeitszeit zu erzwingen, ist eine rein ökonomische Bewegung; dagegen die Bewegung, ein Achtstunden-etc. G e se tz zu erzwingen, ist eine $\mathrm{p} \circ \mathrm{li} \mathrm{t}$ is $\mathrm{ch}$ e Bewegung. Und in dieser Weise wächst überall aus den vereinzelten ökonomischen Bewegungen der Arbeiter eine $\mathrm{p}$ o li t is ch e Bewegung hervor, d.h. eine Bewegung der $\mathrm{K} I$ a s s e, um ihre Interessen durchzusetzen in allgemeiner Form, in einer Form, die allgemeine gesellschaftlich zwingende Kraft besitzt. Wenn diese Bewegungen eine gewisse previous Organisation unterstellen, sind sie ihrerseits ebenso sehr Mittel der Entwicklung dieser Organisation...

Wo die Arbeiterklasse noch nicht weit genug in ihrer Organisation fortgeschritten ist, um gegen die Kollektivgewalt, i.e. die politische Gewalt, der herrschenden Klassen einen entscheidenden Feldzug (zu) unternehmen, muß sie jedenfalls dazu geschult werden durch fortwährende Agitation gegen die (und feindselige Haltung zur) Politik der herrschenden Klassen. ..." (182)

Um die Marxsche Auffassung noch einmal zusammenzufassen: Die politische Bewegung der Arbeiterklasse wächst aus ihren ökonomischen Bewegungen hervor: ihre politische Organisation als Klasse, die nicht mehr nur gegen den einzelnen Unternehmer, sondern gegen die Kapitalistenklasse gerichtet ist, wird nicht einfach von außen an sie herangetragen, sondern entsteht im Zusammenhang der ökonomischen und politischen Kämpfe. Die politischen Organisationen der Klasse haben dann allerdings die Aufgabe, die Kämpfe der Arbeiter weiterzutreiben, indem sie das Proletariat dahingehend schulen, daß der Gegner nicht allein der einzeine Unternehmer, sondern die Klasse der Kapitalisten und der Klassenstaat sind, damit gleichzeitig das Bewußtsein der Zusammengehörigkeit des Proletariats als Klasse über den einzelnen Betrieb hinaus erzeugen.

Verfolgt man: nun in der Geschichte der Arbeiterbewegung die Funktionen, die der von Marx hier als politisch bezoichnete Kampf hat - Kämpfe um die Erzwingung allgemeiner Gesetze durch den Staat, wobei der Staat Adressat der Forderungen des Proletariats ist - so ist es nicht mehr mög. lich, eine einfache Unterscheidung zwischen ökonomischem und politischem Kampf in der Weise

182 Marx: "Brief an Bolte", 23.11.1871, MEW 33, S. $332 \mathrm{f}$. 
zu treffen, daß ökonomischer Kampf ausschließlich ökonomischer Kampf ist und immer in der Gefahr schwebt, den Opprotunismus aus sich zu entlassen, während politischer Kampf als Auseinandersetzung mit dem Staat als auf den Staat gerichtet begriffen wird und als revolutionärer Kampf bestimmt werden kann. Es zeigen sich vielmehr auch gegenteilige Tendenzen: da B nä m lich die Ausrichtung der Kämpfe auf den Staat auch die Basis der Staatsillusion inderGeschichteder Arbeiterbewegung sein kann, die Basis derlllusion, derpolitische Staatkönnedurch Zwangsgesetzedie Macht des Kapitals brechen. Die Eroberung der politischen Macht als Endzweck der Bewegung ergibt sich nicht kontinuierlich und ungebrochen aus dem politischen Kampf der Arbeiterklasse um die Durchsetzung allgemeiner Gesetze zu ihrem Schutz vor den Gewalttätigkeiten des Kapitals. Dieser Kampf kann vielmehr, wie die ganze Geschichte des Revisionismus zeigt, die Diktatur des Proletariats und die Zerschlagung des bürgerlichen Staates als Ziel aus dem Auge geraten lassen.

Nun ist wohl auch der oben zitierte Brief an Bolte nicht so zu verstehen, daß nur der Kampf, der den Staat unmittelbar ins Auge faßt, als politischer Kampf zu werten sei. Die Fabrikgesetzgebung wird hier nur als Beispiel genannt für eine Form des Kampfes, in der das Proletariat als Klasse den herrschenden Klassen gegenübertritt. Dagegen ist in der gegenwärtigen Diskussion innerhalb der Linken die Vorstellung typisch: "Klassenkampf war nach Marx und Lenin politischer Kampf gegen das als Klasse organisierte und vom Staat unterstützte Kapital, Kampf gegen die Staatsmacht." (183) Dabei ist die in diesem Zusammenhang erfolgende Berufung auf die Marxsche Unterscheidung zwischen politischem und ökonomischem Kampf irreführend. Und auf die Darstellung im Kapital kann sich eine solche These erst recht nicht stützen. Dort wird nämlich (was durchaus zu kritisieren ist) ein gewissermaßen naturwüchsiger Prozeß der Konstituierung des Proletariats als Klasse aus den Mechanismen der kapitalistischen Produktionsweise behauptet: "Mit der beständig ab. nehmenden Zahl der Kapitalmagnaten, weiche alle Vorteile dieses Umwandlungsprozesses usurpieren und monopolisieren, wächst die Masse des Elends, des Drucks, der Knechtschaft, der Entartung. der Ausbeutung, aber auch Empörung, der stets anschwellenden und durch de $\mathrm{n} \mathrm{Mecha-}$ nismusdeskapitalistischen Produktionsprozessesselbstgeschul. ten und organisierten Arbeiterklasse." (184)

Sieht Marx also auf der einen Seite nicht, und konnte es damals wohl nicht sehen, daß der Kampf der Arbeiterklasse um rein negative Schutzeingriffe des Steates wesentliche Quelle der bürgerlichreformistischen Strategien und theoretischer Vorstellungen für die Organisation der Arbeiterklasse ist, so erscheint auf der anderen Seite die Vorstellung von der quasi automatischen Konstituierung der Arbeiterklasse als historisch handelndem Subjekt als mechanistisch. Dies wird gegenwärtig vor allem an der Entwicklung in den USA deutlich. Möglicherweise hängen beide Fehleinschätzungen in der Weise miteinander zusammen, daß Marx durchaus richtig die Notwendigkeit der Entstehung einer Organisation der Arbeiterklasse aus ihren ökonomischen Kämpfen einschätzte, andererseits aber die Gefahr der reformistischen Versumpfung solcher Organisationen damals nicht vorauszusehen vermochte. Daß die Arbeiterklasse als Bedingung ihrer Existenz notwendigerweise sich gegen die allgemeinen und tagtäglichen Übergriffe des Kapitals zur Wehr setzen muß, und daß dieser Kampf Organisationen hervorbringt, ist eine historische Tatsache. Daß in diesen Kämpfen die Ar. beiterklasse aber den Kapitalismus immer wieder in seiner Existenz sichert, wenn auch langfristig in seiner Widersprüchlichkeit weitertreibt, trägt zur Deformation der Organisationen des Proletariats bei, die sich nicht ohne weiteres einfach (wie Rosa Luxemburg noch annahm) durch neue spontane Kämpfe des Proletariats, die es entgegen den Absichten seiner Organisationen führt, um. lenken lassen. Dies gilt sowohl für die auf den ökonomischen Kampf sich beschränkenden, als auch für die politischen Organisationen. Sie bilden eine $r$ e ale F e s s e ! für das Proletariat und können auch zeitweise, indem sie einzelne Forderungen der Lohnabhängigen noch zur Geltung bringen, deren selbsttätigen und solidarischen Kampf gegen das Kapital niederhalten. Andererseits können sie eine solche Fessel nur dadurch sein, daß sie diese Forderungen teilweise durchsetzen und ver-

183 ROTE PRESSE KORRESPONDENZ, Nr. 48 1970. S. 2. Der Brief an Bolte. der hier als Be weismittel für diese These herangezogen wird, wird dabei in bezeichnender Verküzung zi tiert.

184 KAPITAL, Bd. I, S. $803 / 790 \mathrm{f}$. 
treten - das gilt selbst für die faschistische Deutsche Arbeitsfront (DAF). (185) Und ohne teilweise Zugeständnisse der Kapitalisten können sie diese Aufgabe der Befriedung nicht erfüllen; solche Zugeständnisse sind aber keineswegs vom guten Willen der Kapitalágenten abhängig.

Demgegenüber ist die Forderung, einer heruntergekommenen politischen Organisation eine neue revolutionäre Organisation einfach entgegenzusetzen, ohne daß diese selbst wieder ihre Begründung in den notwendigen Kämpfen des Proletariats findet, voluntaristisch. Die Auseinandersetzungen zwischen Lohnarbeit und Kapital sind die Basis für die Begründung wirksamer, d.h. im Proletariat verankerter politischer Organisationen.

\section{Abnehmende Rolle des Staates beim Kampf zwischen Arbeit und Kapital}

Marx ging davon aus, daß die staatlichen Eingriffe zum Schutz der Ware Arbeitskraft wesentlichen Anteil an der Ausbildung des Kapitals zur voll e $\mathrm{n}$ Reife haben. Die Fabrikgesetzgebung wirkt in der Richtung der Konzentration des Kapitals und zerstört die altertümlichen sowie die kleinbürgerlichen Formen der Produktion. "Sie verallgemeinert damit auch den direkten Kampf gegen diese Herrschaft. Während sie in den individuellen Werkstätten Gleichförmigkeit, Regelmäßigkeit, Ordnung der Ökonomie erzwingt, ve $r \mathrm{~m}$ e h $\mathrm{r} t \mathrm{~s}$ i e durch den ungeheuren Sporn, den Schranke und Regel des Arbeitstags der Technik aufdrücken, dit An a rchie und $K$ at astrophen der kapitalistischen Produktion imgroßen und ganzen, die intensi$t$ ät der Arbeit und die Konkurrenz der Maschineriemit dem Ar. beiter." (186)

Das bedeutet zum einen, daß im entwickelten Kapitalismus der Kampf der Lohnarbeit gegen das einzelne Kapital, das jetzt in der Tat große Teile der nationalen oder auch internationalen Produk. tion in der Hand hat, nicht einfach bloß mehr ökonomischer Kampf im alten Sinn ist, sondern hier treten sich in der Tat die Arbeiterklasse als Klasse und das Kapital als herrschende Klasse gegenüber. Die Verallgemeinerung des Kampfes, seine Qualität als polit is cher Klassenkampf, ist nicht mehr daran gebunden, daß diese Allgemeinheit über den Staat als Gegner oder auch Adressat vermittelt werden muß. Ein Streik in einem Großkonzern oder einer Branche setzt heutzutage in der Tat das Kapital politisch unter Druck, schon allein durch seine Bedeutung für die Reproduktion des Gesamtkapitals. Bei der Verflechtung der Produktion und ihrer Zentralisation betrifft er große Teile des Kapitals überhaupt.

Aber noch ein anderes Moment ist hier von Bedeutung. Die generellen Regelungen der Arbeitszeit, so sehr sie auch heute noch vom Kapital immer wieder durchbrochen werden. (187) Vor allem in

185 Tim Mason, "Der Primat der Politik", in: ARGUMENT, Heft 41, S. 485 f. "Es war für das nationalsozialistische System, mindestens bis weit in den Krieg hinein, eine unabdigbare Notwendigkeit, der positiven Anteilnahme der Masse der Bevölkerung an seiner Weltanschauung und an allen seinen Maßnahmen sicher zu sein; der Versuch, die Arbeiterschaft durch Propaganda, Verbesserung der betrieblichen Sozialeinrichtungen, $\mathrm{KdF}$ usw. soweit zu bringen, war nachweislich gescheitert - also mußte ihre Zustimmung zum System durch hohe Löhne, bezahlte Feiertage usw. erkauft werden... Der Deutschen Arbeitsfront war die Aufgabe gestellt worden, die Arbeiterschaft für den Nationalsozialismus zu gewinnen - nichts, selbst nicht das ungestörte Funktionieren der Rüstungswirtschaft, durfte der Erfüllung dieser Aufgabe zuwiderlaufen, auch wenn sich die DAF in verkappter Form, aber nach 1936 in zunehmendem Maße als wirtschaftliche Interessenvertretung der Arbeiterklasse betätigte."

186 KAPITAL, Bd. I, S. 528/526. Keine Hervorhebung im Original.

187 Schon die zyklischen Schwankungen in der Bewegung des Kapitals verhindern die Durchsetzung eines generell und genau begrenzten Arbeitstags. Wochenarbeitszeiten bis zu 60 Stunden in der Hochkonjunktur und von 30 Stunden in der Krise (infolge von Kurzarbeit) sind auch heute keine Ausnahme. Hier zeigt sich wieder, daß auch generelle staatliche Gesetze, 'Eingriffe in die Produktion' nicht soweit gehen dürfen, daß sie die naturwüchsigen Bewegungen des Kapitals und die damit verbundene spezifische Anwendung der Arbeitskraft stören. Da der Kapitalist außer den Lohnzuschlägen für Uberstunden Zwangsmittel aller Art in der Hand hat, um Verlängerung des Arbeitstags durchzusetzen, bedeuten 'Errungenschaften' wie die 40-Stundenwoche in der Hochkonjunktur für die Lohnabhängigen nicht viel mehr als eine Lohnerhöhung. 
der Hochkonjunktur, boten sich ihrer inhaltichen Natur nach als a 1 Ig e m e in e Forderung der Arbeiterklasse an, und zwar als Forderung, die der bürgerliche Staat in der Form allgemeiner Gesetze erfüllen konnte. Der Achtstundentag hat nichts mit der besonderen Natur der Produktionsmittel und der Organisation des Produktionsprozesses im einzelnen Unternehmen zu tun. Er ist als allgemeines Gesetz durchsetzbar. Diese allgemeine Beschränkung der absoluten Mehrwerterzeugung durch den Staat lenkt nun den Appetit des Kapitals auf die Produktion des relativen Mehrwerts, die Steigerung der Arbeitsproduktivität durch Veränderungen in der technischen Struk tur der Produktionsmittel und der organisatorischen Struktur des Betriebes, sowie der "Ausfüllung aller Poren des Arbeitstages" durch Intensivierung der Arbeit. "Sobald die Verkürzung des Arbeitstages, welche zunächst die subjektive Bedingung der Kondensation der Arbeit schafft, nämlich die Fähigkeit des Arbeiters, mehr Kraft in gegebener Zeit flüssig zu machen, zwangsgesetzlich wird, wird die Maschine in der Hand des Kapitals zum objektiven und systematisch angewandten Mittel, mehr Arbeit in derselben Zeit zu erpressen. Es geschieht dies in doppelter Weise: durch e $r h$ ö h te $G e$ sch windigkeit der Maschinen und erweiterten Umfang dervon demselben Arbeiter zu überwachenden Maschinerie oder seines Arbeitsfeldes. Verbesserte Konstruktion der Maschinerie ist teils notwendig zur Ausübung des größeren Drucks auf den Arbeiter, teils begleitet sie von seibst die Intensifikation der Arbeit, weil die Schranke des Arbeitstages den Kapita. listen zu strengstem Haushalt der Produktionskosten zwingt." (188)

Mit der Verlagerung von der Form der absoluten auf die Form der relativen Auspressung des Mehrwerts verändern sich auch notwendigerweise die Formen, in denen sich der Konflikt zwischen Lohnarbeit und Kapital primär abspielt, in denen das Kapital die lebendige Arbeit als bloßes Ob. jekt anwendet und die normale Erhaltung der Arbeitskraft in Frage stellt. Intensifikation der Arbeit und absolute Unterordnung des Arbeiters unter die Maschinerie, seine Degradierung zum bloßer: Anhängsel der Maschine, sind die Formen, in denen unter den Bedingungen des entwickelten Kapitalismus primär die Übergriffe des Kapitals erfolgen. Schutz gegen diese Übergriffe können die Lohnarbeiter nicht mehr von einem allgemeinen Gesetz, das dem Kapital vom Staat aufgeherrscht wird, erwarten. Macht die Arbeiterklasse doch schon auf dem Gebiet der Regelung der Arbeitszeit die Erfahrung, daß die von den Gewerkschaften erkämpften Einschränkungen in allgemeiner Form (40-Stundenwoche) vom Einzelkapital je nach den schwankenden Bedürfnissen des Kapitalverwertungsprozesses immer wieder umgangen oder durchbrochen werden, was in ähnlicher Weise auch für andere allgemeine Staatsgesetze, wie Achtstundentat, Mutterschutz, Jugendschutz usw. gilt. (189) Aufgrund solcher Erfahrungen muß den Arbeitern auch die Beschränkung der gewerkschaftlichen Schutzforderungen auf Arbeitszeitverkürzung und Urlaubserhöhung, so wichtig diese nach wie vor sind, als ungenügend erscheinen, da sie die für die Lohnarbeiter um schärfsten spürbaren u $n \mathrm{~m}$ i t $t$ e $\mathrm{l}$ b a re $n$ Übergriffe des Kapitals nicht verhindern können, ja z.T. direkter Anlaß zu weiteren Verschärfungen des Arbeitstempos sind. (190)

188 KAPITAL, Bd. I, S. $432 / 434$.

189 Das System von Sanktionen und Belohnungen, das dem Kapitalisten gegenüber dem Arbeiter zur Verfügung steht, um diese zur Leistung von Uberstunden zu bringen, führt zusammen mit der Tatsache, daß auch heute der tarifliche Lohn zusammen mit der tariflichen Arbeitszeit nur einen sehr knappen Unterhalt ermöglicht, dazu, daß die Kapitalisten immer wieder auf die Bereitwilligkeit der Arbeiter zu Überstunden hinweisen können.

190 Die richtige Forderung nach Verkürzung der Arbeitszeit wird heute von den Gewerkschaften völlig affirmativ begründet. Auf den IG-Metalltagungen wird sie dem Kapital schmackhaft zu machen versucht, indem die Gewerkschaften einen idealen Zusammenhang zwischen Arbeitszeitverkürzung, hohen Löhnen und technischem Fortschritt herstellen. So etwa Otto Brenner in: AUTOMATION UND TECHNISCHER FORTSCHRITT IN DEUTSCHLAND UND DEN USA, Frankfurt/Main 1963, S. 313: "Die Unternehmer und auch Wirtschaftsminister Schiller sollten uns dankbar sein, daß die gewerkschaftliche Lohn- und Arbeitszeitpolitik ihnen steigende Umsäıze und eine wachsende Wirtschaft sichert."

Desgleichen der Gewerkschaftsideologe Theodor Prager: WIRTSCHAFTSWUNDER ODER KEINES, Wien/Köln/Stuttgart/Zürich 1963, S. 100. "Also je höher das Lohnniveau, umso höher der Grad der Mechanisierung und der Produktivität... Vollbeschäftigung, Erhöhung der Produktivität und Steigerung der Löhne sind untrennbar miteinander verbunden! Eine Steigerung der Produktivität ist auf die Dauer nur dort durchzuführen, wo der Arbeiter als 
Den sachlichen und organisatorischen Veränderungen der Gestalt des Produktionsprozesses und der Intensivierung der Arbeit als wichtigste primäre Formen, in denen sich das Kapital die Arbeit unterwirft, läßt sich nicht durch generelle Bestimmungen begegnen - es sei denn, man stelle sich ein ganz ungeheures Gesetzeswerk vor, das solche Einschränkungen in tausenden von Paragraphen und Bestimmungen beschreiben müßte, das aber trotzdem schon im Augenblick seiner Fertigstellung überholt sein würde und neue Lücken hätte, die sogleich vom Kapital ausgenützt werden könnten. Hinzu käme dį̧ Notwendigkeit einer ebenso ungeheuren Bürokratie, die die Einhaltung der Bestimmungen an jedem Arbeitsplatz überwachen müßte. (Abgesehen von der Form der Ausbeutung, die eine absolute Grenze gegen allgemeine regulierende Staatseingriffe setzt, ist diese Grenze auch inhaltlich gegeben. Denn wohin soll sich der Appetit des Kapitals noch wenden, wenn ihm nach der Begrenzung des Arbeitstags auch noch die Produktion des relativen Mehrwerts begrenzt würde?) Die Form der Kontrolle, die dieser Form der Ausbeutung entgegenzusetzen wäre, läßt sich auf jeden Fall nur noch vorstellen als direkte Kontrolle der Produzenten über den Produk tionsprozeß, womit sie sich als Kontrolle einer dem gesellschaftlichen Produktionsprozeß äußerlichen Gewalt selbst aufheben würde.

Wir können, was mit diesem veränderten Verhältnis der Produzenten zu den Produktionsmittein gemeint ist, vermutlich am ehesten klarmachen, wenn wir das Verhältnis der Gebrauchswertstruk. tur, der technischen Seite des Arbeitsprozesses, zur Gebrauchswertstruktur, zur besonderen Qualifikation der Arbeitskraft betrachten. Ein rationelles Verhältnis zu den vergegenständlichten Arbeitsmitteln könnten die Produzenten in der kommunistischen Gesellschaft nur in der Weise herstellen, daß sie selbst $\vee$ o $n \vee$ o $n$ here in die technische Struktur des Arbeitsprozesses unter dem Blickwinkel ih re r Fähigkeiten und Möglichkeiten und deren Entwicklung sowie ihrer konkreten Bedürf́nisse gestalten. Beispieisweise würden die Produzenten im Rahmen eines Betriebes oder eines ganzen Produktionszweiges zusammen mit den Spezialisten die Verbesserung eines bestimmten Produktionsprozesses oder überhaupt eine Neufassung in gemeinsamer Arbeit planen und zuwegebringen. (191) Vo $\mathrm{n}$ vornhere in wird dann das Maschinensystem eben nicht die lebendige Arbeit bloß noch als Lückenbüßer anwenden, sondern die Produzenten organisieren planmäßig die Kooperation, das Zusammenwirken der gegenständlichen und der lebendigen Seite des Arbeitsprozesses.

ihr Träger durch Lohnerhöhungen an ihr interessiert wird. Gleichzeitig wirkt die Lohnerhöhung als der Stachel, der die Unternehmer zum technischen und organisatorischen Fortschritt zwingt. Niedrige Löhne sind gleichbedeutend mit einem Stocken des technischen Fortschritts. S. 101 "Gleichzeitig gilt aber nach wie vor, daß die Produktivität ihren Vorsprung gegenüber den Löhnen beibehalten und sich rascher entfalten konnte, als diese." Hier wird weder gesehen, daf3 Verkürzung der Arbeitszeit die Unterwerfung des Arbeiters unter die Maschinerie verschärft, den Kapitalisten zu Erhöhung der Intensität der Arbeit des Arbeiters zwingt, wie sie andererseits selbst schon als Notwendigkeit aus der Intensivierung der Arbeit entspringt (vgl. dazu KAPITAL I, 438/440). Noch ist auch nur die Spur einer Vorstellung davon vorhanden, daß die mit der Erhöhung der Produktivität der Arbeit steigende organische Zusammensetzung des Kapitals den tendenziellen Fall der Profitrate bedeutet und damit eine Basis der Krisen und Katastrophen der kapitalistischen Gesellschaft ist. So erscheint dann ein ideales Zusammenfallen von Interessen der Lohnarbeit und des Kapitals gegeben. Forderungen gegen die Intensivierung der Arbeit und ihre Unterwerfung unter die Maschinerie werden nicht mehr erhoben. Zu fragen ist, ob dieses Terrain der Ausbeutung von den Gewerkschaften dem Kapital deshalb nicht bestritten wird, weil die Gewerkschaften als zentralisierte und bürokratisch organisierte lnstitutionen unfähig sind, an spezifische Ar. beitsprozesse im Betrieb gebundene Ausbeutungsformen überhaupt noch wahrzunehmen.

191 Aufgabe eines dieser Spezialisten wäre z.B., die langfristigen Auswirkungen bestimmter Arbeitsvorgänge auf die Gesundheit und das Wohlbefinden der Arbeiter zu erforschen, bzw. entsprechende Anderungen schon bei der Konstruktion des technischen Apparates vorzuschlagen. Eben diese Tätigkeit wurde von einem Mediziner, der Teilnehmer am Professorenkolleg im DDR-Fernsehen im März 1970 (1. Programm) war, im einzelnen vorgetragen. Selbstverständlich erfordert eine derartige Entwicklung der Produktivkraft der menschlichen Arbeit, da $\beta$ die Produktion im Rahmen eines gesellschaftlichen Gesamtplans weiterentwickelt wird, und nicht, wie im Kapitalismus aufgrund der zyklischen Bewegungen des Kapitals und der zutälligen Bewegungen der Konkurrenz. 
Das Zurücknehmen der Funktionen des Staates in die Gesellschaft wird offenbar vom Produktionsprozeß her notwendig. Der Staat als abgehobene Institution, die durch allgemeine Gesetze einen gewissen Schutz der Arbeitskraft herbeiführen kann, wird zunehmend untauglich, da der Arbeitsprozeß selbst sich allgemeinen Regelungen immer mehr entzieht. Durch diese Entwicklung der Produktion und des stofflichen Charakters der Produktionsmittel und der Arbeitskraft, durch die Methoden, die von da her dem Kapital zur übermäßigen Aussaugung von Mehrarbeit einfallen und an die Hand gegeben sind, fällt also wenigstens in dieser Hinsicht zunehmend die Basis hinweg, auf der der Staat sich als illusorische Gemeinschaft der Gesamtgesellschaft konstituieren konnte und damit zur Fessel des Klassenbewußtseins wurde.

Dabei ist natürlich die Frage zu stellen, ob es gerechtfertigt ist, hier von einer besonderen Form der Ausbeutung zu sprechen, die erst für die gegenwärtigen und zukünftigen Klassenkämpfe von Relevanz sein wird. Schließlich begleitet die Produktion des relativen Mehrwerts die ganze Geschichte des Kapitalismus; sie ist als Entwicklung der Produktivkräfte sein wesentliches Merkmal, unvergleichlich wichtiger wenigstens, als die Produktion des absoluten Mehrwerts. Dazu ist zu sagen, daß es sich in diesem Zusammenhang nur um den Versuch der Darstellung einer historischen Tendenz handeln kann, und als solche verweist sie in der Tat die Lohnarbeiter in zunehmendem Maße auf die Notwendigkeit der Kontrolle der Produktion durch die Produzenten. Zum zweiten wäre zu untersuchen, inwieweit nicht in der Tat von Phasen in der konkreten historischen Entwicklung des Kapitalismus gesprochen werden kann, in denen es unter dem Druck sich verschärfender Konkurrenz (heute auf dem Weltmarkt), der nichts als der Ausdruck sich verschärfender Verwertungsschwierigkeiten des Kapitals ist, in besonderem Maße auf die Erhöhung des relativen Mehrwerts verwiesen wird. So erfolgt das vehemente Vorantreiben der 'Rationalisierung' der Produktion der BRD ganz deutlich seit der Krise 1967, einer Rationalisierung, die neben der technischen Entwicklung der Produktionsmittel vor allem in die Richtung der Intensivierung der Arbeit geht. (Entlassungen von "überflüssigen" Arbeitskräften; strenges Durchkalkulieren der Organisationsstruktur des Betriebes und der Struktur der Arbeitsplätze nach Möglichkeiten der Arbeitsersparnis, was noch verbliebene Freiräume der Arbeitsgestaltung und der Arbeitszeitgestaltung durch den einzelnen Lohnabhängigen einschränkt - dies gilt besonders für die Angesteliten; die Büroarbeit, aber auch für die Facharbeiter -, Akkorderhöhungen; Arbeitsplatzbewertungsverfahren; MTM-System usw.). Der umfassende und tiefgreifende Charakter dieser 'Rationalisierungskampagne' läßt sich eigentlich nur mit der Phase zwischen 1924 und 1929 vergleichen, in der die Gewerkschaften ebenso euphorisch vom technischen Fortschritt des Kapitalismus als gleichzeitigem Fortschritt für die Möglichkeit der Verbesserung der Lage der Arbeiterklasse schwärmten, wie dies heute Prager und Brenner tun. (192)

Jedenfalls ist festzuhalten, daß die Produktion des relativen Mehrwerts nicht kontinuierlich gesteigert wird und auch nicht einen kontinuierlich steigenden Druck auf die Lohnarbeit ausübt, sondern daß hier Phasen verstärkten Drucks auf die Arbeiterklasse zu beobachten sind, die nicht zufällig mit wachsenden Verwertungsschwierigkeiten des Kapitals zusammenfallen, und daß das Kapital sich gegenwärtig in einer solchen Phase befindet. Zum dritten ist hier wichtig, daß anhand dieser Entwicklungen die Arbeiter auf die selbsttätige Wahrnehmung ihrer Interessen venwiesen werden, und daß hier ein wesentlicher Grund für den Verlust des Einflusses der bürokratisch organisierten und auf integration ins kapitalistische System bedachten Gewerkschaften liegt. Dies zeigen sowohl die Anlässe zu wilden Streiks in den USA, die primär sich gegen Intensifikation der Arbeit und totale Unterordnung unter die Maschinerie richten (193), als auch die wilden Streiks in Schweden, deren Kernpunkt neue Akkordfestsetzungen zusammen mit schikanierenden Antreibermethoden waren, das zeigten die großen Streikbewegungen bei Fiat und Pirelli in Italien (bei Fiat z.B. war die Auspowerung der Arbeiter durch Bandgeschwindigkeiten und Antreiberei soweit fortgeschritten, daß viele Arbeiter einige Tage im Monat krankfeiern mußten, um überhaupt wei-

192 Vgl. Anm. 190. Zur Rationalisierung nach 1924, vgl.: Otto Bauer: KAPITALISMUS UND SOZIALISMUS NACH DEM WELTKRIEG, 1. Bd. Rationalisierung und Fehlrationalisierung SOZIALISMUS NACH DEM WELTKRIEG, 1. Bd. Rationalisierung und Fehlrationalisierung, Berlin 1931. Was die technische Seite der Rationalisierung angeht, so ist hier festzuhalten, daß seit der Krise 1967 die Einführung von elektronischer Datenverarbeitung in den Betrieben einen qualitativen Sprung vorwärts gemacht hat.

193 Vgl. dazu LEVIATHAN, Nr. 1, 1969 (eine Zeitschrift der US-amerikanischen Linken). 
terarbeiten zu können und sich nicht total zugrunde zu richten), das zeigt aber auch die Streikbewegung im September in der BRD. wo die Empörung der Arbeiter über stagnierende Löhne und flotte Gewinnmacherei ihre Vehemenz aus der gleichzeitigen Verschärfung des Arbeitsdrucks in den Betrieben erhielt.

Indem der Staat jedenfalls für Forderungen der Arbeiter wie die Verringerung des Arbeitstempos, Gegenwehr gegen die Erhöhung der Akkordsätze, Kampf gegen weitere Intensivierung der Arbeit, gar nicht mehr als Adressat in Frage kommt, sondern die Auseinandersetzungen hier ausschließlich auf der Ebene zwischen Lohnarbeit und Kapital erfolgt, fällt auch immer mehr die Basis jener lllusion des Bewußtseins fort, daß der Staat es sei der die Verbesserung der Situation der Arbeiter innerhalb des Verhältnisses zwischen Lohnarbeit und Kapital zu betreiben habe. (194)

Unter diesem Aspekt müßten die Kämpfe der norditalienischen Arbeiter seit dem letzten Sommer genau untersucht werden, bei denen der Staat im weseritlichen als hilflose Gestalt im Hintergrund blieb. Im Angesicht dieser Kämpie schwindet der Schein, als ob der Staat aus einer Zaubertüte immer neue sozialpolitische Befriedungsmittel zur Manipulation der Massen hervorziehen könnte. Als Mittel der Herrschaftssicherung des Kapitals bleibt ihm dann in der Tat nichts als die Staatsg a w a I t: Polizei, Heer, Strafjustiz. Dagegen ist eine materielle Grundlage für Sozialstaatsillusionen in den zunehmenden 'Aurgaben' des Staates auf dem Gebiet der 'Bildungspolitik' zu sehen. Bei der Anwendung der bereits qualifizierten Arbeitskraft in der Produktion findet der Kampf immer direkter zwischen Arbeitgeber und Arbeitsanwender, zwischen Lohnarbeit und Kapital statt; bei der Qualifikation der Arbeitskraft dagegen nimmt die Rolle des Staates immer weiter zu. In den im Ausbildungsbereich aufbrechenden Konflikten erscheint der Staat, der 'Staatsapparat', als wesentlicher, ja einziger und einheitlicher Gegner. Hier liegt die materielle Basis für enorme Überschätzung der Folle des Staates im 'Spätkapitalismus', die für einen großen Teil der Studentenund Schülerbewegung kennzeichnend ist. Und zwar ist die Erfahrungsgrundlage dieser Illusion nicht nu: das Erlebnis von Polizeischlachten und Justizverfolgungen, sondern zugleich die Tatsache der errungenen Zugeständnisse und der gewährten Reformen, der 'Modernisierung des Bildungswesens". Wie sehr diese Reformen aus den Widersprüchen der Kapitalverwertung selbst heraus notwendig werden, wie sie nur in langwierigen Auseinandersetzungen und meist in Halbheiten durchgesetzt werden, und vor allem wie es für alle staatlichen Bildungsreformpläne äußerst reale Schranken, die Antastung des Mehrwerts gibt, das bleibe denen leicht verborgen, die immer nur den 'Staatsapparat als Gegner erleben. Ein neuer Revisionismus könnte so bei denen entstehen, die aufgrund der schroffen Trennung des Bildungs. vom Produktionsbereich in der kapitalistischen Gesellschaft vergessen, daß sie nur ausgebildet werden, um den Appetit des Kapitals adäquat zu befriedigen. Diese Einsicht zu verhindern sind die gegenwärtigen politischen Maßnahmen der SPD - Amnestie, Herabsetzung des Wahlalters und der Wehrdienstzeit - besonders geeignet. Kann dagegen diese Einsicht schon den Schülern und Studenten (natürlich nicht denen, die sich bewußt auf den Dienst bei den Unterdrückungsapparaten vorbereiten) vermittelt werden, indem sie ihre Auseinandersetzungen mit dem Staat nicht als Kampf um ständige Privilegierungen, sondern im Zusammenhang des Widerspruchs zwischen Lohnarbeit und Kapital begreifen und daraus Konsequenzen für die politische Praxis ziehen, so kann der Kampf gegen die staatliche Produktion der Arbeitskraft im Dienst des Kapitals zu einer Nebenfront des Klassenkampfes zwischen Lohnarbeit und Kapital werden.

194 Zu fragen ist dabei, ob die Gewerkschaften in der Lage sind, dieser Entwicklung durch Herausstellung von Forderungen, die durch ge $\mathrm{n}$ e r ell e Regelungen zu befriedigen sind (Krankengeld, Rentenerhöhung und Lohnforderungen) auf die Dauer entgegenzuwirken. Wenigstens läßt sich zeigen, daß scheinbare Erfolge in dieser Richiung, wie die Verabschiedung des Gesetzes zur 'Lohnfortzahlung für Arbeiter im Krankheitsfall' im Sommer 1969, keine wirkliche Besserung der Situation der kranken Arbeiter bewirkt hat, da Kautelen in den Gesetzestext eingebaut sind, die eine Umgehung der Zahlungen ermöglicht, so daß z.T. die Unsicherheit der Arbeiter für den Krankheitsfall sogar gestiegen ist. (vgl. dazu: ROTE KOMMEN1 ARE, Hrsg.: SDS Heidelberg, 20.3.70).

\section{ABOMNEMENTS NUR DIREKT VOM VERLAG}

